UNIVERSIDADE DE SÃO PAULO

FACULDADE DE ECONOMIA, ADMINISTRAÇÃO E CONTABILIDADE DEPARTAMENTO DE ADMINISTRAÇÃO

PROGRAMA DE PÓS-GRADUAÇÃO EM ADMINISTRAÇÃO

PLANEJAMENTO ESTRATÉGICO COMO FERRAMENTA PARA A DEFINIÇÃO DE ESTRATÉGIAS CONJUNTAS PARA O SETOR DE SAÚDE SUS DE SANTA MARIA - RS

Roberto da Luz Júnior

Orientador: Prof. Dr. Martinho Isnard Ribeiro de Almeida

SÃO PAULO

2014 
Prof. Dr. Marco Antônio Zago

Reitor da Universidade de São Paulo

Prof. Dr. Reinaldo Guerreiro

Diretor da Faculdade de Economia, Administração e Contabilidade

Prof. Dr. Roberto Sbragia

Chefe do Departamento de Administração

Prof. Dr. Lindolfo Galvão de Albuquerque

Coordenador do Programa de Pós-Graduação em Administração 


\title{
PLANEJAMENTO ESTRATÉGICO COMO FERRAMENTA PARA A DEFINIÇÃO DE ESTRATÉGIAS CONJUNTAS PARA O SETOR DE SAÚDE SUS DE SANTA MARIA - RS
}

\begin{abstract}
Tese apresentada ao Programa de PósGraduação em Administração da Faculdade de Economia, Administração e Contabilidade da Universidade de São Paulo como requisito para a obtenção do título de Doutor em Ciências.
\end{abstract}

Orientador: Prof. Dr. Martinho Isnard Ribeiro de Almeida

\author{
Versão Corrigida \\ (versão original disponível na Faculdade de Economia, Administração e Contabilidade)
}

SÃO PAULO

2014 


\section{FICHA CATALOGRÁFICA}

Elaborada pela Seção de Processamento Técnico do SBD/FEA/USP

\section{Luz Júnior, Roberto da}

Planejamento estratégico como ferramenta para a definição de estratégias conjuntas para o setor de saúde SUS de Santa Maria (RS) / Roberto da Luz Júnior. -- São Paulo, 2014.

$142 \mathrm{p}$.

Tese (Doutorado) - Universidade de São Paulo, 201

Orientador: Martinho Isnard Ribeiro de Almeida.

1. Planejamento estratégico 2. Estratégias 3. Gestão pública I. Universidade de São Paulo. Faculdade de Economia, Administração e Contabilidade.

II. Título.

CDD -658.401 
À Elisete, minha esposa, e meus filhos Lisiane e Roberto Neto. As sinergias de pensamento e de atitudes consolidam resultados gratificantes. 



\section{AGRADECIMENTOS}

A DEUS, ser supremo sem o qual nada é possível.

À minha esposa ELISETE e meus filhos LISIANE DA CRUZ LUZ e ROBERTO DA LUZ NETO, meu agradecimento pelo amor inconteste, companheirismo e estímulo.

Ao Professor Martinho Isnard Ribeiro de Almeida, meu GRANDE MESTRE e Orientador.

À Professora CLÂNDIA MAFFINI GOMES, por seu incansável trabalho para a viabilização desta edição do DINTER, bem como pelas brilhantes contribuições ao meu trabalho.

À Professora HEIDY RODRIGUEZ RAMOS cuja admiração e respeito elevaram-se após sua participação na Banca do Exame de Qualificação e aporte de sugestões.

Ao Professor, SÉRgio ROSSI MADRUGA, colega de UFSM e de Doutorado. Por sua desinteressada colaboração durante todo o tempo.

À Professora LUCIA REJANE MADRUGA, amiga e colega, que gentilmente aceitou participar da Banca.

À Professora ELAINE VERENA RESENER, Diretora Geral do HUSM, que como grande gestora sempre acreditou no Planejamento Estratégico.

A todos os Dirigentes das Unidades Produtoras de Serviços de Saúde de Santa Maria, pela disponibilidade em participar da pesquisa, em evidente confirmação do convencimento da crença no Planejamento Estratégico Conjunto como ferramenta de gestão.

Aos Doutorandos do PPGA UFSM, Professores JORDANA MARQUES KNEIPP e TIAGO PATIAS, meu agradecimento pelas contribuições acadêmicas à tese.

Ao pessoal da ADESM, Presidente, VILSON MARCIMINO SERRO, bem como seu Secretário Executivo, DIOGO DEGREGORI pela gentileza em colaborar.

A minha família: meu Pai e minha Mãe (In Memorian) e minhas Irmãs, devo a eles o perfil de homem que sou.

Aos Professores Martinho Isnard Ribeiro de Almeida e Lindolfo Galvão de Albuquerque, do PPGA-USP, que viabilizaram o convênio para a realização deste Doutorado.

A todos aqueles que de uma forma ou de outra estiveram ao meu lado, enfileirados na torcida pró-Roberto.

OS MEUS MAIS PROFUNDOS SENTIMENTOS DE GRATIDÃO 
“Não basta saber, é preciso aplicar. Não basta querer é preciso fazer”.

Goethe 


\section{RESUMO}

No Brasil pós Constituição Federal de 1988, que instituiu a universalização dos serviços de saúde mediante a implantação do Sistema Único de Saúde, as unidades produtoras de serviços de saúde públicas ou credenciadas para a prestação de serviços ao Sistema, vêem-se cada vez mais, desafiadas a profissionalizar a gestão, o que vem exigindo a adoção de ferramentas como o planejamento estratégico. No caso de Santa Maria, apesar de realizar mesmo que parcialmente, as atividades de planejamento estratégico, alguns deles não o faziam, nem tampouco possuíam experiência nessa técnica administrativa. Dessa forma, era necessário utilizar e disponibilizar uma ferramenta comum de planejamento estratégico, que pudesse responder, de maneira adequada, às várias especificidades. Neste contexto, surge a questão central objeto de estudo: "De que forma o planejamento estratégico pode auxiliar o processo de formulação de estratégias conjuntas para os estabelecimentos de saúde que atendem ao Sistema Único de Saúde (SUS) em Santa Maria?". Para responder à pergunta de pesquisa definiu-se como objetivo principal avaliar a eficácia do planejamento estratégico como uma ferramenta para a formulação de estratégias conjuntas para os estabelecimentos de saúde que atendem ao Sistema Único de Saúde em Santa Maria. A revisão bibliográfica focou modelos de planejamento estratégico, bem como a definição de estratégias conjuntas em saúde. O principal método empregado foi o da pesquisa-ação, desenvolvida em dois momentos, junto ao Hospital Universitário e com os gestores das Unidades Produtoras de Serviços de Saúde. A seguir, junto ao grupo temático de saúde da Agência de Desenvolvimento de Santa Maria, utilizou-se pesquisa exploratória qualitativa e pesquisa descritiva quantitativa, com o objetivo de avaliar respectivamente as percepções do grupo de dirigentes, e dos demais participantes do Grupo Temático. Os resultados indicaram a adequação do modelo de planejamento estratégico definido para o Hospital Universitário, bem como a eficácia do processo de planejamento utilizado para a definição de estratégias conjuntas. Pode-se concluir ainda que a atividade de definição de estratégias conjuntas para a área de saúde pública, para a realidade do Município de Santa Maria, tratou-se de processo inovador, cujos frutos já vêm sendo colhidos.

Palavras Chave: Planejamento Estratégico, Estratégias Conjuntas em Saúde, Gestão Pública. 


\begin{abstract}
In Brazil after the Federal Constitution of 1988, which established the universalization of health services through the implementation of the National Health System, the production units of public health services or accredited to provide services to the system, find themselves increasingly challenged to professionalize the management, which has required the adoption of tools such as strategic planning. In the case of Santa Maria, despite perform even partially, the strategic planning activities, some of them did not, nor had experience that administrative technique. Thus, it was necessary to use and provide a common tool of strategic planning, which could respond, as appropriate, to the various specificities. In this context, the core issue subject: "How does strategic planning can help the process of formulating joint strategies for health facilities serving the Unified Health System (SUS) in Santa Maria? “. To answer the research question was defined as main objective to evaluate the effectiveness of strategic planning as a tool for formulating joint strategies for health facilities that meet the Health System in Santa Maria. The literature review focused on strategic planning models, and the definition of joint strategies in health. The main method used was the action research, developed in two phases, with the University Hospital and the managers of Health Services service units. Then, with the thematic group health from Santa Maria Development Agency, used -If exploratory qualitative research and quantitative descriptive research, in order to respectively evaluate the perceptions of the group leaders, and other participants of the Theme Group. The results indicated the suitability of the strategic planning model set to the University Hospital, and the effectiveness of the planning process used to define joint strategies. It can also be concluded that the joint strategies definition of activities in the area of public health, to the reality of the city of Santa Maria, this was an innovative process; the fruits are already being harvested.
\end{abstract}

Keywords: Strategic Planning, Strategies for Joint Health, Public Management. 


\section{SUMÁRIO}

LISTA DE ABREVIATURAS E SIGLAS ….............................................................. 4

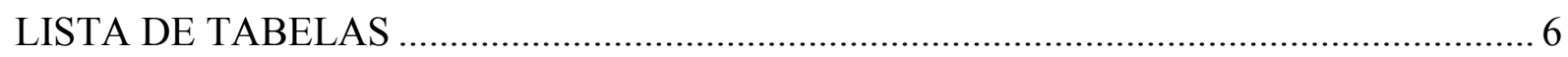

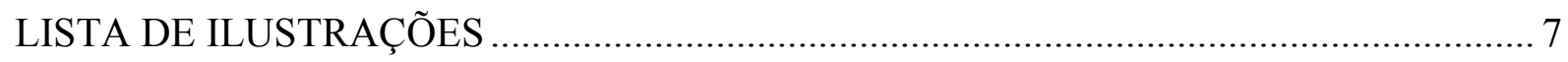

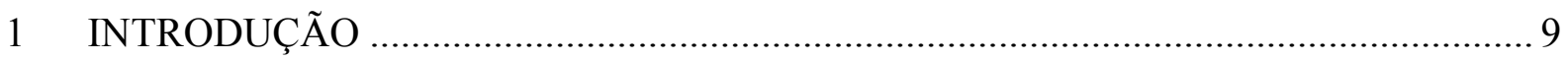

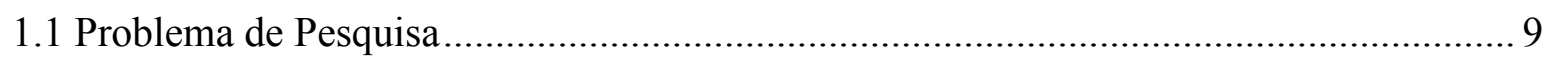

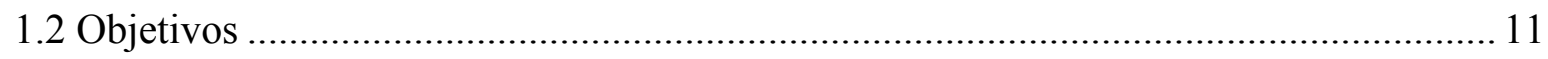

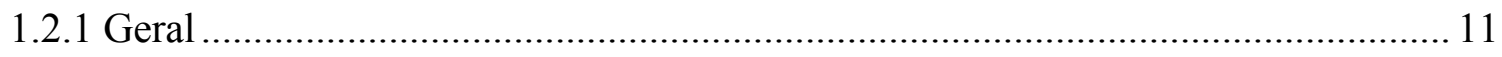

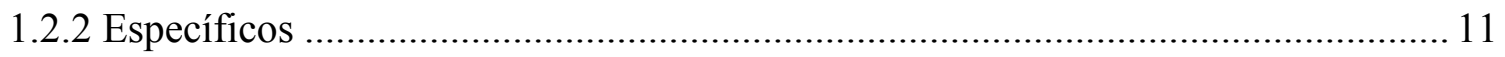

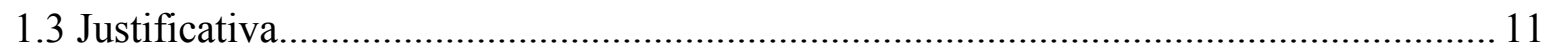

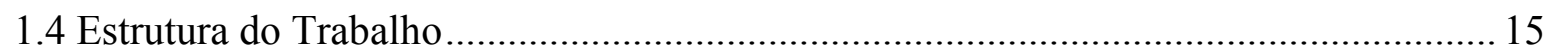

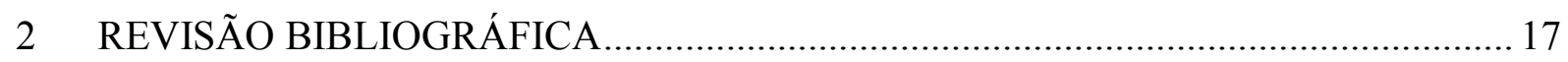

2.1 O processo de formulação de estratégias conjuntas e a intersetorialidade na gestão da

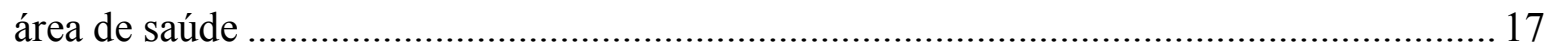

2.2 O Planejamento Estratégico como instrumento de gestão ........................................... 25

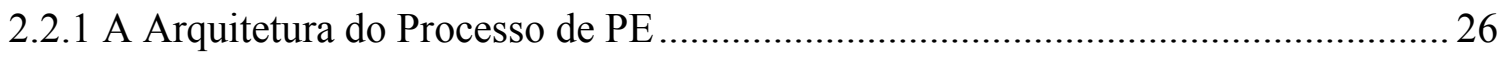

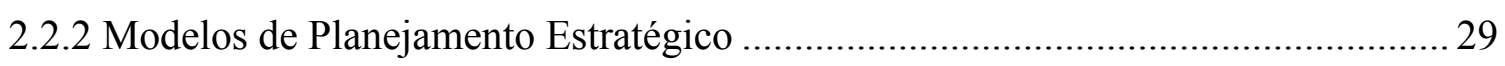

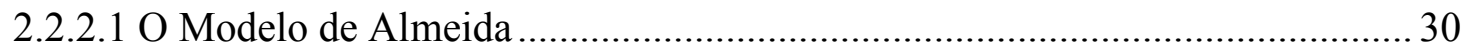

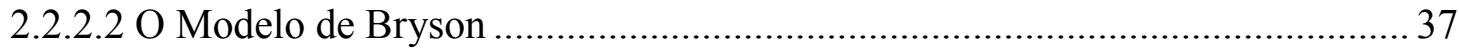

2.2.2.3 Comparação dos Modelos ............................................................................... 43

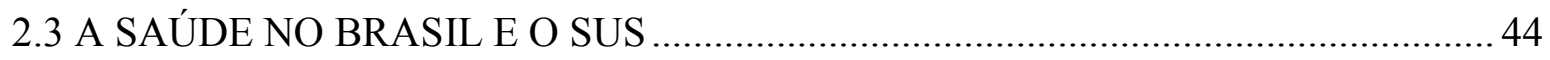

2.3.1 Evolução da gestão de serviços de saúde no Brasil .................................................. 44

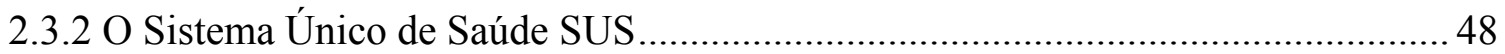

2.3.3 - A Gestão da Saúde no Município ..................................................................... 49

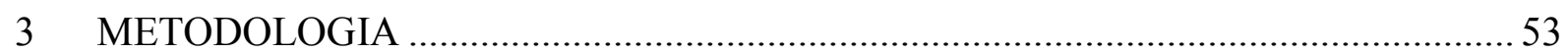

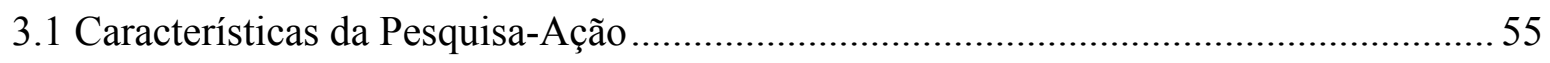

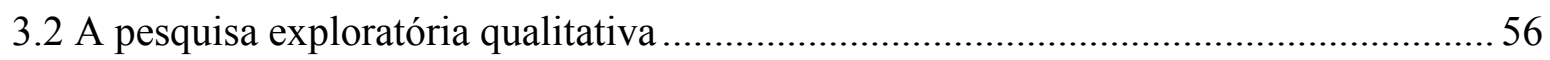

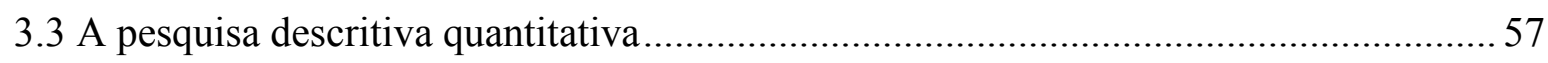




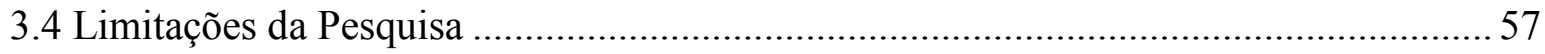

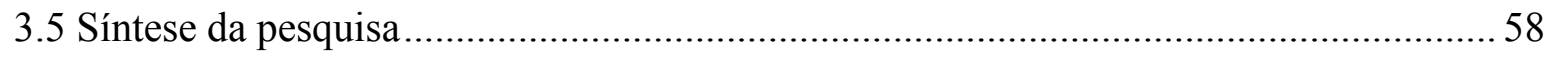

4 ANÁLISE E INTERPRETAÇÃO DO PROCESSO DE INTERVENÇÃO..................... 61

4.1 Planejamento Estratégico do Hospital Universitário de Santa Maria .............................. 61

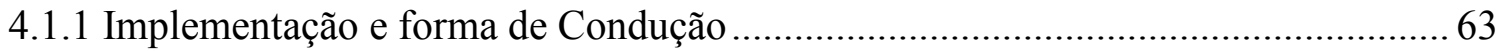

4.1.2 Primeiro Processo de Planejamento HUSM - 2003-2006 ...................................... 67

4.1.3 Segundo Período do Processo de PE do HUSM 2010-2013 ................................... 70

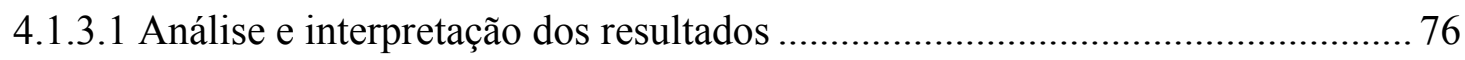

4.1.3.2 Seminários de treinamento e suporte ao processo de PE .............................. 79

4.1.3.3 Forma de Condução do Processo ..................................................................... 80

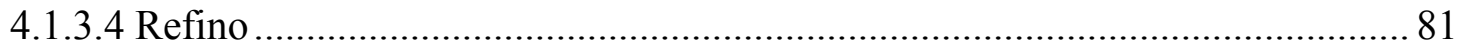

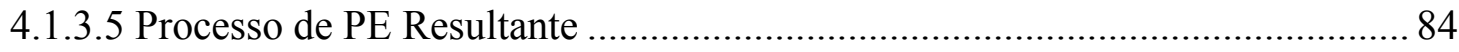

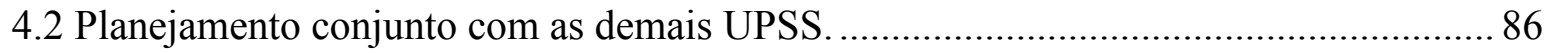

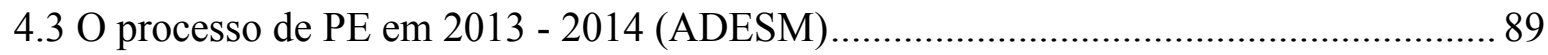

4.3.1 A Gênese da Agência de Desenvolvimento de Santa Maria ................................. 89

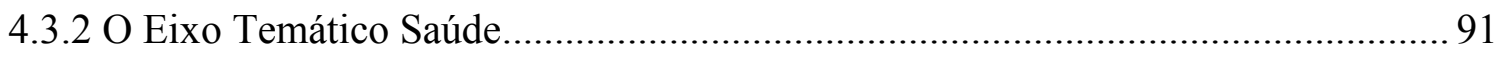

4.3.3 Condução do processo do Grupo Temático Saúde - ADESM ................................. 95

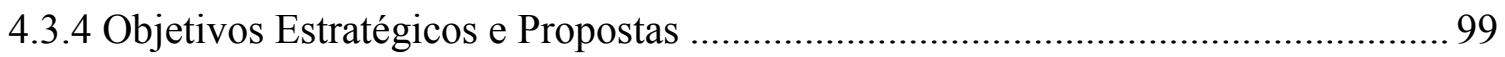

4.4 Avaliação da percepção dos gestores das unidades produtoras de serviços de saúde.. 103

4.4.1 Quanto à Maximização dos Leitos Hospitalares .................................................... 104

4.4.2 Quanto à prática profissional dos acadêmicos da área da saúde .......................... 105

4.4.3 Quanto ao credenciamento SUS aos hospitais por nível de complexidade........... 106

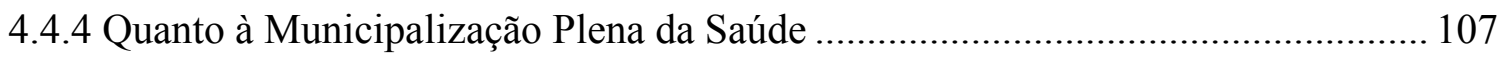

4.4.5 Quanto ao papel da Coordenadoria Regional de Saúde ...................................... 108

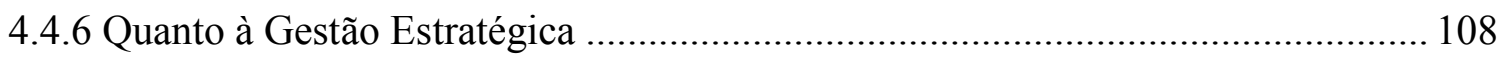

4.5 Avaliação da percepção dos participantes do eixo temático da saúde do processo de PE

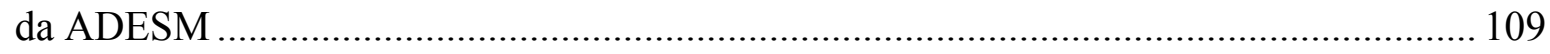

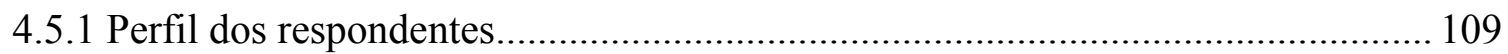

4.5.2 Percepção em relação às diretrizes definidas para a saúde no processo de Planejamento Estratégico 


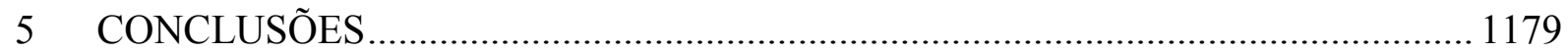

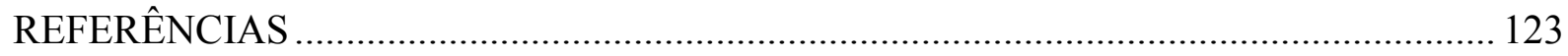

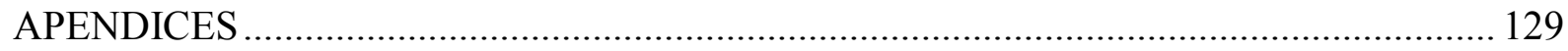




\section{LISTA DE ABREVIATURAS E SIGLAS}

AC: Aprendizado e crescimento

ADESM: Agência de Desenvolvimento de Santa Maria

AE: Administração Estratégica

AI: Ambiente Interno

CAP: Caixa de Aposentadoria e Pensões

CCS: Centro de Ciências da Saúde

CL: Cliente

CLT: Consolidação das Leis Trabalhistas

CONASS: Conselho Nacional de Secretários da Saúde

CRS: Coordenadoria Regional de Saúde

CTMO: Centro de Transplantes de Medula Óssea

DIREX: Direção Executiva

DNS-MS: Departamento Nacional de Saúde - Ministério da Saúde

ENAP: Escola Nacional de Administração Pública

FATEC: Fundação de Apoio à Tecnologia e Ciência

FCS: Fator Crítico de Sucesso

FEE: Fórum de Entidades Empresariais

FIOCRUZ: Fundação Osvaldo Cruz

FN: Financeira

GT: Grupo Temático

HCAA: Hospital de Caridade Astrogildo de Azevedo

HRE: Hospital Regional Estadual

HU: Hospital Universitário

HUSM: Hospital Universitário de Santa Maria

IAP: Instituto de Aposentadorias e Pensões

IBGE: Instituto Brasileiro de Geografia e Estatística

IDESE: Índice de Desenvolvimento Sócio Econômico

INSS: Instituto Nacional de Seguridade Social

MC: Macroambiente Clima

MIRA: Martinho Isnard Ribeiro de Almeida

MPEs: Modelos de Planejamento Estratégico

MS: Macroambiente Solo

MS/MEC: Ministério da Saúde/Ministério da Educação

MTPS: Ministério do Trabalho e Previdência Social

NOB: Norma Operacional Básica

PACS: Programa de Agentes Comunitários de Saúde

PAP: Pesquisa-ação participativa

PDI: Plano de Desenvolvimento Institucional

PE: Planejamento Estratégico

PGQP: Programa Gaúcho de Qualidade e Produtividade

PI: Processos Internos

PMSM: Prefeitura Municipal de Santa Maria

PROPLAN: Pró Reitoria de Planejamento

PSF: Programa Saúde da Família

SEFAS: Sociedade Franciscana de Assistência à Saúde

SES: Secretarias Estaduais de Saúde

SMS: Secretaria Municipal da Saúde 
SUS: Sistema Único de Saúde UFSM: Universidade Federal de Santa Maria UPA: Unidade de Pronto Atendimento

UPSS: Unidades Produtoras de Serviços de Saúde 


\section{LISTA DE TABELAS}

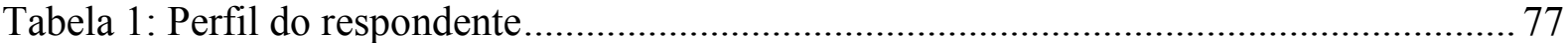

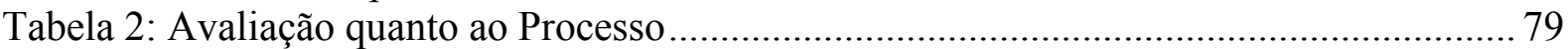

Tabela 3: IDESE Saúde e a posição de Santa Maria comparada com os municípios do RS ao

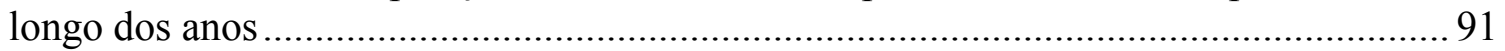

Tabela 4: Ranking do IDESE Saúde de 2009 comparado com os 10 maiores municípios do RS

Tabela 5: Número de leitos por especialidade nos hospitais em Santa Maria (2010)..............93

Tabela 6: Total de estabelecimentos de Saúde em Santa Maria (2012) ................................. 93

Tabela 7: Número de profissionais da área da saúde em Santa Maria e no Rio Grande do Sul

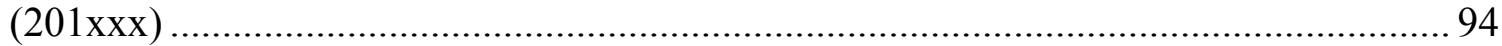

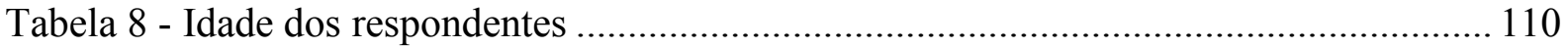

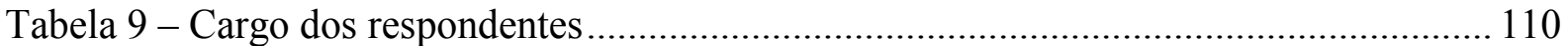

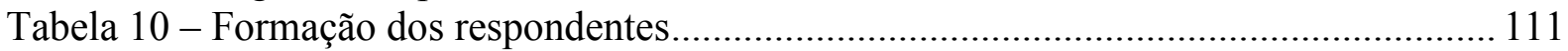

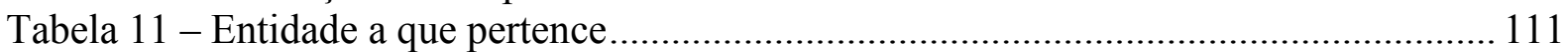

Tabela 12 - Tempo de atuação na entidade ......................................................................... 112

Tabela 13 - Tempo de atuação no setor de saúde ............................................................... 112

Tabela 14 - Percepção em relação à maximização de leitos hospitalares .............................. 113

Tabela 15 - Avaliação com uma nota (de 0 a 10) da importância da maximização dos leitos hospitalares

Tabela 16 - Percepção em relação ao Aprimoramento da prática profissional dos Acadêmicos da Área da Saúde

Tabela 17 - Avaliação com uma nota (de 0 a 10) a importância do aprimoramento da prática profissional dos acadêmicos da área de saúde.

Tabela 18 - Percepção em relação à Municipalização do Setor de Saúde, Contratualização e Criação de Comitê Estratégico.

Tabela 19 - Avaliação com uma nota (de 0 a 10) a importância da municipalização do setor de saúde

Tabela 20 - Avalição com uma nota (de 0 a 10) o processo de elaboração das estratégias conjuntas de saúde em Santa Maria

Tabela 21 - Priorização das ações estratégicas numerando de 1 a 3, da mais a menos importante: 


\section{LISTA DE ILUSTRAÇÕES}

Figura 1: O modelo dos múltiplos fluxos de Kingdon ....................................................... 24

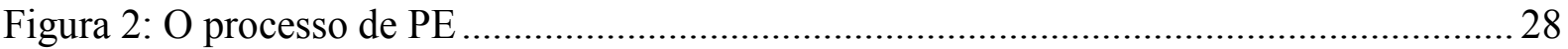

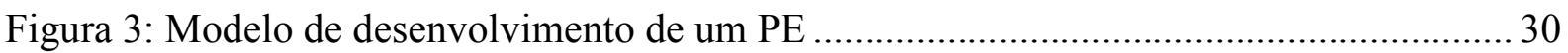

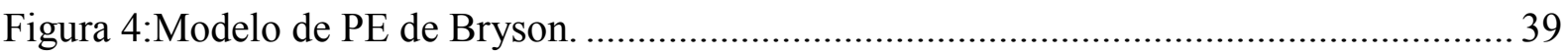

Figura 5: Modelo de Planejamento Estratégico - UFSM/HUSM.......................................... 64

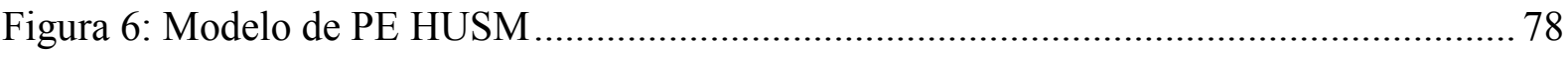

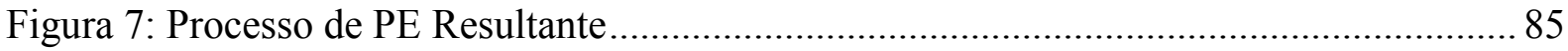

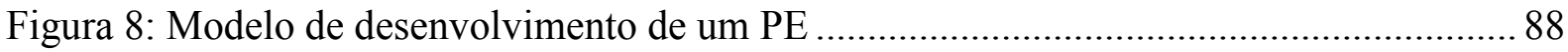

Figura 9 - Proposta metodológica do Plano Estratégico de Desenvolvimento de Santa Maria 


\section{INTRODUÇÃO}

\subsection{Problema de Pesquisa}

Cada vez mais os pesquisadores em administração têm-se preocupado com as técnicas de Planejamento Estratégico (PE) e de formulação de estratégias. As abordagens são tão diversificadas que, num estudo sistêmico (Mintzberg; Ahlstrand; e Lampel, 2000) identificaram distintas escolas de planejamento e formulação de estratégias. Essa técnicase constitui em uma ferramenta gerencial, extremamente utilizada por executivos na indústria. Segundo Rigby (2003), responsável pelo desenvolvimento a técnica de PE tem sido uma das utilizadas por instituições e empresas em todo mundo, dentre todas as ferramentas administrativas identificadas em sua pesquisa.

A expressão PE ultrapassou os meios acadêmicos, chegando a fazer parte da linguagem coloquial do cotidiano empresarial. Se por um lado essa popularização tem seu lado positivo, por causa de sua ampla divulgação, por outro lado, segundo Almeida (2010), interpretações erradas das técnicas de PE podem levar as pessoas a perpetuarem conceitos falsos, e cometerem erros indesejáveis em seus negócios, ou atividades.

Como evidência desses problemas, ainda segundo Almeida (2010), é comum existir organizações que elaboram, por exemplo, a sua missão, sua visão e procedem à análise de seus pontos fortes e fracos e oportunidades e ameaças, sem ter a clareza do que estão fazendo. Investem enormes somas de dinheiro com a análise ambiental, e gastam um tempo enorme de seus executivos, para ao final, chegar a resultados que não refletem sua realidade, e acabam não tendo o devido impacto sobre a sua dinâmica organizacional. Pior ainda, sem que isso seja traduzido em qualquer mudança na organização, servindo, apenas, para cumprir uma obrigação, ou para dar, apenas, uma aparência de que na empresa há PE.

Adicionalmente, as organizações mudam constantemente, como mudam o ambiente e as condições de operação. Dessa forma, os processos de planejamento devem adaptar-se às organizações e às novas situações pelas quais passam. O simples crescimento de uma organização a transforma em um sistema estruturalmente complexo, e operacionalmente 
heterogêneo. Obviamente, formato e aumento da complexidade são fatores de mutação organizacional, que requerem adaptação das técnicas de PE. As técnicas comuns funcionam mais eficientemente em estruturas simples e monolíticas, não em estruturas complexas e heterogêneas. Desatenção aos reflexos da complexidade estrutural e heterogeneidade operacional de uma organização, na elaboração do PE, pode invalidar todo o esforço de planejamento, mesmo que o plano de elaboração tenha sido construído de forma participativa.

É preciso desenvolver um modelo de processo e uma forma de condução do PE, que possa garantir o mínimo de conflitos internos, pela motivação e participação dos envolvidos, de forma percebida, por eles, como satisfatória.

A definição do problema de pesquisa consistiu na necessidade da proposição de estratégias conjuntas por parte dos produtores de serviços de saúde via Sistema Único de Saúde (SUS) em Santa Maria e Região. Apesar de realizar mesmo que parcialmente, as atividades de PE, alguns deles não o faziam, nem tampouco possuíam experiência nessa técnica administrativa. Dessa forma, era necessário utilizar e disponibilizar uma ferramenta comum de PE, que pudesse responder, de maneira adequada, às várias especificidades.

Nesse estudo procurou-se efetuar a aplicação do processo de PE Almeida (2004), como uma possibilidade de uso na elaboração do processo de planejamento estratégico do Hospital Universitário de Santa Maria (HUSM), bem como descrever um processo de PE visando ao estabelecimento de estratégias conjuntas por parte das Unidades Produtoras de Serviços de Saúde (UPSS) via SUS em Santa Maria.

Portanto, procura-se desenvolver a aplicação dos principais conceitos relacionados ao PE em um estabelecimento Hospitalar de Ensino Público Federal, HUSM, bem como descrever e avaliar o processo de PE conjunto de estabelecimentos de saúde com características bastante distintas, de naturezas privada e pública, estes vinculados às esferas federal, estadual e municipal, vinculados ao SUS.

Uma das características do processo deverá ser a de observar estreita coerência com as características de independência institucional das organizações envolvidas. Assim, o processo proposto deverá, também, obedecer a um novo estilo de administração para desenvolver o PE. 
Neste contexto, surge o problema de pesquisa objeto de estudo: "De que forma o planejamento estratégico pode auxiliar o processo de formulação de estratégias conjuntas para os estabelecimentos de saúde que atendem ao SUS em Santa Maria?".

\subsection{Objetivos}

Nesta seção, apresentam-se os objetivos definidos para viabilizar a resposta ao problema de pesquisa.

\subsubsection{Geral}

Avaliar a eficácia do planejamento estratégico como uma ferramenta para a formulação de estratégias conjuntas para os estabelecimentos de saúde que atendem ao SUS em Santa Maria.

\subsubsection{Específicos}

a) Definir e avaliar o processo de condução do PE junto ao HUSM;

b) Descrever o processo de definição de estratégias conjuntas pelos gestores das UPSS;

c) Descrever o processo de PE desenvolvido pelo Grupo Temático (GT) da Saúde da Agência de Desenvolvimento de Santa Maria (ADESM);

d) Avaliar a percepção dos gestores das UPSS em relação às estratégias conjuntas definidas pelo GT Saúde da ADESM.

e) Avaliar a percepção dos participantes do processo de $\mathrm{PE}$ em relação às estratégias conjuntas definidas pelo GT Saúde da ADESM.

\subsection{Justificativa}

O Brasil atual vem revelando cada vez mais a participação do Estado na economia, e por conseqüência das atividades em geral. Indicadores como a participação do orçamento público da União em relação ao Produto Interno Bruto, segundo dados da Secretaria de Orçamento e 
Finanças do Ministério do Planejamento para 2014, alcançam preocupantes 51,5\% em relação ao PIB 2013. Por outro lado, para um orçamento 2014 com receitas estimadas segundo a mesma fonte, em dois trilhões e quatrocentos e oitenta e nove bilhões, seiscentos e cinqüenta e cinco bilhões são representados por receitas provenientes do refinanciamento da dívida, ou seja, 27\% (MINISTÉRIO DO PLANEJAMENTO 2014).

Frente a estes números, os $12,2 \%$ previstos sobre o orçamento fiscal acrescido do orçamento da seguridade social, para uso no custeio e investimentos na saúde conforme previstos na LOA para 2014, sem dúvida indicam a escassez de recursos para fazer frente às necessidades de atendimento satisfatório pelo SUS.

Ainda segundo a mesma fonte, outro fato preocupante diz respeito à participação das 3 esferas, União, Estados e DF, mais os Municípios, no total da receita pública, para o exercício de 2014, acha-se partilhada em 70,14\% para a União, 25,75\% para os Estados e DF, e apenas $4,2 \%$ para os Municípios.

Esta situação amplia grandemente as exigências em termos de aprimoramento da gestão pública municipal em saúde, um dos maiores problemas atuais do País.

A presente pesquisa pode ser justificada levando-se em conta a importância do tema. O sistema público de saúde vem passando por um processo de reforma importante, desencadeado por um amplo movimento que envolveu diversas forças políticas, articuladas desde a segunda metade dos anos 70. Segundo Lotufo (2003), esse movimento, singular no âmbito das políticas sociais, conseguiu inscrever na Constituição Federal elaborada em 1988, o Direito à Saúde, entendido como direito de cidadania e dever do Estado, consagrando, ademais, como princípios e diretrizes para a reorganização do sistema de saúde, a universalidade, a integralidade, a equidade, a descentralização e a participação (BRASIL, CF, 1988: art.198).

Garantidas as conquistas no âmbito jurídico-normativo, inicia-se no Brasil uma longa trajetória em direção à construção efetiva do SUS, nos aspectos relativos à explicitação de planos, projetos e programas de governo, desenho de sua arquitetura institucional, a definição das organizações, preparação dos profissionais para atuarem dentro desse novo arcabouço jurídico e institucional, e definição de articulações políticas, entre outras questões importantes 
que precisavam ser definidas para que se conseguisse alcançar as desejadas mudanças no campo de prestação de serviços (BARROS 1997).

O processo de descentralização da gestão do sistema, especificamente, vem sendo operacionalizado através de Normas Operacionais Básicas (NOBs), que têm como objetivo a “definição de passos sucessivos a serem percorridos por Estados e Municípios, de maneira a operar o sistema de saúde sobre a base de um pacto político cooperativo entre instâncias e instituições específicas e sustentado por procedimentos técnicos" (GERSCHMAN, 2000, p. 159).

Nesse contexto, foram sendo redefinidas as responsabilidades de cada esfera do Governo no SUS e se delimitou melhor o novo objeto de trabalho das Secretarias de Saúde dos Estados. Apesar de terem clareza de suas novas funções no Sistema, as Secretarias Estaduais de Saúde (SES), de modo geral, demonstravam-se incapazes de responder aos novos desafios, que foram sendo colocados na construção do SUS. Mais do que uma "crise de identidade", portanto, configurava-se uma situação que pode ser entendida como resultante das limitações das instituições gestoras em termos da sua "capacidade de governar" o SUS (MINISTÉRIO DA SAÚDE (MS), 1999, p. 2).

O Município de Santa Maria, cidade de porte médio com aproximadamente 300.000 habitantes, constitui-se em um importante pólo regional de prestação de serviços da Região Central do Estado do Rio Grande do Sul. Destaque especial merece a polarização exercida sobre os demais municípios da região nos serviços de saúde, notadamente via SUS abriga a $4^{\mathrm{a}}$ Coordenadoria Regional de Saúde (4 $\left.{ }^{\mathrm{a}} \mathrm{CRS}\right)$ do Estado do Rio Grande do Sul, com abrangência de 31 municípios.

Segundo Universidade Federal de Santa Maria (2012), Santa Maria é sede de uma Universidade Federal com 28.726 alunos possui um Hospital Universitário (HUSM) com 335 leitos, o qual muito além de desempenhar seu papel de "Laboratório de Ensino", atua como "prestador de serviços" de médias e altas complexidades, exclusivamente via SUS, aos habitantes dos 31 municípios integrantes da ${ }^{\text {a }}$ CRS do Estado do Rio Grande do Sul. 
Segundo Prefeitura Municipal de Santa Maria (2013), o Município possui, ainda, um Hospital Municipal, Casa de Saúde, com 121 leitos, credenciados para a prestação de serviços de baixas e médias complexidades, administrado de forma terceirizada mediante contrato firmado entre a Prefeitura Municipal e a Associação Franciscana de Assistência à Saúde (SEFAS), bem como um Hospital privado, Hospital de Caridade Dr. Astrogildo de Azevedo, que acaba de inaugurar um anexo, denominado Hospital Alcides Brum, com 140 leitos, totalmente credenciados via SUS para a prestação de serviços hospitalares de média complexidade.

Acrescenta-se ainda, segundo igual fonte, uma rede de Ambulatórios Municipais de Saúde, bem como uma Unidade de Pronto Atendimento Municipal (UPA) e um Hospital de Pronto Atendimento Municipal, todos prestando atendimentos exclusivamente via SUS.

Importante destacar que toda esta infraestrutura de serviços de saúde, com vinculações federal, estadual, municipal e também privada, bem como abrangências desde regional até local, apesar de sujeita às diretrizes nacionais do SUS, não vem atuando de forma conjuntamente planejada o que tem levado às práticas de gestão ineficientes e ineficazes.

Pode-se citar como exemplo, a superlotação do Pronto Socorro do HUSM por força dos atendimentos de casos de baixa e média complexidade, por força da falta de estratégias conjuntas com os demais estabelecimentos hospitalares. Isto tem levado, por vezes, à impossibilidade de atendimento aos casos de alta complexidade, para os quais é o único que se acha devidamente credenciado. Em contrapartida, ao mesmo tempo, sobram leitos de média complexidade junto ao Hospital Casa de Saúde, para cujo atendimento acha-se devidamente credenciado.

Assim, este estudo tem importância teórica e prática eminente. Teórica, porque, ao examinar a aplicação do planejamento estratégico conjunto para unidades produtoras de serviços de saúde via SUS em Santa Maria e Região, os achados deste estudo poderão revelar as vantagens e desvantagens do processo. Este exame deverá produzir possíveis adaptações para o processo de PE, para melhorar o seu uso. Além disso, pode criar um novo modelo, a partir do processo desenvolvido junto ao HUSM, enriquecendo assim a literatura que existe e incentivando para que outros trabalhos possam vir a ser desenvolvidos nesta área. 
Sob o ponto de vista prático, o estudo viabilizará para os dirigentes de unidades produtoras de serviços de saúde via SUS em Santa Maria e Região a definição de estratégias conjuntas.

\subsection{Estrutura do Trabalho}

O presente trabalho está estruturado em cinco capítulos. No capítulo um, introdução, é realizada a contextualização da pesquisa, com o problema de pesquisa, os objetivos que nortearam o desenvolvimento deste, a justificativa, bem como a estrutura do trabalho.

O capítulo dois trata da revisão bibliográfica que fundamenta a pesquisa. O terceiro capítulo trata da metodologia que dá orientação à pesquisa; no capítulo quatro, encontram-se a análise e interpretação do processo de intervenção; no capítulo cinco, encontram-se as conclusões e limitações da pesquisa. As referências bibliográficas e os apêndices são as seções de encerramento da pesquisa. 


\section{REVISÃO BIBLIOGRÁFICA}

A revisão bibliográfica deste trabalho circunscreve-se primordialmente da Estratégia, focando-se naquelas construídas conjuntamente, em direção ao Planejamento Estratégico (PE). Focou-se na definição do próprio PE e analisaram-se dois modelos de PE, aplicáveis ao presente caso em estudo, os modelos de Almeida (2010) e Bryson (1995). Finalmente, abordou-se a arquitetura do processo de PE, necessária à definição do objeto da pesquisa: um processo de PE conjunto para os estabelecimentos de saúde, que atendem ao Sistema Único de Saúde.

\subsection{O processo de formulação de estratégias conjuntas e a intersetorialidade na gestão}

Tomando em consideração a proposição do estabelecimento de um processo de planejamento conjunto para as unidades produtoras de serviços de saúde, percebeu-se a necessidade de proceder a uma revisão teórica relativa ao desenvolvimento de estratégias conjuntas.

Estratégia tem sua origem denotada aos gregos, que deram ao conceito uma conotação militar. O termo origina-se do grego "strategos", traduzida como "general no comando de tropas" ou "a arte do general", ou ainda "plano de destruição de inimigos através do efetivo uso de recursos" (STEAD; STEAD 2008).

A definição de estratégia é controversa, Ansoff (2007, p. 03) afirma que "se não há uma definição clara do que um termo como estratégia significa, é difícil imaginar o conceito empregado como parte de uma explicação maior, por exemplo, em uma teoria da gestão estratégica".

Porter (1999, p.63) ensina que Estratégia "é criar uma posição exclusiva e valiosa, envolvendo um diferente conjunto de atividades". A essência do posicionamento estratégico consiste na escolha de diferenciais em relação às demais organizações. 
Philip Kotler (2003, p. 63) define estratégia como "o adesivo por meio do qual se constrói e fornece posição de valor consistente e diferenciada ao mercado-alvo". O autor defende que a estratégia, para ser poderosa e sustentável, deve ser diferenciada e de difícil imitação.

Henry Mintzberg et al. (2006), no texto intitulado "Cinco Ps para Estratégia", apresentam cinco definições para estratégia (Quadro 1). Para o autor, estratégia pode ser definida como plano, pretexto, padrão, posição e perspectiva. Afirma, ainda, que todas as cinco definições podem ser relacionadas.

Quadro 1: Definições para estratégia

\begin{tabular}{|l|l|}
\hline Abordagem da estratégia & Definição \\
\hline Estratégia como Plano & $\begin{array}{l}\text { Curso de ação consciente pretendido, uma } \\
\text { diretriz (ou conjunto de diretrizes) para } \\
\text { lidar com uma situação. }\end{array}$ \\
\hline Estratégia como Pretexto & $\begin{array}{l}\text { Relacionada à estratégia como plano, no } \\
\text { intuito de “manobrar" a concorrência } \\
\text { induzindo os concorrentes a uma } \\
\text { percepção equivocada. }\end{array}$ \\
\hline Estratégia como Padrão & $\begin{array}{l}\text { Padrão em uma corrente de ações. } \\
\text { Consistência no comportamento, } \\
\text { consciente ou não. }\end{array}$ \\
\hline Estratégia como Posição & $\begin{array}{l}\text { Meio de localizar uma organização no } \\
\text { ambiente. }\end{array}$ \\
\hline Estratégia como Perspectiva & $\begin{array}{l}\text { Consiste não apenas em uma posição } \\
\text { escolhida, mas em uma maneira fixa de } \\
\text { ver o mundo. }\end{array}$ \\
\hline
\end{tabular}

Fonte: Mintzberg, 2006.

Mainardes, Ferreira e Raposo (2011) identificaram mais de 30 conceitos de estratégia, em robusta revisão teórica realizada sobre o tema, reforçando a diversidade de entendimentos.

Um dos elementos fundamentais no processo de PE é a formulação de estratégias. Além de constituir-se num instrumento da gestão administrativa de comprovada eficiência, a estratégia é a diretriz condutora dos destinos e distintiva da forma de atuação de uma organização. 
Dentre a extensa literatura sobre estratégias, não há nenhuma definição universalmente consagrada do que seja estratégia. Em Mintzberg (1987 e 2000), podem-se encontrar quatro conceituações diferentes para estratégia. Em Porter (1988; 1996a e 1996b; 1997), encontra-se duas definições distintas: estratégia como a criação de uma posição única e valiosa, envolvendo um diferente conjunto de atividades, e estratégia como a determinação de ajustes entre as distintas atividades da empresa. Vários outros autores possuem distintas abordagens de estratégias, como Miles e Snow (1978), Tregoe e Zimmerman (1988), Herbert e Deresky (1987), Miller e Dess (1993), Hambrick (1983), Hamel e Prahalad (1995), Ries e Trout (1995), Zaccarelli (1996, 2000), Bertero (1983, 2003) e Slywotzky e Morrison (1998).

Tratando da pluralidade de definições existentes sobre estratégia, Mintzberg et al (2006), a partir de pesquisa histórica sobre a literatura estratégica sugerem que ela tem sido caracterizada por dez principais escolas que tratam do tema, identificando limitações e contribuições referentes à formulação da estratégia. As escolas perpassam a natureza prescritiva, descritiva e integrativa da formação de estratégia.

Quadro 2: Escolas e a formulação de estratégias

\begin{tabular}{|c|c|c|}
\hline Escolas & Formulação da estratégia & \multirow{2}{*}{ Natureza } \\
\hline Escola do Design & Processo de concepção & \multirow{2}{*}{ Prescritiva } \\
\hline Escola do Planejamento & Processo formal & \\
\hline Escola do Posicionamento & Processo visionário & \\
\cline { 1 - 2 } Escola Empreendedora & Processo visionário & \multirow{2}{*}{ Descritiva } \\
\hline Escola Cognitiva & Processo mental & \\
\hline Escola de Aprendizado & Processo emergente & \\
\hline Escola do Poder & Processo de negociação & \\
\hline Escola Cultural & Processo coletivo & \\
\hline Escola Ambiental & Processo reativo & \\
\hline Escola de Configuração & Processo de transformação & \\
\hline
\end{tabular}

Fonte: adaptado de Mintzberg, Ahstrand e Lampel (2000)

As estratégias de natureza prescritiva se preocupam mais com a forma do que como elas serão formuladas. As descritivas consideram aspectos específicos do processo de formulação de 
estratégias. Já as integrativas agrupam o processo de formulação de estratégias, os conteúdos das mesmas, as estruturas organizacionais e seus contextos.

A presente tese apresenta contribuições de natureza prescritiva e descritiva, mas busca a formação estratégica integrativa, própria da Escola de Configuração, que tenta integrar conceitos de todas as escolas, numa perspectiva de constante mudança, que necessita de estratégias conjuntas entre os diferentes stakeholders, em opção às estratégias puramente competitivas (MINTZBERG et al., 2006; BRONZERI e BULGACOV, 2014).

Com a globalização da economia e os avanços tecnológicos, as mudanças estão cada vez mais rápidas, com incremento de riscos e forte competição, exigindo das empresas estratégias e soluções inovadoras. Diante da necessidade de adaptação, intensifica-se a necessidade da reorganização dos modos de gestão com a finalidade de compatibilizar a organização com padrões mais avançados de qualidade e produtividade (BASSO, 1998).

De acordo com Leon e Amato (2001), esse movimento de mudanças nas relações organizacionais vem se intensificando, à medida que, se acumulam e consolidam as transformações técnicas, organizacionais e econômicas. Todas essas mudanças provocam alterações na forma de produzir, de administrar, de distribuir, visando alterações nas relações entre empresas, entre empresas e trabalhadores e entre empresas e instituições.

Nos últimos trinta anos, ocorreram inúmeras transformações econômicas, como por exemplo, clientes mais exigentes, ampla oferta de produtos similares, mercados mais competitivos e crescente pressão pela redução de custos. A maioria das organizações não consegue suportar ou acompanhar essas mudanças de forma isolada, necessitando adotar estratégias de cooperação. O incentivo para cooperar está na percepção de que é possível a obtenção de ganhos através da ajuda mútua, ou seja, o desempenho de cada um pode ser superior ao que seria possível caso não contasse com a cooperação dos demais (AXEROLD, 1990; BORTOLASO, VERSCHOORE, ANTUNES, 2012).

As estratégias cooperativas ganharam destaque na década de 80 por meio dos estudos de Astley (1984), no qual defendia a existência de um terceiro nível de estratégia: aquelas suportadas por ações conjuntas. Em um artigo seminal, Astley e Fombrum (1983) já deixavam 
claro que a adoção de estratégias cooperativas consistia em uma importante alternativa para amortecer os impactos das transformações econômicas, unindo forças e minimizando o impacto das ações dos concorrentes. Os autores conceituam as estratégias cooperativas como tentativas de grupos de organizações que gerenciam sua interdependência de maneira mútua no ambiente dinâmico das relações interorganizacionais (ASTLEY; FOMBRUM, 1983).

A estratégia cooperativa necessita oferecer suporte para a concretização dos objetivos definidos coletivamente (Park, 1996). As estratégias cooperativas representam a necessidade das organizações em promover ações de cooperação para lidar com suas naturais interdependências dinâmicas, constituindo uma organização que pode ser deliberada para melhor lidar com a instabilidade ambiental (Bresser; Harl, 1986; Bresser, 1988; Oliver, 1988), da mesma forma que, na natureza, muitos animais aglutinam-se em grupos para se protegerem e sobreviverem.

No contexto do setor de saúde, é relevante afirmar que a operacionalização da estratégia deva ser realizada por meio de ações conjuntas alinhadas, conforme prevê as Diretrizes para organização da rede de atenção à saúde do SUS - Decreto 4.279/2010 (Brasil, 2010). Neste decreto há menção à intersetorialidade, como um dos princípios orientadores da promoção da saúde, entendida como um processo articulado e integrado de formulação e implementação de políticas públicas, no sentido do desenvolvimento humano e da qualidade de vida, que pressupõe a integração de estruturas, recursos e processos organizacionais e que se caracteriza pela co-responsabilidade de setores governamentais e não governamentais (FERNANDEZ e MENDES, 2003; FERNANDEZ et al., 2014).

Considera-se a intersetorialidade como a integração dos mais diversos setores para a consecução das ações públicas, mantendo as especificidades de cada área, buscando a superação de práticas fragmentadas e a eficiência para atingir os objetivos e resultados. É uma articulação maior entre diversos saberes para alcançar um objetivo mais amplo (BELLINI et al. 2013).

A prática intersetorial não corresponde unicamente a articular setores do governo, com o objetivo da racionalização econômica da gestão, mas implica examinar criticamente valores, 
práticas, posturas, poderes e modos de pensar na perspectiva de transformação (FERNANDEZ et al. 2014).

Pode-se considerar a intersetorialidade como um modelo de gestão de políticas públicas que se baseia na contratualização de relações entre diferentes setores, onde responsabilidades, metas e recursos são compartilhados, compatibilizando uma relação de respeito à autonomia de cada setor, mas também de interdependência. A intersetorialidade tem como valor fundamental a totalidade do cidadão e da família, quanto à oferta de serviços públicos e acesso a direitos sociais. A definição das estratégias e metas em uma política pública precisa estar definida claramente, caso contrário, corre-se o risco de incorrer uma "guerra de inimigos", caminhando em direção oposta à proposta da intersetorialidade.

A intersetorialidade apresenta potencialidade de ser uma inovação na política pública, na condução, operacionalização e reorganização da gestão dos serviços ofertados, viabilizando uma nova relação entre o munícipe e os gestores, levando em consideração as peculiaridades locais (INOJOSA, 1998; 2011).

Intrínsecos ao campo da intersetorialidade há princípios básicos, a se destacar: senso de responsabilidade, de compartilhamento, parceria, envolvimento, articulação, cooperativismo, interface, conexão, participação, diálogo, trabalho em rede, integração, dentre outros. Esta envolve ações integradas de distintos setores no atendimento à população cujas necessidades são pensadas a partir de sua realidade concreta, de modo a colocar em pauta as peculiaridades de suas condições de vida (INOJOSA, 1998; JUNQUEIRA, 2000).

Devido à amplitude de ações para que a intersetorialidade seja implementada, Garajau (2013) define três dimensões necessárias. A primeira dimensão condiz ao diagnóstico ou mapeamento da rede para permitir que se desenvolva o conhecimento transversal dos possíveis envolvidos no processo na perspectiva da articulação Intersetorial. Na segunda dimensão devem-se estabelecer contatos e estreitar relações visando buscar suporte para projetar ações comuns, definir possibilidades de intervenções, dialogar, pactuar funções e diretrizes. Na terceira dimensão é o momento de executar e planejar o papel de cada um dos envolvidos e gerar decisões coletivas, planejamento integrado e atividades continuadas com 
os atores envolvidos no desenvolvimento da ação em si, na busca da efetivação de ações integradas.

A intersetorialidade na saúde pressupõe necessariamente a ampliação da compreensão do ambiente organizacional e institucional. O exercício do poder, a racionalidade, o oportunismo, os conflitos de interesse, são alguns dos elementos presentes quando do processo de elaboração das políticas públicas para a saúde. Um modelo que tem sido utilizado com resultados satisfatórios é o dos múltiplos fluxos, originário dos estudos sobre a formação da agenda pública, de Kingdon (2003) e Zahariadis (2007), com origem no modelo de decisão em organizações. O modelo preconiza a presença da ambigüidade na tomada de decisão em função de três fatores: (i) participação fluida pela grande rotatividade dos atores envolvidos nas arenas decisórias; (ii) preferências vulneráveis, uma vez que não há a compreensão clara dos impactos das decisões; (iii) tecnologias mal definidas, especialmente no setor público, marcado por crescente interdependência, disputas intra e intergovernamentais, conflitos jurisdicionais, contestações em relação à divisão de atribuições e de responsabilidades (GOTTEMS et al., 2013).

Kingdon (2003) propõe que o processo de tomada de decisão nas políticas públicas pode ser representado pela integração de três grandes correntes dinâmicas: a corrente dos problemas (problems), a das propostas ou alternativas (policies) e a da política (politics). Assim, a agenda governamental segue um processo não intencional que se caracteriza por: 1) surgimento ou reconhecimento de um problema pela sociedade em geral; 2) existência de idéias e alternativas para conceituá-los - originadas de especialistas, investigadores, políticos e atores sociais, dentre outros; 3 ) contexto político, administrativo e legislativo favorável ao desenvolvimento da ação (Figura 1) (KINGDON, 2003; ZAHARIADIS, 2007; MANNHEIMER et al., 2007; GOTTEMS et al., 2013). 


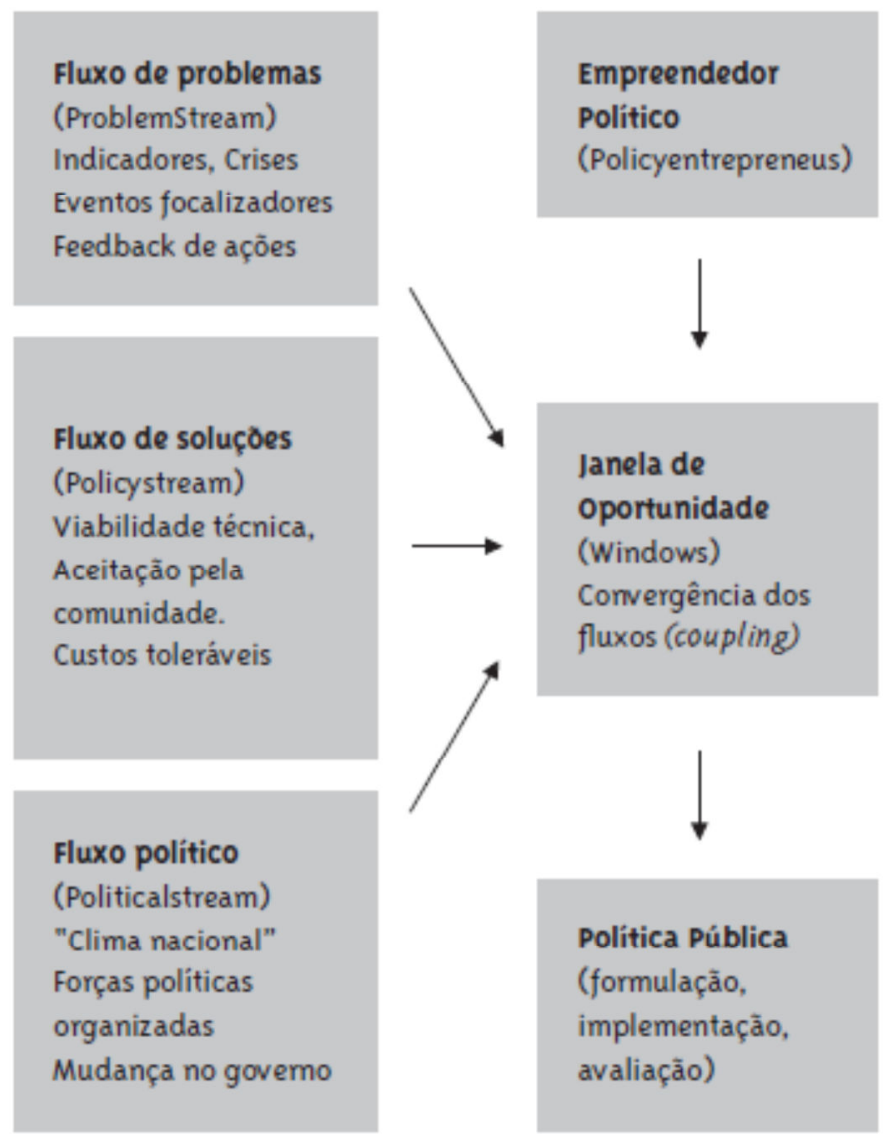

Figura 1: O modelo dos múltiplos fluxos de Kingdon Fonte: adaptado de Capella, 2007: pág. 98 e Zahariadis, 2007: pág. 71.

O fluxo dos problemas do modelo Kingdon analisa a forma que as questões são reconhecidas, sendo que a ação governamental se dará em função de três acontecimentos: 1) indicadores que apontam e mensuram a magnitude de uma situação; 2) a ocorrência de eventos, crises, desastres ou uma experiência pessoal; e 3) o feedback do monitoramento sobre o orçamento, custos e gastos. A resposta dos agentes governamentais depende da forma como estes percebem e interpretam a realidade. No setor de saúde os indicadores sociais e epidemiológicos são importantes na formação da agenda.

O fluxo das soluções inclui um conjunto de idéias e propostas em disputa, que buscam a aceitação dos atores envolvidos. Alguns padrões são percebidos nas alternativas escolhidas, tais como: a confiabilidade técnica; a aceitabilidade e compatibilidade entre os valores vigentes na sociedade; e a capacidade de antecipar contingenciamentos futuros, como os orçamentários (KINGDON, 2003). 
No fluxo político do modelo dos múltiplos fluxos três elementos são considerados: o clima nacional (national mood), as forças políticas organizadas e as mudanças no governo (KINGDON, 2003; ZAHARIADIS, 2007).

A intersetorialidade se dá pelos atores governamentais - o staff do poder executivo e os servidores de carreira - e os não governamentais - compostos pelos grupos de interesse e pelos grupos acadêmicos. Há entre estes, aqueles que exercem um papel fundamental na integração dos fluxos, chamados pelo modelo de Kingdon de empreendedor político, que detêm qualidades básicas, tais como: o apelo para se fazer ouvir, articulações políticas, habilidades para negociar e persistência. A integração dos três fluxos - problemas, alternativas e política - abre uma janela de oportunidades. Assim como as janelas podem se abrir, elas também fecham, na medida em que não há convergência (KINGDON, 2003; ZAHARIADIS, 2007; GOTTEMS et al., 2013).

O desafio desta tese é integrar o modelo dos múltiplos fluxos de Kingdon (2003) e as ferramentas do planejamento estratégico amplamente difundidas na sociedade, na perspectiva de construção de um modelo alternativo de políticas públicas para o setor de saúde.

\section{.2 O Planejamento Estratégico como instrumento de gestão}

Segundo Almeida (2010), duas distinções devem ser feitas para compreender a definição de PE. A primeira delas refere-se ao PE da Administração Estratégica (AE). A segunda, à diferença da ferramenta $\mathrm{PE}$ em relação às outras formas de formular estratégias.

Para auxiliar a conceituar a AE, utiliza-se aqui, a definição de administração e dos níveis da organização. Administração pode ser definida como planejar, dirigir, organizar e controlar, baseada no enfoque funcional de Henri Fayol (Maximiano, 1995, p. 61). Os níveis organizacionais podem ser divididos em estratégico, administrativo ou integrativo e operacional (Ansoff, 1977, p. 6 - 7). A junção dos dois conceitos ajuda a definir AE, como sendo a "administração no nível estratégico da organização" (Fischmann e Almeida, 1991, p. 123). Com base nessa definição, pode-se deduzir que o PE é uma das etapas da AE. Apesar da 
importância da AE para implementar as ações propostas no planejamento, esta pesquisa está focada em apenas uma etapa deste processo, que é a ferramenta de formular a estratégia.

Fischmann e Boaventura (2003), analisando definições de PE, concluem que alguns autores definem o PE como sendo uma ferramenta (ou técnica) administrativa e outros como um conceito mais amplo. Neste trabalho, o conceito de PE não é qualquer forma de pensar sobre o futuro da organização, mas uma forma organizada de realizar este processo. Quando se fala em forma organizada de realizar, está-se referindo a uma estratégia. Nesta pesquisa, porém, PE não está restrito à definição de Gaj (1987, p. 22), que se refere ao PE como "ao processo utilizado para formular a estratégia", aproximando-se, mas sem a mesma amplitude da definição proposta por Fischmann e Almeida (1991. p. 25):

Planejamento estratégico é uma técnica administrativa que, através da análise do ambiente de uma organização, cria a consciência das suas oportunidades e das ameaças dos seus pontos fortes e fracos para o cumprimento da sua missão e, através desta consciência, estabelece o propósito de direção que a organização deverá seguir para aproveitar as oportunidades e evitar as ameaças.

Para facilitar a compreensão do processo de PE, ele pode ser dividido em três partes distintas e complementares: a arquitetura do processo, o modelo e a formulação de estratégias.

\subsubsection{A Arquitetura do Processo de PE}

A denominação de "Arquitetura do Processo" não é consagrada na literatura de PE, mas foi a expressão que Almeida (2004) melhor encontrou para denominar o desenho que se realiza antes de iniciar um processo de PE.

A arquitetura do processo compreende a justaposição, de forma congruente e racional, dos elementos constitutivos do processo, garantindo assim, a elaboração e a implementação do PE, eficazmente, numa organização (ALMEIDA 2004).

Outros autores, como Kay (1996, p.73), também trataram deste assunto, mas com uma conotação distinta, definindo como uma "rede de contratos consensuais dentro e em torno da organização". O valor da arquitetura está na capacidade de uma organização em criar 
conhecimento e rotinas organizacionais, que a tornem flexível e capaz de responder com mais propriedade às variáveis circunstanciais.

O singular, no conceito de arquitetura de processo, para Kay (1996), é que, sendo uma rede de contratos internos, ela é específica para cada organização. A arquitetura do processo prevê o arranjo dos conteúdos a serem desenvolvidos e a forma de tratamento desses conteúdos, respeitando as características individualizantes da organização. Estas últimas, tais como valores culturais e estilo de governança, são determinantes do perfil do arranjo.

Bem mais simplificada, a proposta da Alliance for Nonprofit Management (2004), identifica cinco passos, como processo de PE: (1) ficando pronto; (2) articulando missão e visão; (3) acessando a situação; (4) desenvolvendo estratégias, metas e objetivos e (5) completando o plano escrito.

No primeiro passo, desenvolve-se um plano de trabalho. Nele, as questões iniciais são tratadas como a direção que a organização deveria tomar a identificação dos papéis, ou funções dos participantes, o perfil da organização e a formação do Comitê de PE.

No segundo passo, desenvolve-se a missão e a visão da organização. Nesse passo, é importante deixar claros três aspectos: o propósito da organização; o negócio em que a organização está envolvida e os valores, os princípios ou crenças que guiam os membros da organização.

No passo três - acessando a situação - buscam-se informações para construção e disponibilização de uma base de dados de informações de qualidade, que possam ser usadas para tomar decisões. Elabora-se, uma lista de questões que requeiram resposta ou uma posição da organização.

No passo quatro, desenvolvendo estratégias, metas e gols, constrói-se um desenho das direções estratégicas da organização. Em outras palavras, gera-se aqui, as estratégias gerais, objetivos de longo prazo e objetivos específicos para as respostas da organização às questões estratégicas. 
Por fim, no passo cinco, completa-se o plano estratégico por escrito. Estando a missão bem articulada, identificadas as questões estratégicas, e definidos os objetivos e metas de longo prazo, fecha-se o plano estratégico.

Similar com o processo da Alliance for Nonprofit Management (2004), o processo de PE do QuickMBA (2004) parte diretamente da determinação da missão e objetivos, passa pela análise ambiental, formulação de estratégia, implementação das estratégias e avaliação. Um diagrama simplificado, desse processo, é apresentado na figura 2.

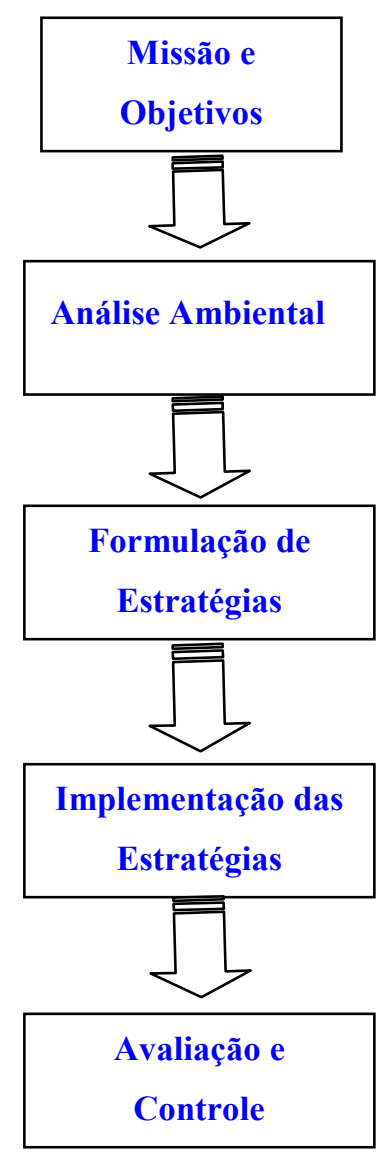

Figura 2: O processo de PE Fonte: QuickMBA (2012).

Semelhante ao processo determinado no Modelo de Almeida (2010), que será apresentado na seqüência, com exceção da determinação das diretrizes superiores para Unidades, o processo, inicia-se na identificação da missão e visão organizacionais, passa à análise ambiental, à formulação da estratégia, sua implementação, avaliação e controle. A maioria dos processos sugeridos, na literatura específica também se inicia pela identificação da missão e visão. Outra semelhança, ao modelo de Almeida (2010), é que este processo, após a análise ambiental, 
sugere a formulação de estratégias, e não a formulação dos objetivos e metas estratégicos, como a maioria dos autores desenvolve. Obviamente, a prática desse processo deve incluir a formulação de objetivos, sem os quais não seria possível a implementação da estratégia, o passo seguinte.

Da análise dos vários processos aqui apresentados, fica claro que, embora muitos autores tenham se esforçado para apresentarem um processo racional de PE, algumas abordagens, nitidamente tentam explicar o que as abordagens de outros não perceberam ou não foram consideradas. A história dos sucessos e falhas do PE, nessas organizações, justifica a grande busca pelas tentativas de explanação aqui discutidas.

Em alguns casos, o processo apresenta uma super simplificação, como no caso do QuickMBA (2004), eventualmente prejudicial à eficácia da mudança organizacional pretendida pelo planejamento. Em outros, as abordagens apresentam vieses que não, necessariamente, permitem a tais processos serem generalizados. Não há, portanto consenso para a maioria dos autores e as abordagens tendem a adaptar-se às nuances de cada situação, ou características de cada organização.

\subsubsection{Modelos de Planejamento Estratégico}

Para Mintzberg; Ahlstrand e Lampel (2000, p. 45) "existem centenas de modelos diferentes de planejamento estratégico". Cada organização traz especificidades diferenciadoras, quer por suas singularidades culturais, quer por suas características de tamanho e complexidade constitutiva.

Um modelo de PE é a forma de sistematizar a realização das atividades de planejamento, dentro de uma concepção racional de execução. Normalmente, um modelo pode ser representado por um esquema, ou diagrama seqüencial, indicando as etapas que devem ser percorridas para se cumprir o processo (BRYSON, 1995).

Neste trabalho são apresentados dois Modelos de Planejamento Estratégico - MPE, com foco em seus processos. O primeiro a ser descrito é o de Almeida (2010) que serve de base ao 
modelo aplicado no processo do Hospital Universitário da UFSM, escolhido em função da tese de livre docência do Autor, Almeida (2004), cuja aplicação prática mostrou-se adequada para o caso da Universidade de São Paulo. E o segundo é o modelo de Bryson (1995), desenvolvido para aplicação em instituições públicas ou de fins não lucrativos.

\subsubsection{O Modelo de Almeida}

A figura 3 mostra o processo de estabelecer a estratégia seguindo os passos determinados pelo Modelo de Almeida (2010).

O modelo de PE ilustrado apresenta cinco dimensões constitutivas: orientação, diagnóstico, direção, viabilidade e operacional. A orientação contém os elementos básicos que estabelecem para onde os esforços que vão determinar as mudanças organizacionais devem convergir. Aí se concentram as diretrizes e políticas organizacionais maiores, que brotam da missão e da visão institucionais, necessárias para que as unidades e as divisões inferiores possam estabelecer seus objetivos, metas e estratégias.

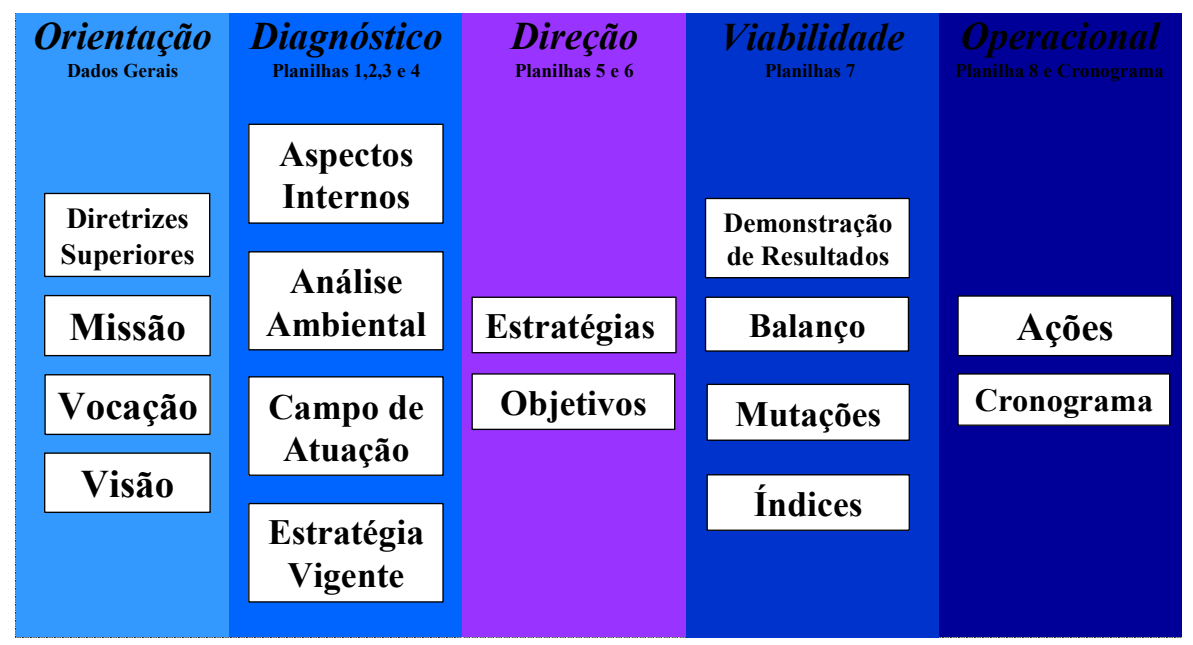

Figura 3: Modelo de desenvolvimento de um PE Fonte: ALMEIDA, (2010, p.42)

O diagnóstico é a seguinte dimensão, que contém os elementos críticos do PE: os aspectos internos, análise ambiental, campo de atuação e estratégia vigente. Os dados obtidos com a diagnose da organização, e de seu entorno, provêm às informações necessárias para as 
decisões de direcionamento, que são representadas pelas possíveis estratégias que são levantadas nesta dimensão do processo.

A direção é a terceira dimensão do PE, segundo o Modelo de Almeida (2004). Compreende as estratégias e os objetivos, isto é, a definição das estratégias como base para o estabelecimento dos objetivos estratégicos.

A quarta dimensão é a viabilidade. Essa dimensão compreende a demonstração dos resultados, o balanço, as mutações e os índices. Aqui, verifica-se a viabilidade das alterações propostas no plano estratégico, por meio dos resultados e tipo de resultados a que se quer chegar, do balanço (já que os números econômicos são essenciais para continuidade da organização), as mutações pretendidas, ou necessárias, para a organização alcançar os objetivos estratégicos e os índices. Estes últimos determinam a intensidade e a realidade da eficácia da estratégia.

Finalmente, a última dimensão é a operacional, que compreende o conjunto de ações relativas à implementação do plano estratégico. Nesta dimensão são determinadas as ações, as responsabilidades e o tempo para que o $\mathrm{PE}$ aconteça de forma efetiva.

a) Detalhamento do modelo

As ações de elaboração do plano estratégico iniciam com a dimensão de Orientação Para nortear as atividades das seguintes dimensões, é necessário que sejam, primeiramente, emitidas as diretrizes superiores e discutidas a missão e/ou vocação da entidade, a sua visão aproximada e, no caso de unidades, sejam entendidas as diretrizes estratégicas superiores.

A missão é a razão de ser da entidade e serve para delimitar seu campo de atuação, como também para indicar as possibilidades de expansão de suas ações. Dentro do conceito de missão podem-se acrescer os valores da organização, que também nortearão toda a estratégia da empresa. O conceito de missão é mais aplicado a grandes empresas podendo ser também utilizados para unidades ou pequenas empresas. Porém, terá pouco sentido o conceito aplicado a indivíduos, já que a missão 
de um indivíduo extrapola o seu campo profissional, estando, este, mais relacionado ao seu sustento e satisfação, que, por sua vez, está ligado ao conceito de vocação.

Sendo o conceito de vocação vinculado ao indivíduo, engloba o gosto e a facilidade de executar uma determinada atividade. Quando se fala de empresas, ou de suas unidades, a vocação poderá ser identificada a partir de um conjunto de pessoas com vocações comuns, sendo que, em geral, é predominante a vocação da pessoa que lidera a entidade.

A visão não é apenas um grande objetivo, mas um desafio e deve, também, indicar de como atingi-lo. Em uma organização, onde as pessoas têm a visão estratégica, não é necessário que se determine tudo o que elas devem fazer, pois a visão orienta as ações.

O processo de PE inicia com o estabelecimento de uma visão aproximada e, ao final, chega-se a uma visão mais precisa, que deve ser compartilhada com todos os stakeholders (funcionários, terceirizados, clientes, fornecedores, governo etc.)

As unidades, filiais ou departamentos, de uma organização, serão denominados de unidades. Neste caso, é recomendável que as entidades superiores estabeleçam diretrizes estratégicas que irão nortear o plano estratégico. Essas diretrizes devem ser de número restrito, mas abrangente, de forma que se possa desenvolver a estratégia da unidade.

Caso a entidade superior não tenha definidas as diretrizes estratégicas para a unidade, esta poderá orientar-se por definições que possam existir em unidades superiores (como Missão e Visão).

b) Atividades do PE

A dimensão do Diagnóstico apresenta quatro elementos, ou atividades, que dão início ao envolvimento das camadas da organização realmente responsáveis pela elaboração do PE. As quatro atividades poderão ser desenvolvidas em qualquer ordem e servirão para estabelecer a estratégia. 
Inicialmente descreve-se a Análise dos Aspectos Internos. Nesta atividade ocorre a conscientização sobre os pontos fortes e fracos. Esta é a forma de maximizar a eficiência da entidade. Neste exercício, de análise dos aspectos internos são identificados, inicialmente, os fatores de sucesso de uma empresa em seu ramo de atividade, de uma unidade de empresa ou de um profissional, que levam a entidade ao cumprimento de sua Missão (razão de ser) ou Vocação (ALMEIDA, 2004) .

Esses fatores, que levam uma entidade ao sucesso, são chamados de Fatores Críticos de Sucesso (FCS). Os FCS são aqueles considerados como chaves, ou seja, fatores cujo desenvolvimento será determinante e principal responsável para que uma entidade se sobressaia em relação a outras entidades.

A seguir, procura-se comparar os FCS com o dos concorrentes, ou entidades semelhantes, para verificar aqueles que são superiores, inferiores ou semelhantes aos das entidades comparadas. Essa análise levará aos pontos fortes e fracos. Para os pontos fortes será indicada a estratégia que possa tirar vantagem desta condição, e, para os pontos fracos, a estratégia deverá ser de reduzi-los.

Quando se pede para um empresário comparar sua organização com um seu concorrente, a primeira reação daquele é achar que não conhece suficientemente o concorrente, mas quando solicitamos para que identifique os FCS de sua organização, sempre tem uma idéia, mesmo que não seja precisa e, a partir desta constatação, há uma maior facilidade de estabelecer as comparações. Observa-se que o desconhecimento dos concorrentes também pode ser um ponto fraco, pois é importante, para o sucesso, conhecer os concorrentes. O mesmo acontece quando se compara com outra unidade de uma empresa ou outro profissional.

Na comparação dos FCS serão identificados aqueles em que se está melhor ou pior que o padrão de comparação. É claro que a base dos pontos fracos são os FCS em que se está pior, e o inverso em relação aos pontos fortes. Mas quando forem mencionados os pontos fortes e fracos, estes devem ser descritivos e, se possível, englobar os vários pontos em uma só frase. 
c) c) Análise do Ambiente

Um importante diferencial apresentado pelo modelo de Almeida (2010) consiste na etapa do diagnóstico denominada análise ambiental. Segundo Almeida (2004, p.44), "dentro do processo de estruturar a análise ambiental, deve-se, inicialmente, entender seus vários segmentos, que têm características e formas de análise diferente”. A proposta de segmentação ambiental é ilustrada no Quadro 3.

- Macro ambiente Clima (MC)

As variáveis do MC estão ligadas ao poder político, muitas vezes relacionadas às ações de governo municipais, estaduais, federais ou de outros países. As ações podem refletir desde restrições por mudança de leis, até projeções de crescimento da economia de um país, que terá uma influência mais abrangente.

Nas variáveis do MC também estão inclusas as variáveis políticas da organização em que a unidade está inserida, como possíveis mudanças de diretoria.

A previsibilidade do MC, de uma entidade, é semelhante ao que ocorre ao clima físico, onde se pode prever com certa facilidade, apenas o tempo a curtíssimo prazo, como uma frente fria que chegará nos próximos dias, ou uma tendência em longo prazo, como a certeza de que se terão mais dias quentes no verão do que no inverno, embora possa haver alguns dias mais frios no verão do que alguns dias quentes do inverno.

Como existem os meteorologistas, que são capazes de prever o clima físico, também existem os experts, que são capazes de prever as mudanças na economia e na política. Geralmente, estes experts são economistas, que se especializam em analisar as tendências e as previsões do futuro da política e da economia.

Da mesma forma que no clima físico, pode-se prever, com certa precisão, qual será a inflação deste mês, mas será difícil precisar qual será a inflação daqui a um ano. Nesse caso, pode-se ter uma tendência, que será aproximada, mas deverá indicar se existirá um período com maior ou menor inflação. 
Para a unidade de uma organização, é necessário visualizar, além das mudanças na economia e na política do país e do mundo, o que deverá ocorrer com a política de sua organização no futuro. Para isso, pode-se conversar com funcionários mais antigos, que seriam os experts da organização, para formar uma idéia de como deverá ser a estratégia da unidade. De qualquer forma, a previsão do $\mathrm{MC}$ possui grau de variabilidade, sendo incerto.

Quadro 3: Segmentação Ambiental

\begin{tabular}{|c|c|c|c|}
\hline $\begin{array}{c}\text { Segmento } \\
\text { Ambiental }\end{array}$ & Variáveis Ambientais & Características & Método de Análise \\
\hline $\begin{array}{l}\text { Macroambiente } \\
\text { Clima }\end{array}$ & $\begin{array}{l}\text { Variáveis decorrentes do Poder } \\
\text { Político: Inflação, Crescimento } \\
\text { do PIB, Legislação. }\end{array}$ & $\begin{array}{l}\text { Difícil de ser previsto em curto } \\
\text { prazo, mas pode-se projetar uma } \\
\text { tendência em longo prazo. }\end{array}$ & $\begin{array}{l}\text { Deve-se ouvir a opinião de } \\
\text { Experts e apostar em uma } \\
\text { tendência política em longo } \\
\text { prazo. Na análise tem-se que } \\
\text { traduzir em fatos políticos como } \\
\text { eleição e aprovação de leis. }\end{array}$ \\
\hline $\begin{array}{l}\text { Macroambiente } \\
\text { Solo }\end{array}$ & $\begin{array}{l}\text { Variáveis do futuro da } \\
\text { população e suas características: } \\
\text { crescimento por região, por } \\
\text { faixa de renda, por sexo. }\end{array}$ & $\begin{array}{l}\text { As previsões são precisas e } \\
\text { disponíveis em } \\
\text { como o IBGE }\end{array}$ & $\begin{array}{l}\text { Devem-se usar estudos } \\
\text { estatísticos, que normalmente } \\
\text { estão disponíveis. }\end{array}$ \\
\hline $\begin{array}{l}\text { Ambiente } \\
\text { Operacional }\end{array}$ & $\begin{array}{l}\text { Variáveis decorrentes das } \\
\text { operações: } \\
\text { fornecedores, clientes diretos. }\end{array}$ & $\begin{array}{l}\text { As previsões procuram } \\
\text { identificar como serão as } \\
\text { relações operacionais no futuro, } \\
\text { levando-se em conta a evolução } \\
\text { tecnológica. }\end{array}$ & $\begin{array}{l}\text { O método de análise é o estudo } \\
\text { de Cenários, que se utiliza das } \\
\text { tendências atuais para identificar } \\
\text { o relacionamento operacional } \\
\text { futuro. }\end{array}$ \\
\hline $\begin{array}{l}\text { Ambiente } \\
\text { Interno }\end{array}$ & $\begin{array}{l}\text { Valores e aspirações das pessoas } \\
\text { relevantes. No caso de empresas } \\
\text { pode-se segmentar entre } \\
\text { proprietários e funcionários. }\end{array}$ & $\begin{array}{l}\text { Os valores e aspirações das } \\
\text { pessoas são difíceis de serem } \\
\text { mudados. As empresas ou suas } \\
\text { áreas normalmente agrupam } \\
\text { pessoas com } \\
\text { semelhantes. }\end{array}$ & $\begin{array}{l}\text { Para identificação dos valores } \\
\text { de empresas ou de suas áreas, é } \\
\text { utilizado o sistema de análise da } \\
\text { Cultura Organizacional. }\end{array}$ \\
\hline
\end{tabular}

Fonte: Almeida (2010).

- Macroambiente Solo (MS)

As variáveis do MS estão ligadas ao estudo da tendência da população e suas características, que compõem a finalidade última de toda atividade profissional. As tendências da população poderão ser de crescimento ou redução, segundo características que nos interesse estudar, como, por exemplo: por faixa de renda, escolaridade, por idade ou por região.

A previsibilidade das variáveis do MS é muito precisa, existindo estatísticas elaboradas pelo governo, como as do Instituto Brasileiro de Geografia e Estatística (IBGE), com fácil acesso e baixo custo. 
Um cuidado que se deve tomar, é identificar as influências das variáveis do MC no MS, pois, da mesma forma que no ambiente físico, as variáveis do clima têm influências em longo prazo no Solo, ou seja, um crescimento maior ou menor da economia pode afetar não apenas a evolução da população por classe de renda, como a afetar a evolução da escolaridade, e até crescimento demográfico.

Note-se que a análise desse segmento ambiental para uma unidade, ou um profissional, não tem diferenças significativas de uma organização, pois se está analisando o mercado potencial, seja da empresa onde a unidade está inserida, seja do mercado de trabalho onde o profissional pretenda se desenvolver.

- Ambiente Operacional (AO)

A análise do AO implica entender como a entidade deverá funcionar, no futuro, nas suas operações, dentro das futuras tecnologias, com os demais componentes que se inter-relacionam, tais como fornecedores, prestadores de serviço, clientes e concorrentes.

Para se projetar como será o futuro do AO, deve-se usar uma técnica conhecida como elaboração de cenário, onde se projeta, pelas tendências conhecidas, como será o relacionamento operacional futuro. Tome-se como exemplo o setor de vendas de uma empresa, que tenha uma equipe que faça visitas aos clientes para anotar os pedidos. Hoje, já muitas empresas deixaram de ter o vendedor, que é apenas "tirador de pedido", com a evolução da informática e das comunicações, existirá ainda menos este trabalho, que poderá ser substituído com vantagem por outras formas de relacionamento, ficando, para o vendedor, um trabalho técnico de orientação quanto à utilização de seus produtos.

As técnicas de cenário também são utilizadas para o $\mathrm{MC}$, quando se discute as tendências políticas e econômicas, mas, neste caso, quase sempre a coleta de informações baseia-se em opiniões de experts, e não no relacionamento entre as variáveis. 
- Ambiente Interno (AI)

Muitos autores não utilizam a análise do AI para orientar a realização do Plano Estratégico, como também alguns autores chamam de AI o que são os aspectos internos, em que a entidade tem possibilidade de agir.

A pouca utilização da análise do AI para a realização do $\mathrm{PE}$, justifica-se pelas mudanças que estas técnicas vêm enfrentando. No início da realização do PE, dificilmente considerava-se a importância de se conhecer as necessidades, valores e aspirações dos funcionários, para se elaborar a estratégia das empresas. Os funcionários eram, muitas vezes, ainda, considerados como "Recursos", o que, de uma forma imprópria, leva, até hoje, a tratar a área, que cuida da parte humana da empresa, de "Recursos Humanos".

Mais recentemente, a ciência da administração vem mostrando que as empresas servem para satisfazer a diversos grupos, como os clientes, fornecedores, proprietários, governo e, inclusive, os funcionários e dirigentes.

Dessa forma, não se pode deixar de lado, na análise ambiental, o segmento que procura conhecer as aspirações e valores das pessoas que compõem a entidade, ou se relacionam com ela, principalmente no caso de profissionais.

Antigamente, as organizações eram voltadas para atender aos interesses apenas dos acionistas (shareholders). Hoje, no PE, deve-se levar em conta o conjunto das pessoas que se beneficiam da organização, chamados de stakeholders, que são, não só os acionistas, mas também os clientes, os fornecedores, os funcionários, dentre outros.

\subsubsection{O Modelo de Bryson}

Bryson (1995) propôs um modelo de PE para organizações públicas ou sem fins-lucrativos. O modelo é composto por 10 passos, destacados na Figura 4, a seguir, que formam o ciclo de mudança estratégica. Apesar dos passos estarem numerados de um a dez, o autor salienta que 
o processo pode ter início em qualquer uma das etapas. Na figura 4, estão apontados os pontos onde o autor julga mais comum que o processo seja iniciado. Consideração semelhante é feita sobre os pontos onde as metas podem ser formuladas, ou onde a visão pode ser formulada. Outra ressalva é feita quanto à linearidade do processo: as ações, resultados e avaliações podem surgir a qualquer momento. Isso é, a implementação e a avaliação do processo não precisam esperar o término de um para iniciar as ações do outro.

O primeiro passo - Acordo Inicial - tem por objetivo criar um compromisso com, pelo menos, os principais tomadores de decisão. Outros autores, como Cunha (1996), defendem a importância de um acordo inicial, destacando dois pontos: o sistema organizacional e as relações de cultura e poder. Já a importância de ter o compromisso dos principais executivos é destacada por diversos autores, tais como: Thompson Jr. e Strickland III (2000); Wright, Kroll e Parnell (2000) e Fischmann (1987). O acordo inicial deve buscar o compromisso da organização com o processo de planejamento, buscando uma compreensão coletiva (entre as pessoas-chave) do propósito do esforço de PE. Além desse acordo sobre a importância do processo para a organização, o acordo inicial deve buscar um consenso sobre a arquitetura do processo, o modelo e como será a sua condução.

O passo seguinte - esclarecimento das atribuições organizacionais - tem o propósito de clarear as atribuições formais da organização. Isto é, divulgar as legislações, estatutos e contratos que regem a organização. Bryson (1995) salienta a importância de clarear as atribuições informais (ou políticas), pois ele afirma que é comum o fato de uma pessoa, que não recebeu uma ordem direta para fazer alguma tarefa, achar que essa tarefa não deva ser feita.

O terceiro passo - clareando a missão e os valores - é a busca da razão de ser da organização, ou o seu papel social. É importante frisar que a razão de ser de uma organização pública ou sem fins-lucrativos, é determinada por seus colaboradores internos e externos (stakeholders no original). Já em empresas privadas, a missão está voltada para os clientes e proprietários. 


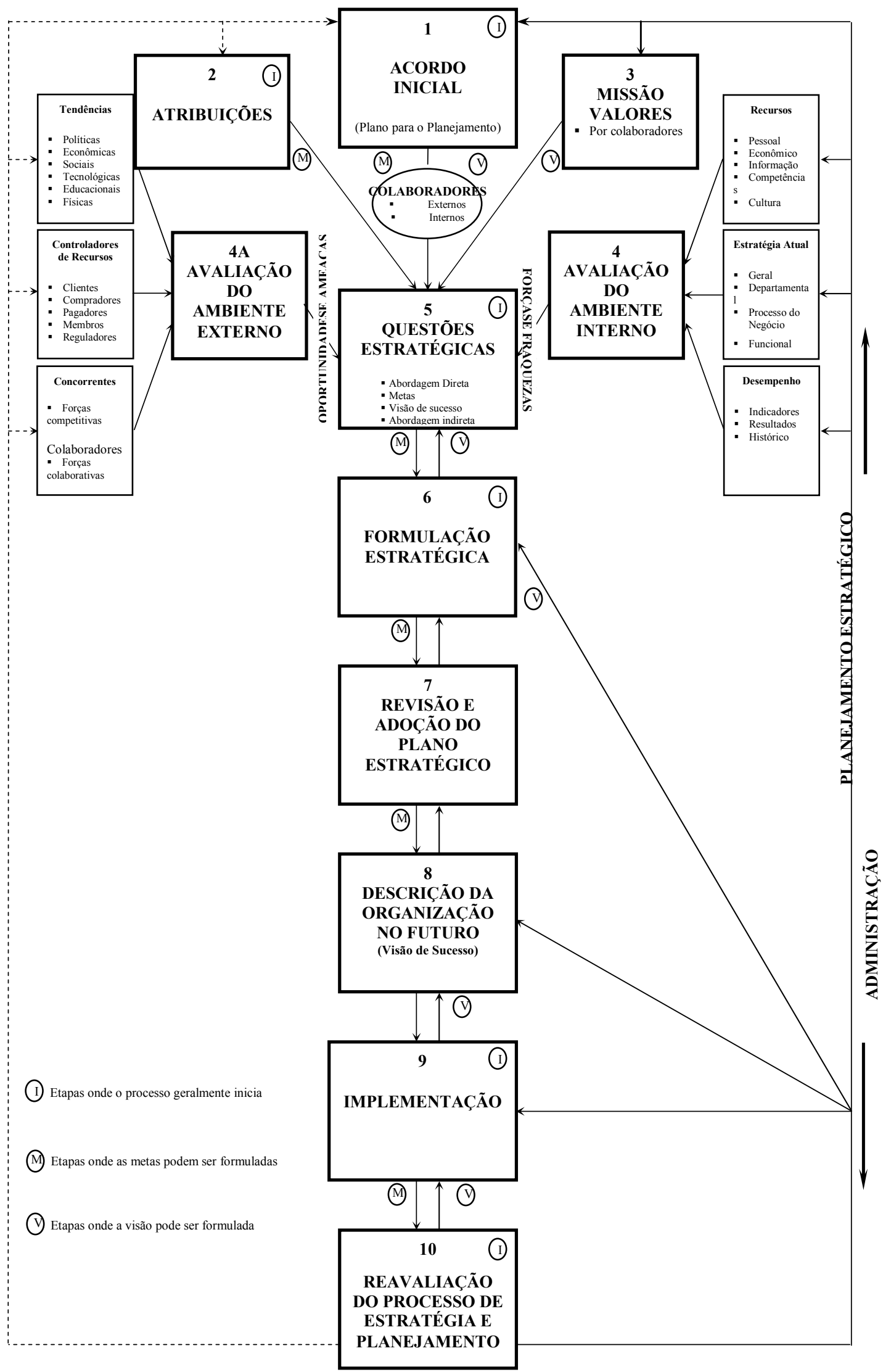

Figura 4:Modelo de PE de Bryson.

Fonte: Adaptado de BRYSON (1995, p. 24) 
Bryson (1995) salienta que a missão é importante para uma organização pública, ou sem finslucrativos, porque ela não é um fim em si mesma, mas a organização existe como um meio para cumprir um propósito.

Assim como no modelo de Almeida (2010), Bryson sugere que os valores façam parte da missão. Bem como a razão de ser e o seu propósito, os valores não são aqueles dos funcionários e proprietários, mas de toda a sociedade onde a organização atua (stakeholders).

Devido à importância dada aos colaboradores externos e internos (stakeholders) para clarear a missão da organização, é necessário ser feita, nesta etapa, uma análise dos principais colaboradores.

O passo de número quatro é a avaliação ambiental interna e externa, para identificar pontos fortes, pontos fracos, oportunidades e ameaças. Apesar de chamar de ambiente interno e não aspectos internos como é proposto por Almeida (2010), Bryson (1995) e Almeida (2004) afirmam que os pontos fortes e fracos vêm de fatores controlados pela organização, e as oportunidades e ameaças vêm daqueles que a organização não tem controle.

O quinto passo - identificação e organização das questões estratégicas - é, segundo Bryson (1995, p. 104), o “coração do processo de planejamento estratégico". É nesse passo que a organização busca conciliar as diversas demandas organizacionais, tanto as internas que buscam a eficiência, e quanto às externas, que buscam a eficácia. Para ajudar nesse processo, a questão estratégica (strategic issue, no original) deve ser sucintamente descrita, deve conter os fatores que tornam essa questão importante e ter uma lista das conseqüências, caso a organização falhe em lidar com essa questão.

O autor sugere quatro abordagens possíveis para levantar as questões estratégicas:

- A abordagem direta, semelhante à proposta por Almeida (2010), é aquela em que as questões estratégicas aparecem direto da discussão das etapas anteriores: etapa de orientação (passo 1, 2 e 3) e etapa de diagnóstico (passo 4). 
- A abordagem por metas, semelhante à proposta por Ansoff $(1977$, p. 20 24), inicia pela determinação de metas ou objetivos, e as questões estratégicas são formuladas no sentido de atingirem determinada meta.

- A abordagem pela visão de sucesso é semelhante à abordagem das metas, porém no lugar de uma meta clara, tem-se uma visão do futuro, ou um cenário. Esse tipo de formulação estratégica é defendido por Hamel e Prahalad (1995). Almeida (2010), em seu modelo, também utiliza a abordagem de visão na fase de orientação.

- A abordagem indireta é aquela em que os participantes propõem questões e, através da combinação das diversas idéias, e suas conseqüências, faz com que as questões estratégicas sejam formuladas. A mudança (ou inovação) estratégica surge da combinação, e não da mutação.

O passo seguinte é a formulação das estratégias e planos para administrar as questões estratégicas. A definição de estratégia, segundo Bryson (1995, p. 32) é "um padrão de propósitos, políticas, programas, ações, decisões ou alocação de recursos que definem o que a organização é, o que ela faz e por que ela faz isso" (tradução do autor). Além disso, a estratégia pode variar entre os diversos níveis organizacionais (corporativa, unidade de negócio etc.), pode ter diversas funções e limites de tempo. Bryson (1995) assume que a sua definição é ampla, mas ele faz isso para englobar a retórica das pessoas (o que elas falam), suas escolhas, suas ações e conseqüências. A estratégia efetiva é aquela que liga todos esses fatores e a cultura da organização. O autor sugere que o processo de formulação de estratégias ou escolha de estratégia, pode ser feito seguindo duas abordagens:

- O desenvolvimento de estratégia pode ser feito seguindo o modelo baseado no trabalho do Institute of Cultural Affairs que possui cinco etapas. A primeira é a identificação de alternativas práticas, na segunda, as barreiras devem ser enumeradas, a terceira etapa é o desenvolvimento de propostas para atingir as alternativas. A escolha entre as alternativas levará as ações que deverão acontecer nos próximos dois ou três anos (etapa quatro). A última etapa é a preparação de um programa de ação detalhado para os próximos seis meses (etapa cinco). 
- A outra abordagem, para desenvolver estratégias, é criar um "mapa" que indique, através de flechas (baseadas em considerações qualitativas), a influência de uma estratégia sobre a outra. A compreensão desse mapa levará a uma escolha sistêmica (buscando uma compreensão do todo), trabalhando com a sinergia entre as possibilidades estratégicas.

A revisão e adoção do plano estratégico (passo sete) têm como propósito ganhar um comprometimento formal para adotar, divulgar e realizar a implementação do plano. Em uma pequena organização ou em um processo mais participativo, este passo pode se fundir com o anterior (passo seis).

O passo oito - estabelecimento de uma visão organizacional efetiva para o futuro - é a descrição da organização, caso ela tenha conseguido implementar as estratégias. Essa descrição permite que os membros da organização saibam o que é esperado deles e possam trabalhar sem uma supervisão próxima da gerência. Almeida (2010) também menciona que o processo de PE leva à visão mais precisa sobre o futuro, e que isso facilita a tomada de decisões estratégicas por todos que tenham a visão, e, sendo assim, as pessoas passam a pensar estrategicamente.

O passo nove - efetivar o processo de implementação - para uma pequena organização, pode ser fundido com o passo seis. Porém, em uma grande organização, é importante o detalhamento do plano.

O último passo é a reavaliação das estratégias e do processo de PE. Esta etapa para as empresas que já estão envolvidas com o processo de administração estratégica é a preparação para uma nova rodada de planejamento, como apresentam, também, Fischmann e Almeida (1991). 


\subsubsection{Comparação dos Modelos}

Ambos os modelos apresentados, Bryson (1995) e Almeida (2010), explicitam um considerável arcabouço teórico. Bryson desenvolve um processo de dez (10) estágios (ver figura 3) para elaboração e implementação de um PE para organizações sem fins lucrativos, tipicamente organizações do terceiro setor. Almeida (2010) apresenta seu modelo sobre um arcabouço de elementos institucionais, assentados sobre cinco (5) bases (Orientação; Diagnóstico; Direção; Viabilidade; e Operacional).

Similarmente ao modelo de Almeida (2010), porém de forma mais simplificada, Bryson (1995) também entende que os fatores ambientais são basicamente fatores que não estão sob o controle da organização. Parte dos fatores do Ambiente Interno de Bryson (1995), porém, (aspectos internos, não ligados ao ambiente, no modelo de Almeida) são controláveis pela organização.

Apesar de reconhecer que as variáveis incontroláveis fazem parte do ambiente da organização, Bryson (1995) não usa o impacto destas variáveis sobre as organizações como mecanismo para apropriar as estratégias, como no modelo de Almeida (2010).

Por outro lado, com o mesmo entendimento de Ansoff (1980) acerca do processo de formulação da estratégia, Bryson (1995) aponta a necessidade de análise e identificação de questões estratégicas (desafios críticos que afetam o desempenho, continuidade, missão, valores, clientes, financiamentos e administração) da organização como base para elaboração da estratégia. As estratégias, atuais, da organização, são avaliadas à luz de questões estratégicas, como assinala Ansoff (1980), e somente, então, são elaboradas novas estratégias. Almeida (2010) em seu modelo, igualmente, orienta a avaliação das estratégias atuais, mas as novas estratégias são elaboradas diretamente a partir das estratégias correntes. A garantia da execução das mesmas é obtida com uma análise subseqüente de viabilidade. Obviamente, as ações somente serão implementadas se forem viáveis, sob o ponto de vista financeiro, humano e de infraestrutura.

Uma das grandes diferenças do modelo de Bryson (1995) é sua ênfase na ciclização do planejamento. Os passos do planejamento não obedecem a uma estrutura rígida, e a ação não 
precisa esperar o final do plano para iniciar. Apesar de Almeida (2010) no seu manual não reforçar essas características do PE, em seu livro escrito junto com Fischmann (Fischmann e Almeida, 1991), a necessidade de flexibilidade do processo de planejamento são enfatizadas.

\subsection{A SAÚDE NO BRASIL E O SUS}

No presente capítulo, apresenta-se uma avaliação das questões relativas à prestação dos serviços de Saúde no Brasil, abordando um breve histórico, os seus aspectos legais, a caracterização do Sistema Único de Saúde - SUS, e a gestão da saúde no município.

\subsubsection{Evolução da gestão de serviços de saúde no Brasil}

A situação sanitária do Brasil colonial e imperial foi marcada por doenças transmissíveis oriundas dos colonos portugueses e, mais tarde, dos escravos africanos e demais estrangeiros que imigravam para o país para então formar a classe trabalhadora assalariada, após a abolição da escravatura, em 1889. Muitas dessas doenças, como lepra, tuberculose, doenças sexualmente transmissíveis, malária, febre amarela, tornaram-se endemias ou epidemias terríveis e acabaram por atingir uma parcela razoável da população. Isto acontecia devido o acesso à assistência médica ser exclusiva às classes dominantes, constituídas principalmente pelos coronéis do café e era exercida pelos raros médicos que vinham da Europa. Contudo, apenas medidas paliativas foram adotadas para que os problemas da saúde não afetassem demasiadamente a produção econômica e o comércio internacional, sendo todas e quaisquer medidas temporárias e descartadas o mais breve possível (AGUIAR, 2011).

Em 1904, já no período da República Velha, houve a imposição legal da vacinação contra a varíola, a qual veio por desencadear a famosa Revolta da Vacina. Liderada por opositores políticos e médicos contrários à vacinação, a revolta fora controlada dias depois, mediante o uso de força política e extrema repressão.

Em 1923 surgem as Caixas de Aposentadorias e Pensões (CAPs), criadas a partir da Lei Eloy Chaves. As CAPs foram criadas para diminuir as tensões sociais, como greves, revoltas e o 
medo de contágio de doenças transmissíveis que acabam por afastar do país os imigrantes que tanto eram necessários para fomentar a classe trabalhadora da economia. As CAPs eram financiadas com recursos oriundos de três departamentos: recursos das empresas, dos trabalhadores e da União. Os trabalhadores dessas empresas ganharam o direito, com a implementação das CAPs, de benefícios previdenciários, assistência médica (aos trabalhadores e também seus familiares). A população restante, ou seja, a classe pobre e desempregada, não tinha direito às CAPs, restando a si, apenas os serviços oferecidos pelos poucos hospitais filantrópicos mantidos pela Igreja ou a prática popular da medicina, os chamados curandeiros (SOUTO DE MORAES, 1997 apud AGUIAR, 2011).

Em 1930, governado por Getúlio Vargas, o Brasil viu-se caracterizado como clientelista populista, dada a forma de intervenção do Estado na economia. Segundo Luz (1984, apud Souza, 2001),fora exatamente nesse período que houve a criação de institutos de seguridade social, organizados por categorias de profissões. Assim, as até então Caixas de Aposentadorias e Pensões (CAPs), consideradas poucas e ineficientes, passam a serem Institutos de Aposentadorias e Pensões (IAPs).

A gestão dos IAPs passou gradativamente para o controle do Estado, que visava manter a força de trabalho em condições de produção para o crescimento acelerado da industrialização brasileira. Contudo, enquanto nas CAPs a assistência médica era prerrogativa fundamental, nos IAPs passou a ser desempenhada em caráter secundário, pois a prioridade era a contenção de gastos, visto que os recursos dos IAPs sempre foram aplicados pelo governo no financiamento da industrialização do país.

Em 1966, já no período de ditadura militar, ocorre a unificação dos IAPs em um regime único para todos os trabalhadores regidos pela Consolidação das Leis Trabalhistas (CLT), o que excluía trabalhadores rurais, empregados domésticos e funcionários públicos. Viu-se, nesse contexto, a criação do Instituto Nacional de Previdência Social (INPS), subordinado ao Ministério do Trabalho e Previdência Social, responsável pela assistência médica e benefícios previdenciários. Em 1974, o INPS passa a ser subordinado ao Ministério da Previdência e Assistência Social. Ocorreu, ainda, no período ditatorial, uma expansão da assistência médica da previdência, a partir da inclusão dos trabalhadores rurais, das empregadas domésticas e dos 
trabalhadores autônomos. Tal medida contribuiu com a elevação dos gastos públicos, que já eram demasiadamente elevados.

Já em 1988, com a promulgação da nova Constituição Federal, a saúde tornou-se um direito de todos e dever do Estado, caracterizada no tão almejado Sistema Único de Saúde (SUS), o qual incorporou a maioria das propostas do movimento da Reforma Sanitária, apresentada por emenda popular. Tal concepção ampliada de saúde, bem como o principio da saúde como um direito universal foram consagrados na VIII Conferência Nacional de Saúde, realizada em 1986.

A inscrição do SUS na carta magna acatou as proposições da sociedade civil organizada, incorporando mudanças no papel do Estado e alterando de forma significativa o arcabouço jurídico do sistema público de saúde brasileiro, pautando-se por um conjunto de princípios e diretrizes válidos para todo o território nacional (AGUIAR, 2011, p. 43).

O artigo 196 da Constituição Federal descreve o direito à saúde como um direito de todos e dever do Estado, que deve garantir o acesso universal e igualitário às ações e serviços para sua promoção, proteção e recuperação.

Art. 196. A saúde é direito de todos e dever do Estado, garantido mediante políticas sociais e econômicas que visem à redução do risco de doença e de outros agravos e ao acesso universal e igualitário às ações e serviços para sua promoção, proteção e recuperação. (BRASIL, 1988, Título VIII - Capitulo II - Seção II - Art. 196) -

A saúde passou a ser dever constitucional de todas as esferas de governo, sendo que antes era competência restrita da União e o acesso reservado ao trabalhador segurado. $\mathrm{O}$ conceito de saúde foi ampliado e vinculado às políticas sociais e econômicas. Segundo a Organização Mundial da Saúde, por saúde entende-se "um estado de completo bem-estar físico, mental e social, e não meramente a ausência de doença".

O art. 196 da CF conforme já destacado, define a universalidade da cobertura do SUS. Posteriormente, a Lei $\mathrm{n}^{\circ}$ 8.080, de 19 de setembro de 1990, instituiu o Sistema Único de Saúde - SUS, constituído pelo "conjunto de ações e serviços de saúde, prestados por órgãos e instituições públicas federais, estaduais e municipais, da administração direta e indireta e das fundações mantidas pelo poder público" (CONASS, 2011, p.26). 
Os princípios organizacionais e doutrinários que regem o SUS são: a universalidade, integralidade, equidade, descentralização, conjunção de recursos da União, estados e municípios, participação comunitária através dos conselhos, regionalização e hierarquização.

A Lei $n^{\circ}$ 8.080/90 também estabelece a organização, a direção e a gestão do SUS, definindo as competências e atribuições das três esferas públicas envolvidas. A descentralização não apenas transfere serviços, mas também responsabilidades, poder e gestão dos recursos federais, estaduais e municipais.

Os recursos financeiros de que dispõem os gestores de saúde advêm de três esferas, com valores vigentes desde 2004, conforme disposto pela Emenda Constitucional no 29/2000 e

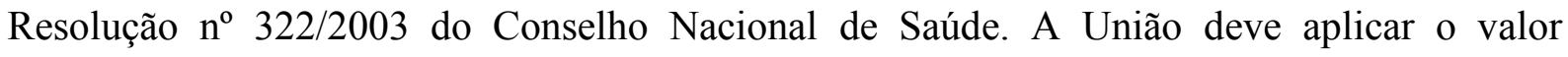
empenhado no ano anterior mais a variação nominal do PIB. Estados e Distrito Federal devem destinar no mínimo $12 \%$ de sua receita ${ }^{1}$ para a saúde. Quanto aos municípios, o percentual fixado é de $15 \%$ no mínimo ${ }^{2}$ (BRASIL, CONASS, 2011, p.53).

A Emenda Constitucional $n^{\circ} 29$, com o conceito de "ações e serviços públicos de saúde", abria espaço para várias interpretações e controvérsias. Por isso, o Conselho Nacional de Saúde editou a Resolução no 322/2003 com o objetivo de uniformizar critérios. Mesmo assim, a medida acrescentava custos adicionais e apresentava dificuldades para garantir a eficácia e viabilizar a aplicação e a fisscalização da Emenda.

A Lei Complementar (LC) $\mathrm{n}^{\mathrm{o}} 141$, de 16 de janeiro de 2012, regulamentou a Emenda Constitucional $n^{\circ} 29$, prevista no $\$ 3^{\circ}$ do art. 198 da CF. Em relação ao montante que cada ente federativo deve aplicar à saúde, não houve alteração nenhuma. O principal mérito da LC em

\footnotetext{
${ }^{1}$ A receita do Estado compõe-se de: A) Impostos estaduais: ICMS, IPVA e ITCMD (sobre herança e doações); B) Transferências da União: cota-parte do Fundo de Participação dos Estados, cota-parte do IPI- Exportação, transferências da LC nº 87/96; C) Imposto de Renda Retido na Fonte; D) Outras receitas Correntes: receita da dívida ativa de impostos e multas; juros de mora e correção monetária de impostos. E) Do total devem ser subtraídas as transferências constitucionais e legais que são feitas aos municípios: 25\% do ICMS, 50\% do IPVA e 25\% do IPI-Exportação. Ou seja $=(\mathrm{A}+\mathrm{B}+\mathrm{C}+\mathrm{D}-\mathrm{E}) \times \mathrm{x} 0,12$

${ }^{2}$ Para o cálculo dos 15\%, deve-se considerar: A) Impostos municipais: ISS, IPTU, ITBI (Imposto sobre Transmissão de bens imóveis); B) Transferências da União: cota-parte do FPM, cota-parte do ITR e transferências da LC nº 87/96; c) Imposto de Renda Retido na Fonte; D) Transferências do Estado: cota-parte do ICMS, cota-parte do IPVA e cota-parte do IPI- Exportação; E) Outras Receitas Correntes: receita da dívida ativa de impostos, multas, juros e correção monetária de impostos. Ou seja $=(\mathrm{A}+\mathrm{B}+\mathrm{C}+\mathrm{D}+\mathrm{E}) \mathrm{x} 0,15$
} 
questão refere-se à definição conceitual dos gastos em saúde, o que proporciona um monitoramento mais eficaz do cumprimento da legislação por estados e municípios. Os recursos devem ser aplicados a ações e serviços públicos de acesso universal, igualitário e gratuito. Assim, são considerados gastos em saúde: compra e distribuição de medicamentos, gestão do sistema público de saúde, desenvolvimento científico e tecnológico e controle de qualidade promovido por instituições do SUS.

\subsubsection{O Sistema Único de Saúde SUS}

O Sistema Único de Saúde - SUS - foi criado pela Constituição Federal de 1988 e regulamentado pelas Leis n. ${ }^{\circ} 8080 / 90$ e $n^{\circ}$ 8.142/90, Leis Orgânicas da Saúde, com a finalidade de alterar a situação de desigualdade na assistência à Saúde da população, tornando obrigatório o atendimento público a qualquer cidadão, sendo proibidas cobranças de dinheiro sob qualquer pretexto.

Do Sistema Único de Saúde fazem parte os centros e postos de saúde, hospitais - incluindo os universitários, laboratórios, hemocentros, bancos de sangue, além de fundações e institutos de pesquisa, como a Fundação Oswaldo Cruz (FIOCRUZ) e o Instituto Vital Brasil. Através do Sistema Único de Saúde, todos os cidadãos têm direito a consultas, exames, internações e tratamentos nas Unidades de Saúde vinculadas ao SUS da esfera municipal, estadual e federal, sejam públicas ou privadas, contratadas pelo gestor público de saúde.

O SUS é destinado a todos os cidadãos e é financiado com recursos arrecadados através de impostos e contribuições sociais pagos pela população e compõem os recursos do governo federal, estadual e municipal.

O Sistema Único de Saúde tem como meta tornar-se um importante mecanismo de promoção da equidade no atendimento das necessidades de saúde da população, ofertando serviços com qualidade adequados às necessidades, independente do poder aquisitivo do cidadão. O SUS se propõe a promover a saúde, priorizando as ações preventivas, democratizando as informações relevantes para que a população conheça seus direitos e os riscos à sua saúde. O controle da ocorrência de doenças, seu aumento e propagação, assim como a vigilância epidemiológica 
são algumas das responsabilidades de atenção do SUS, assim como o controle da qualidade de remédios, de exames, de alimentos, higiene e adequação de instalações que atendem ao público, onde atua a Vigilância Sanitária.

O setor privado participa do SUS de forma complementar, por meio de contratos e convênios de prestação de serviço ao Estado quando as unidades públicas de assistência à saúde não são suficientes para garantir o atendimento a toda população de uma determinada região.

\subsection{3 - A Gestão da Saúde no Município}

Por gestão, entende-se "a atividade e a responsabilidade de comandar um sistema de saúde (municipal, estadual ou nacional) exercendo as funções de coordenação, articulação, negociação, planejamento, acompanhamento, controle, avaliação e auditoria” (BRASIL, CONASS, 2011, p.33).

Pelos termos da Lei $n^{\circ} 8.080 / 90$, o município é o principal responsável pela gestão da saúde de sua população. Desde o Pacto pela Saúde, assinado em 2006, o município pode assinar um Termo de Compromisso de Gestão. Conforme a Cartilha Entendendo o SUS (BRASIL/MS, 1990), "se o termo for aprovado na Comissão Bipartite do estado, o gestor municipal passa a ter a gestão de todos os serviços em seu território", o que seria uma forma do município receber os recursos de "forma regular e automática para todos os tipos de atendimento em saúde que ele se comprometeu a fazer". No entanto, isso não é obrigatório. A LC n ${ }^{0} 141$, em seu art. 18, determina que os recursos "serão transferidos diretamente aos respectivos fundos de saúde, de forma regular e automática, dispensada a celebração de convênio ou outros instrumentos jurídicos".

Os recursos repassados pelo Estado e pela União variam de acordo com o número de habitantes do município. Caso não tenha condições para procedimentos de média e alta complexidade, o município pode firmar parcerias com outros municípios para atender plenamente as necessidades de sua população. 
Para poder receber os recursos da União e do Estado, os municípios devem criar os fundos de saúde $^{3}$ e os conselhos municipais de saúde ${ }^{4}$. A criação do fundo é necessária para a transferência direta "fundo a fundo", isto é, da União ou do Estado para o fundo municipal. Através do conselho, a população garante a sua participação na fiscalização e na formulação de estratégias da aplicação pública dos recursos.

Os recursos financeiros destinados às ações e serviços de saúde devem ser otimizados através de planejamento voltado para o atendimento das necessidades de saúde da população. Por isso, é necessária a construção de uma gestão orçamentário-financeira do SUS que integre as funções planejar, orçar, executar, acompanhar, fiscalizar e avaliar os recursos aplicados em saúde (BRASIL, 2003).

O Relatório de Gestão é o instrumento pelo qual o poder público comprova a aplicação dos recursos programados, destinados às ações e aos serviços de saúde realizados em conformidade com a legislação vigente.

A prestação de contas para o Ministério da Saúde e para a Secretaria de Saúde do Estado também se dá por meio de relatório de atendimento do objeto, consistindo em apresentar documentação comprobatória da despesa realizada, inclusive se vinculada a convênio, acordo, ajuste ou outro instrumento do gênero, celebrados para a execução de programas e projetos específicos. O relatório de gestão, assim como as demais prestações de contas, deve ser aprovado pelo respectivo Conselho de Saúde.

O gestor municipal do SUS também deve apresentar a cada três meses, ao Conselho de Saúde e em audiência pública ou na Câmara de Vereadores, relatório detalhado, contendo dados sobre o montante e a fonte de recursos aplicados, as auditorias concluídas ou iniciada no período, bem como dados sobre a oferta e produção de serviços na rede assistencial própria, contratada ou conveniada (BRASIL, 2003).

\footnotetext{
${ }^{3}$ Lei Fundo Municipal de Saúde no 070, de 18 de agosto de 1997.

${ }^{4}$ Conselho Municipal de Saúde: Lei no 966, de 14 de junho de 2011 (reestruturação).
} 
Após revisar-se o referencial teórico pertinente, bem como situar a questão saúde, incluindo o Sistema Único de Saúde, encerra-se a revisão bibliográfica passando, no capítulo a seguir, ao detalhamento da metodologia adotada. 


\section{METODOLOGIA}

O presente capítulo apresenta o método de desenvolvimento do estudo. A pesquisa foi conduzida em quatro (4) etapas. A primeira consistiu na aplicação de um modelo da pesquisaação, objetivos 1 e 2, para a qual foi utilizada a seqüência de atividades e a condução do processo de PE no HUSM e no início das atividades para a definição de estratégias conjuntas, nesta fase, pelos dirigentes das Unidades Produtoras de Serviços de Saúde. A segunda, descritiva, objetivo 3, usada para descrever o processo de PE desenvolvido pelo GT saúde da ADESM. A terceira, exploratória e qualitativa, objetivo 4, foi operacionalizada a partir da realização de entrevista semiestruturada, com vistas a identificar a percepção dos dirigentes das UPSS. A quarta parte do estudo, de natureza descritiva e quantitativa, objetivo 5, foi realizada por meio de uma pesquisa survey que consistiu na aplicação de questionário visando conhecer a percepção dos participantes do processo de PE da ADESM.

A partir da definição do problema objeto da pesquisa são elaborados os objetivos a ser atingidos, cujo objetivo geral no presente caso é o de avaliar a eficácia do planejamento estratégico como uma ferramenta para a definição de estratégias conjuntas para os estabelecimentos de saúde que atendem ao SUS em Santa Maria.

Nesse sentido, Stephen (1969, p. 14) enfatiza que as pesquisas podem ser enquadradas como teóricas ou práticas, puras ou aplicadas. Dados os objetivos desta pesquisa, pode-se enquadrála como uma pesquisa eminentemente de cunho prático. A principal variável que se busca identificar, aqui, é a aceitação ou um nível de aceitação genericamente satisfatório de um processo de PE. Como aceitação, referindo-se à percepção das pessoas, a pesquisa adquire uma característica claramente subjetiva e qualitativa.

A utilização das abordagens qualitativa e quantitativa visa a obter um maior aprofundamento dos resultados. Para Triviños (2007), a triangulação permite um aprofundamento sobre o tema investigado e a sua eficácia refere-se à complementaridade entre os métodos qualitativo e quantitativo. Goldenberg (2000) afirma que a triangulação permite que o pesquisador faça um cruzamento de suas conclusões, de modo a ter maior confiança nos resultados. 
É importante distinguir entre método e metodologia. Thiollent (2003, p.25) menciona: “A metodologia é entendida como disciplina que se relaciona com a epistemologia ou a filosofia da ciência. Seu objetivo consiste em analisar as características dos vários métodos disponíveis". Método, como bem aponta Gil (2002), constitui-se num procedimento técnico utilizado para atingir um objetivo de pesquisa. Dessa forma, como deduz Thiollent (2003), a pesquisa-ação não é considerada uma metodologia, mas um método inserido dentro da metodologia das ciências sociais, mais especificamente das sociais aplicadas.

Em sua obra, Stephen (1969) apresenta nove métodos de pesquisa, que considera como básicos: Histórico; Descritivo; Desenvolvimentista; Estudo de Caso no Campo; Correlacional; Ex-Post-Facto; Experimental; Quase Experimental; e Ação. Assim, na descrição de Stephen (1969), o método que caracterizará a primeira etapa desta pesquisa é o da ação, norteando aos dois primeiros objetivos específicos.

Essa colocação tem sua lógica, quando se entende que as ciências sociais tratam das relações entre as pessoas e que estas relações sofrem influência de infinitas variáveis. Isto provoca uma relação imprecisa de causa e efeito, mas nem por isso menos importante de ser pesquisado do que nas ciências físicas, por exemplo.

Como menciona Roesch (1996, p. 79), “a administração está muito mais próxima do mundo real do que do acadêmico, o que a caracteriza, antes de tudo, como uma ciência aplicada e voltada às especificidades das organizações". Isso demonstra que a metodologia da pesquisaação, por ser eminentemente prática, adéqua-se aos trabalhos da ciência da administração.

Na metodologia das ciências sociais, podem-se citar métodos ou técnicas de análise, como por exemplo, o uso da técnica de brainstorm; A técnica de brainwrite; A técnica delphi; A técnica de cenário; O estudo de caso; e o método de pesquisa-ação. Este tem a característica de ser ativo. É por meio do desenvolvimento de uma ação promovida pelo pesquisador que se procura conhecer como poderia ser aprimorada a ação. Esse conhecimento acontece neste tipo de método, pela reação dos sujeitos sociais que participam da ação, na pesquisa. E dessa forma, pode-se observar que os pesquisados passam a ser mais diretamente responsáveis pelos resultados da pesquisa. 
Como se caracterizou acima, a pesquisa proposta possui caráter prático, pois pretende validarse por meio de um processo de planejamento, e subjetivo, pois depende da percepção de satisfação dos sujeitos sociais acerca do processo proposto. Mais que isto, o processo de validação, que definitivamente faria os sujeitos sociais aceitar o processo proposto, não é um processo de mensuração mecânica que se aproxima de um método quantitativo correlacional.

Ao contrário, a validação do processo proposto, também ela constitui-se em um processo, porque inclui a aprendizagem dos atores envolvidos.

\subsection{Características da Pesquisa-Ação}

A metodologia de pesquisa-ação, segundo Almeida (2004), é um instrumento pouco utilizado na administração, mas de grande utilidade para trabalhos acadêmicos, que procurem criar o conhecimento através da interação entre pesquisador e pesquisado. A interação do pesquisador, que conhece o fenômeno a ser estudado academicamente, combinado com a experiência prática do pesquisado no campo de negócios, cria uma sinergia particular a este tipo de metodologia para os administradores.

Spink (1978, p. 31), esclarece, de forma simples, o que é pesquisa-ação: "Pesquisa-ação é um termo aplicado à pesquisa corrente com o duplo e explícito propósito de auxiliar a reflexão, formulação ou implementação da ação e de desenvolver, enriquecer ou testar quadros referenciais teóricos ou modelos relevantes ao fenômeno em estudo. Caracteriza-se por uma relação ativa e explícita entre os pesquisadores e os responsáveis pela ação numa área específica como, por exemplo, gerentes, funcionários públicos, políticos, líderes trabalhistas, membros de uma associação de bairros, operários ou qualquer combinação destas categorias. Pesquisa-ação é a fusão da pesquisa e da assessoria".

A metodologia de pesquisa-ação tem a característica de ser participativa, ou seja, a pesquisa estabelece relações comunicativas com pessoas, ou grupos, da situação investigada Thiollent (2003, p.15). Não é, porém, uma pesquisa participante, nos termos em que distingue Thiollent (2003). Para esse autor, uma pesquisa participante dá um grau de maior ênfase ao conhecimento empírico dos sujeitos sociais, como dominante do processo. 
Spink (1978, p.34) menciona, também, que a pesquisa-ação, enquanto pesquisa, está mais orientada para o problema do que para a hipótese. A teoria pode sugerir áreas para a coleta de dados e dirigir a sua interpretação, mas à medida que a pesquisa é realizada com o espírito aberto à investigação, e não como simples instrumento verificador de fatos já esperados, aumenta a probabilidade de haver maior interação entre os dados e a teoria.

$\mathrm{Na}$ etapa da pesquisa relativa ao PE desenvolvido junto ao HUSM, realizou-se uma palestra inicial aos participantes e foi dado treinamento a todos que, desta forma, puderam discutir e influir no processo.

Ao término dos trabalhos, foram enviados questionários (Apêndice 1) com perguntas voltadas ao feedback, tendo, inclusive, ofertado a possibilidade de se realizar comentários livres sobre o processo. De uma população de 100 participantes treinados, obteve-se um retorno do questionário de 85 respondentes, distribuídos da seguinte maneira: 5 diretores, 14 coordenadores, 43 chefes de serviço, 8 chefes de setor, 4 coordenadores de cursos e de 11 outros representantes.

\subsection{A pesquisa exploratória qualitativa}

A execução desta etapa da pesquisa deveu-se à necessidade de operacionalizar o quarto objetivo específico, qual seja: Avaliar a percepção dos gestores das UPSS em relação às estratégias conjuntas definidas pelo GT saúde da ADESM.

Nesta etapa da pesquisa definiu-se um instrumento constante de questões semi estruturadas, num total de seis (6) itens selecionados dentre as diretrizes definidas para melhorar a qualidade de saúde de Santa Maria, tornando-a o principal pólo na área de saúde do interior do Rio Grande do Sul (apêndice 2), por ocasião do PE da ADESM.

Entrevistou-se a totalidade dos gestores das Unidades Prestadoras de Serviços de Saúde de Santa Maria, em número de seis (6). Para tanto, enviou-se por e-mail as questões bem como a solicitação para o agendamento da entrevista. Num prazo de sessenta (60) dias, meses de abril e maio de 2014, conseguiu-se realizá-las. 


\subsection{A pesquisa descritiva quantitativa}

Utilizou-se este método com a finalidade de operacionalizar o quinto e último objetivo específico, avaliar a percepção dos participantes em relação às estratégias conjuntas definidas pelo GT saúde da ADESM.

Para esta etapa utilizou-se a pesquisa descritiva quantitativa, constante do envio por e-mail de quarenta (40) questionários (Apêndice 3) para a totalidade de participantes em no mínimo três (3) reuniões de um total de seis (6) realizadas. O retorno no prazo de trinta (30) dias foi de 34 respostas, equivalentes a oitenta e cinco por cento $(85 \%)$.

O questionário, enviado aos participantes no mês de junho de 2014, foi estruturado em dois grandes blocos. O primeiro, contendo nove (9) questões, visou identificar o perfil dos respondentes. O segundo, subdividido em quatro (4) partes, buscou identificar a importância das diretrizes resultantes do Planejamento "A Santa Maria que queremos" para a melhoria da qualidade de saúde de Santa Maria.

Os dados obtidos foram tabulados com o uso de software excell e analisados de forma descritiva com base nas freqüências absolutas observadas.

\subsection{Limitações da Pesquisa}

Como toda pesquisa, o presente trabalho apresenta limitações. A principal limitação de uma pesquisa é sua impossibilidade de generalização. Algumas vezes, os resultados interessam somente a uma amostra, ou população restrita. Nesse caso, esta pesquisa interessa a organizações produtoras de serviços de saúde via SUS. Dada a subjetividade da pesquisa, não é possível generalizar, para todas as instituições os resultados aqui obtidos. Os resultados também não devem ser generalizados para unidades que não sejam produtoras de serviços de saúde via SUS.

As principais limitações desta pesquisa relacionam-se à sua natureza, desenho e ambiente. Pesquisas-ação apresentam restrições à sua natureza, porque dependem do processo e da 
conduta deste, não da imparcialidade dos resultados. Pesquisas-ação, como método subjetivo, contrapõem-se exatamente aos métodos objetivos, porque, enquanto a última busca a verdade pela verdade, a primeira busca os resultados pelos processos. Isso significa dizer que a "verdade" da pesquisa-ação está na mudança obtida (resultados) junto aos indivíduos participantes, mediante a aplicação de um processo de alteração comportamental, não de uma coleta imparcial e isenta de dados. Dessa forma, em termos de resultados, o efeito (resultado) observado pode ter causas diversas, não necessariamente aquelas que supostamente estão atribuídas à provocação dos resultados.

Em segundo lugar, o desenho da pesquisa tem que obedecer ao seu lócus. Como se está lidando com organizações complexas e heterogêneas, não se especificam o tipo de complexidade, exatamente, nem tampouco o tipo de heterogeneidade. Outras organizações igualmente complexas e heterogêneas podem exigir desenhos de pesquisa-ação diferentes e chegar a resultados diversos, especialmente se combinarem-se estes com os argumentos anteriores.

Por fim, o lócus da pesquisa é outro fator restritivo. Ao aplicar-se a pesquisa aos produtores de serviços de saúde via SUS de Santa Maria, ajusta-se seu desenho à estrutura das mesmas, que é sui generis. Outras unidades não possuem iguais características de complexidade e heterogeneidade, a diferença essencial, que em tese, estaria restringindo os resultados aqui obtidos a outro lócus com semelhança em natureza, tamanho, complexidade e heterogeneidade. Isso, porém, não invalida a utilidade da pesquisa, nem seu potencial em ser utilizado por outras organizações semelhantes, já que seu objeto é um processo, passível de ser utilizado em condições similares.

\subsection{Síntese da pesquisa}

Para um melhor entendimento dos procedimentos adotados, estruturou-se o quadro4 contendo, por etapa, os respectivos objetivos específicos, entidade(s) envolvida(s), participantes, método de pesquisa, objetivos, e instrumento de coleta de dados, quando for o caso. 
Quadro 4 : Síntese da Pesquisa

\begin{tabular}{|c|c|c|c|c|}
\hline ETAPA & OBJETIVO & ENTIDADES & PARTICIPANTES & INSTRUMENTO \\
\hline $\begin{array}{l}\text { Pesquisa } \\
\text { Ação }\end{array}$ & $\begin{array}{l}\text { Definir e avaliar o processo } \\
\text { de condução do PE } \\
\text { desenvolvido junto ao HUSM. }\end{array}$ & HUSM & $\begin{array}{l}\text { Produtores de } \\
\text { Serviços de Saúde }\end{array}$ & APÊNDICE 1 \\
\hline $\begin{array}{l}\text { Pesquisa } \\
\text { Ação }\end{array}$ & $\begin{array}{l}\text { Descrever } \begin{array}{c}\text { o processo de } \\
\text { definição de }\end{array} \text { estratégias } \\
\text { conjuntas pelos gestores das } \\
\text { UPSS. }\end{array}$ & $\begin{array}{l}\text { HUSM, } 4^{\mathrm{a} C R S,} \\
\text { HCAA, SMS, UPA, } \\
\text { Casa de Saúde }\end{array}$ & $\begin{array}{l}\text { Gestores da } \\
\text { Produção de Serviços } \\
\text { de Saúde- } \\
\text { Seis (6) participantes }\end{array}$ & \\
\hline Descritiva & $\begin{array}{l}\text { Descrever o processo de PE } \\
\text { Desenvolvido pelo GT Saúde } \\
\text { da ADESM. }\end{array}$ & $\begin{array}{l}\text { HUSM, } 4^{\mathrm{a} C R S}, \\
\text { HCAA, SMS, UPA, } \\
\text { Casa de Saúde }\end{array}$ & $\begin{array}{l}\text { Produtores e } \\
\text { Usuários de Serviços } \\
\text { de Saúde }\end{array}$ & \\
\hline $\begin{array}{l}\text { Exploratória } \\
\text { Qualitativa }\end{array}$ & $\begin{array}{l}\text { Avaliar a percepção dos } \\
\text { gestores das UPSS em relação } \\
\text { às estratégias conjuntas } \\
\text { definidas pelo GT }\end{array}$ & $\begin{array}{l}\text { HUSM, } 4^{\mathrm{a} C R S,} \\
\text { HCAA, SMS, UPA, } \\
\text { Casa de Saúde }\end{array}$ & $\begin{array}{l}\text { Gestores da } \\
\text { Produção de Serviços } \\
\text { de Saúde - Seis (6) } \\
\text { participantes }\end{array}$ & APÊNDICE 2 \\
\hline $\begin{array}{l}\text { Descritiva } \\
\text { Quantitativa }\end{array}$ & $\begin{array}{l}\text { Avaliar a percepção dos } \\
\text { participantes do processo de } \\
\text { PE em relação às estratégias } \\
\text { conjuntas definidas pelo GT. }\end{array}$ & $\begin{array}{l}\text { HUSM, } 4^{\mathrm{a} C R S}, \\
\text { HCAA, SMS, UPA, } \\
\text { Casa de Saúde, } \\
\text { acrescidos de mais }\end{array}$ & $\begin{array}{l}\text { Produtores e } \\
\text { Usuários de Serviços } \\
\text { de Saúde - Quarenta } \\
\text { (40) participantes }\end{array}$ & APÊNDICE 3 \\
\hline
\end{tabular}




\section{ANÁLISE E INTERPRETAÇÃO DO PROCESSO DE INTERVENÇÃO}

No presente capítulo apresentam-se a analise e interpretação referente aos objetivos propostos quais sejam: Definir o processo de condução do PE desenvolvido junto ao HUSM; Descrever o processo de definição de estratégias conjuntas pelos gestores das UPSS; Descrever o processo de PE desenvolvido pelo GT saúde da ADESM; Avaliar a percepção dos gestores das UPSS em relação às estratégias conjuntas definidas pelo GT; e Avaliar a percepção dos participantes do processo de PE em relação às estratégias conjuntas definidas.

\subsection{Planejamento Estratégico do Hospital Universitário de Santa Maria}

O Hospital Universitário de Santa Maria (HUSM) nasceu junto com o projeto da Universidade Federal de Santa Maria (UFSM), tendo por finalidade desenvolver um sistema de ensino, pesquisa e extensão por meio da assistência à comunidade na área da saúde. A necessidade de um hospital-escola surgiu com a criação do Curso de Medicina, em 1954, que no início era vinculado à Faculdade de Medicina da Universidade Federal do Rio Grande do Sul em Porto Alegre (UNIVERSIDADE FEDERAL DE SANTA MARIA, 2012).

Em 1970 o prédio destinado ao Hospital Regional de Tuberculose (do Serviço Nacional de Tuberculose, DNS-MS) foi transformado em Hospital Universitário da Universidade Federal de Santa Maria, localizado na Rua Floriano Peixoto, centro. O término da transferência do Hospital Universitário Setor Centro para o Campus Universitário ocorreu em 18 de julho de 1982, quando todas as internações passaram a ser feitas no Hospital Universitário de Santa Maria.

Constitui-se no único hospital público da região centro oeste do Estado do Rio Grande do Sul, para onde são canalizados pacientes terciários de alta complexidade, portadores de complicações clínicas ou cirúrgicas, gestantes de alto risco e transplantes, além de ser um dos poucos hospitais universitários com Pronto Socorro Regional e referência para trauma na região. 
Numa área de 2.922,89 m2 o Pronto Socorro, inaugurado em outubro de 2002, aumentou a capacidade para 40 leitos contando com todas as áreas de apoio, entretanto faltam recursos materiais e humanos para a abertura de 03 salas cirúrgicas e sala de trauma. Ao tempo que é a única referência para poli trauma e outras emergências cirúrgicas para a área de abrangência de mais de um milhão de pessoas.

O Centro de Transplante de Medula Óssea (CTMO), único no interior do Estado que atende pacientes de todo o Rio Grande do Sul e Santa Catarina. Por necessidade de demanda assistencial e de ensino, a partir de 2001, o HUSM também reativou a Cirurgia Cardíaca com aquisição de equipamento de hemodinâmica e reestruturação do serviço de Cardiologia, incluindo a Cardiologia Intervencionista em nível de diagnóstico e tratamento, e que atualmente já necessita de investimentos para expansão e qualificação.

Ainda segundo Universidade Federal de Santa Maria (2012), o Hospital Universitário de Santa Maria conta com $29.800 \mathrm{~m}^{2}$ de área construída, presta serviços assistenciais em todas as especialidades médicas e serve de campo de estágio para alunos de graduação e pósgraduação nos cursos da área da saúde. Possui em sua infraestrutura ambulatórios de diversas especialidades, unidades de internação e de tratamento intensivo (adulto, pediátrica e neonatal), centro cirúrgico, centro obstétrico, centro de transplante de medula óssea, unidade de internação hemato-oncológica, unidade renal, setor psiquiátrico, pronto socorro, laboratório de traçados gráficos, setor de endoscopia, serviço de diagnóstico por imagem (radiologia, tomografia, ultrassonografia e medicina nuclear), radioterapia, hemodinâmica, fisioterapia, controle de infecção hospitalar e vigilância epidemiológica, internação domiciliar.

A assistência secundária e terciária é oferecida em mais de 70 especialidades, sendo disponibilizados atualmente 303 leitos para internação uma vez que 32 leitos acham-se indisponíveis em processo de reforma. O HUSM atende uma média mensal de 11,3 mil consultas especializadas, 4,6 mil consultas emergenciais e realiza aproximadamente 760 mil exames e 10,8 mil internações ao ano. No quadro de pessoal permanente conta com 1.332 servidores federais, 369 terceirizados e 339 bolsistas. No entanto a estrutura do HUSM, projetada na década de 60 está defasada do ponto de vista física e tecnológico e, por ser considerado o maior hospital de ensino do interior do estado, a administração e a academia 
trabalham na direção de sua reestruturação e dos novos cenários da saúde que prevêem a deshospitalização crescente, com conseqüente necessidade de investimento na expansão física e na resolutividade ambulatorial.

O HUSM foi um dos primeiros hospitais do país a ser certificado como hospital de ensino, pelos Ministérios da Saúde e da Educação. No Programa de Residência Médica conta com 100 médicos residentes distribuídos em 24 programas credenciados pela Comissão Nacional de Residência Médica, sendo 19 especialidades: Anestesiologia, Cancerologia Clínica, Cancerologia Pediátrica, Cardiologia, Cirurgia Geral, Cirurgia do Aparelho Digestivo, Dermatologia, Gastroenterologia, Infectologia, Medicina Intensiva, Nefrologia, Obstetrícia e Ginecologia, Ortopedia e Traumatologia, Pediatria, Pneumologia, Psiquiatria, Radiologia e Diagnóstico por Imagem e 06 áreas de atuação: endoscopia respiratória, infectologia Pediátrica, Medicina Intensiva Pediátrica, Neonatologia, Neurologia Pediátrica e Psicoterapia, com perspectivas de 03 novos programas. Além disso, merece destaque especial a Residência Multiprofissional que contempla as áreas: doenças crônicas degenerativas, hemato-oncologia, mãe-bebê e saúde mental.

Um dos principais descompassos entre o crescimento do Hospital Universitário no que se refere ao ensino, assistência e pesquisa e criação de novas Pós-Graduações, está na falta de reposição, pelo Ministério da Educação, do quadro de pessoal necessário, que somado ao pico de aposentadorias (grande parte dos servidores iniciaram suas atividades com o início do hospital), traz crescentes dificuldades econômicas e jurídicas aos gestores do HUSM e reitor da UFSM.

\subsubsection{Implementação e forma de Condução}

Um dos objetivos estratégicos do Plano de Desenvolvimento Institucional da UFSM (PDI) consiste em aperfeiçoar os processos e métodos gerenciais de gestão administrativa, por meio do incremento ao Programa da Qualidade e Avaliação Institucional que utiliza como ferramenta o processo de Planejamento Estratégico. 
Em cumprimento a esse objetivo, a Pró-Reitoria de Planejamento (PROPLAN) se comprometeu a aplicar a sua metodologia de Planejamento Estratégico no âmbito da Universidade Federal de Santa Maria e, atendendo a uma solicitação voluntária, assessorou na implementação da metodologia do Planejamento Estratégico no Hospital Universitário de Santa Maria (HUSM).

Considerando a vasta bibliografia existente sobre planejamento, tornou-se imprescindível adaptar um modelo (figura 5) que melhor se ajustasse à realidade organizacional da Universidade Federal de Santa Maria, repassada ao Hospital Universitário de Santa Maria.

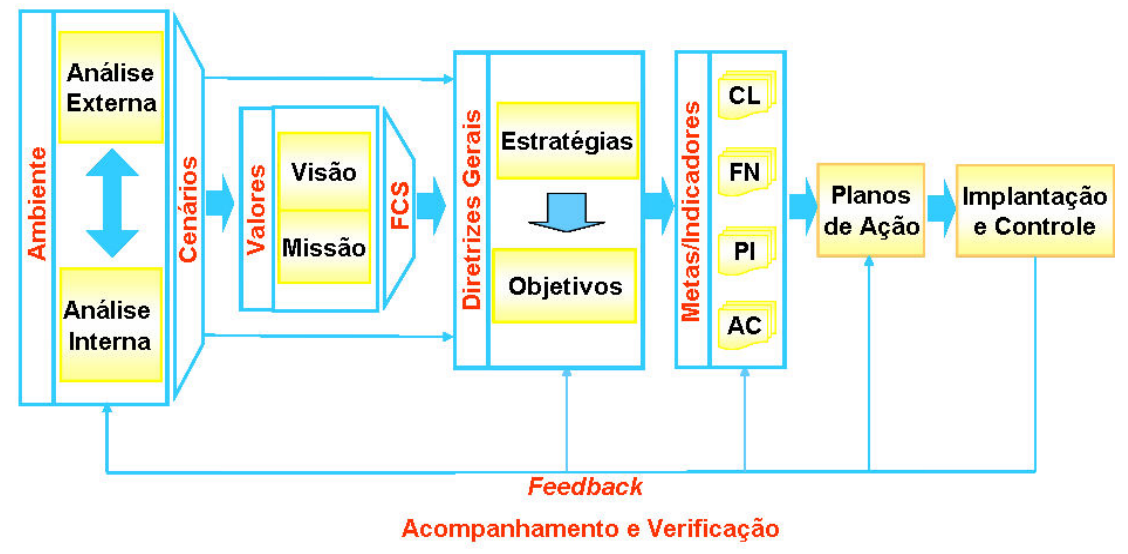

Figura 5: Modelo de Planejamento Estratégico - UFSM/HUSM.

A metodologia adotada prevê a realização da análise do ambiente da organização criando a consciência de suas oportunidades e ameaças, assim como dos aspectos internos, identificando seus pontos fracos e fortes (CERTO E PETER, 1993, p.13).

Segue-se, conforme o modelo adotado, a definição da missão institucional, a qual pode ser entendida como sendo a razão pela qual, uma organização existe (Certo e Peter, 1993, p.76). Após, é elaborada a Visão de Futuro a qual pode ser definida como um conjunto preciso e bem elaborado de palavras que anunciam para onde a empresa está caminhando ou traçam um quadro do que ela deseja ser (TIFFANY, 1998, p.52).

A seguir, se definem os Fatores Críticos do Sucesso os quais podem ser entendidos como sendo as condições fundamentais que precisam necessariamente ser satisfeitas para que a 
organização tenha sucesso no ambiente (PGQP, 1999/2000) e estão diretamente relacionados às capacidades e recursos existentes ou necessários à organização.

Após a elaboração dos fatores descritos no parágrafo anterior, são fixadas as diretrizes gerais que são princípios orientadores e canalizadores das decisões e do desencadeamento das ações, com vistas ao alcance dos objetivos pretendidos (Lefebvre \& Rosa, 1983). Se objetivos são os fins, as diretrizes servem para balizar os meios adequados para atingi-los (ENAP, 1999, p.53).

O passo seguinte do processo trata da definição das estratégias que podem ser definidas como sendo o padrão ou plano que integra as principais metas políticas e seqüência de ações de uma organização em um todo coerente. Uma estratégia bem formulada ajuda a ordenar e alocar os recursos de uma organização para uma postura singular e viável, com base em suas competências e deficiências internas relativas, mudanças no ambiente antecipadas e providências contingentes realizadas por oponentes inteligentes (MINTZBERG E QUINN, 2001, p.20).

O desenvolvimento de uma estratégia competitiva é, em essência, o desenvolvimento de uma fórmula ampla para o modo como uma empresa irá competir, quais deveriam ser as suas metas e quais as políticas necessárias para levarem-se a cabo essas metas (PORTER, 1986, p.15).

$\mathrm{Na}$ seqüência da elaboração do modelo definem-se as estratégias, agrupadas em quatro Perspectivas, Stakeholders, Financeira, Processos Internos e do Aprendizado e Crescimento. As quatro perspectivas têm-se revelado adequadas em diversas empresas, embora elas devam ser consideradas um modelo e não uma camisa de força, isto é, dependendo das circunstâncias do setor e da estratégia, é possível que seja preciso agregar uma ou mais perspectivas complementares (KAPLAN E NORTON, 1997, p. 35).

As instituições precisam identificar os segmentos de mercado em suas populações atuais e potenciais de clientes, e depois selecionar os segmentos nos quais preferem atuar. A identificação das propostas de valor dirigidas a esses segmentos específicos é o segredo para o desenvolvimento de objetivos e medidas na perspectiva dos clientes (KAPLAN E NORTON, 1997, p.68). 
A perspectiva financeira, no caso dos Hospitais Universitários públicos, representa uma limitação, não um objetivo, pois essas instituições devem limitar seus gastos a quantias orçadas. Nesse contexto, o sucesso de tais organizações não pode ser medido pela precisão com que se mantém dentro desses limites, ou mesmo se restringem seus gastos para que as despesas reais sejam mantidas bem abaixo das quantias orçadas.

As instituições tentam melhorar a qualidade, reduzir os tempos de ciclo, aumentar a produção, maximizar a produtividade e reduzir os custos de seus processos de negócios, sendo que as medidas para a perspectiva dos processos internos derivam de estratégias explícitas voltadas para o atendimento às expectativas dos clientes (KAPLAN E NORTON, 1997, p.99).

A perspectiva da aprendizagem e crescimento permite à organização assegurar sua capacidade de renovação em longo prazo, um pré-requisito para a sobrevivência no decorrer do tempo. Sob essa perspectiva, a instituição deve considerar não apenas o que deve fazer para manter e desenvolver o know-how necessário para entender e satisfazer as necessidades dos stakeholders, mas também como pode manter a eficiência e a produtividade necessárias dos processos que criam valor para o cliente (OLVE E WETTER, 2001, p.70).

$\mathrm{Na}$ próxima fase do planejamento estratégico elabora-se uma componente importante do processo denominada objetivos estratégicos, os quais podem ser entendidos como sendo o que fazer a curto e médio prazo para atingir a visão de futuro e cumprir a missão.

O estabelecimento dos objetivos é a ferramenta necessária para transmitir a estratégia para os níveis inferiores da organização e assegurar a congruência das metas, em outras palavras, assegurar que todos os que estão no barco remem na mesma direção (ROESCH, 1996, p.30).

Os objetivos estratégicos refletem a missão organizacional e são importantes porque os administradores podem usá-los como auxílio na tomada de decisão e como guias para aumentar a eficiência da organização e conduzir avaliações de desempenho (CERTO E PETER, 1993, p.104).

Posteriormente elaboram-se os indicadores de desempenho que na gestão das organizações são essenciais por propiciarem o estabelecimento de metas quantificadas e seu respectivo 
desdobramento, bem como os resultados apresentados são fundamentais para a análise crítica do desempenho e a tomada de decisão (TAKASHINA E FLORES, 1996, p.1).

Nesse sentido, os indicadores servem para internalizar na organização as expectativas e necessidades dos clientes, possibilitarem o desdobramento das metas, embasarem a análise crítica dos resultados e tomada de decisão, contribuir para a melhoria contínua e facilitar o planejamento e o controle do desempenho (ENAP, 1999, p. 43).

A fase seguinte trata da implementação do plano por meio do plano de ação, o qual estimula responsabilidades pela execução e prazos, para que cada um possa tomar as medidas necessárias à efetivação. Finalizando o modelo de planejamento estratégico organizacional encontra-se o acompanhamento e avaliação que possui como finalidade acompanhar e avaliar, sistematicamente, o desempenho do processo do referido planejamento.

\subsubsection{Primeiro Processo de Planejamento HUSM - 2003-2006}

Incumbida da aplicação da referida metodologia, a Pró-Reitoria de Planejamento (PROPLAN)/UFSM realizou seminários de treinamento em planejamento estratégico com a participação de todos os setores do HUSM, ocasião em que se distribuíram a todos os presentes, visando um nivelamento de conhecimentos, o documento intitulado "Planejamento Estratégico - Referencial Teórico", juntamente com o material de apoio.

Numa primeira fase, foi apresentado o referencial teórico para, em pequenos grupos, serem desenvolvidos os exercícios práticos, os quais foram analisados e consolidados.

Reunidos em oficinas de trabalho, os representantes de todos os Setores definiram, discutiram e consolidaram a análise do ambiente externo (oportunidades e ameaças), dos aspectos internos (pontos fortes e pontos fracos) os possíveis cenários, os valores, a missão e a visão de futuro do HUSM, os quais balizaram o estabelecimento das diretrizes gerais, das estratégias, dos objetivos estratégicos, dos indicadores e das ações que compõem o Processo de Planejamento do HUSM. 
O processo de planejamento estratégico no Hospital Universitário foi desenvolvido por meio de nove oficinas de trabalho de oito horas cada, perfazendo um total de setenta e duas horas, realizadas em anfiteatros previamente locados, fora do ambiente do HUSM. O público participante das oficinas foram os dirigentes do HUSM, composto por cinco diretores, 14 coordenadores, 45 chefes de serviço e 11 chefes de setores bem como coordenadores de cursos da área de saúde dentre outras lideranças do HUSM, os quais foram convidados mediante protocolo a cada reunião.

Por ocasião da implantação do Processo de Planejamento Estratégico no HUSM, em 2003, realizou-se a primeira análise ambiental, adotando a análise SWOT, cujos resultados obtidos explicitam-se a seguir:

a) Oportunidades: a possibilidade de convênios e parcerias; na condição de hospital de ensino, participar na formulação de políticas públicas; forma de financiamento diferenciada por ser hospital-escola; participar da organização do SUS; maior integração (HUSM, UFSM, estabelecimentos congêneres e comunidade); múltiplas fontes de financiamento; financiamento por projetos; acreditação hospitalar; ser hospital pólo macrorregional; implementação do Hospital Sarah; políticas públicas vigentes; Hospital-Piloto para gestão (MS/MEC); novas demandas de serviços (alta complexidade crescente, desospitalização precoce, programas de prevenção à saúde, medicina genética); projeto Hospital Sentinela; localização geográfica; clientela preferencial do SUS com demanda reprimida; possibilidade de melhoria contínua com a crescente consciência coletiva dos direitos em saúde; estar inserido em uma universidade com múltiplos cursos; mercado (sem concorrência);

b) Ameaças: a Imagem negativa do Serviço Público e do Sistema Público de Saúde; o desequilíbrio entre remuneração e custo/HUSM (reajuste e tabela); burocracia da União para a legislação de compras e contratos; política de Pessoal (Plano de carreira, baixa remuneração, não reposição de pessoal, capacitação profissional), rigidez do RJU; credenciamento de outras instituições congêneres; implementação inadequada do SUS; custo elevado para aquisição e manutenção de novas tecnologias; rápida obsolescência tecnológica; mercantilização da saúde; crise socioeconômica nacional e mundial com agravo regional; demandas judiciais crescentes; migração progressiva da 
previdência privada para a pública; desordem social (criminalidade, corrupção, desestruturação familiar); falta de compromisso com a saúde e educação pública; mudança político-partidária, saúde, educação e administração (alternância de governo); dupla militância; indefinição da vinculação administrativa e de financiamento; Reforma do Estado (tributária e da previdência); contingenciamento orçamentário;

c) Pontos Fortes: a referência de alta complexidade; adequação contínua de área física e equipamento; qualificação dos recursos humanos; relacionamento interpessoal e multiplicação de conhecimentos; alternativa de horário; oportunidade de qualificação; processo de descentralização das decisões; liberdade de expressão e oportunidade de atuação; Projeto de Humanização na Instituição; Ouvidoria; hospital piloto para modelo de gestão; comissões de padronização; qualificação de profissionais da Rede SUS; qualificação tecnológica; inserção e integração na rede de saúde; residência médica; cursos de pós-graduação Stricto Sensu e Lato Sensu; processo de Acreditação; Gerência de Risco ANVISA; imagem do HUSM como centro de referência; imagem positiva do HUSM na comunidade; orgulho de atuar no HUSM; busca contínua de integração com academia;

d) Pontos Fracos: elevado número de Alunos com Bolsas de Trabalho que suprem precariamente a falta de pessoal Administrativo (UFSM e Fundação de Apoio à Tecnologia e Ciência); deficiência no gerenciamento dos leitos - alta média de permanência; falta de programa de humanização; incapacidade de gerar melhores projetos; desmotivação de pessoal (gerência, financeira, acomodação, falta de reconhecimento); ingerência no processo de compras: falta de planejamento, de materiais indispensáveis, prioridade, relatório; falta de padronização de equipamentos; deficiência na padronização de materiais; falta de uma política interna referente à educação continuada; falta de integração entre o HUSM e o Centro de Ciências da Saúde; o paciente não é o foco da ação; falta de suporte dos serviços de apoio; falta de Comissão de Ética Hospitalar; falta de monitoramento dos trabalhos das comissões; falta de assessoria de comunicação; tecnologia de alto custo de manutenção; excesso na solicitação de exames; ineficiência na preceptoria; falta de um programa efetivo de saúde ocupacional; descontinuidade do processo de acreditação hospitalar; pouca 
produção científica; uso inadequado de materiais, medicamentos e equipamentos; falta de pessoal administrativo.

Desta forma foram propostos os seguintes objetivos estratégicos do HUSM para o período 2003-2006:

a) Implementar o programa de acreditação hospitalar.

b) Consolidar o programa de humanização

c) Buscar financiamento por meio de projetos.

d) Buscar equilíbrio receita $\mathrm{x}$ despesa.

e) Atualizar o regimento interno.

f) Estabelecer normas, rotinas e procedimentos.

g) Melhorar processo de compras de bens e serviços.

h) Implementar o programa de gestão ambiental

i) Implementar uma política de gestão de pessoas.

Seguiu-se a definição do Plano de Ação 2003-2006, completo, definindo metas e responsabilidades pela respectiva execução. Anualmente realizaram-se reuniões de avaliação do processo, até o final de 2005.

Ao final do ano realizaram-se eleições para a Direção Geral do HUSM sagrando-se vencedora a Chapa de Oposição que culminou por interromper o processo de Planejamento. Como resultado, somente em 2010, após nova eleição e conseqüente nova Direção Geral, retoma-se o Processo de Planejamento Estratégico.

\subsubsection{Segundo Período do Processo de PE do HUSM 2010-2013}

Em 2010, com a posse da nova Direção Geral, ocorreu a revisão/atualização do processo de Planejamento Estratégico do HUSM por ocasião da elaboração do Plano de reestruturação dos Hospitais Universitários Federais - REHUF, tendo como parâmetros sua missão e visão de futuro. 
Nesta oportunidade, para a realização da análise ambiental, adotou-se o Modelo Almeida, a seguir explicitado.

A segmentação ambiental proposta por Almeida (2010) no modelo de planejamento estratégico divide o ambiente para facilitar a análise de cada segmento. Outros autores, como Miller, Narayanan e Fahey, Glueck e Bethlem, já haviam sugerido outras formas de segmentação ambiental (Almeida, 1997). A segmentação de Almeida divide o ambiente em quatro segmentos: Macro ambiente Clima, Macro ambiente Solo, Ambiente Operacional e Ambiente Interno e sugere as técnicas mais apropriadas para a previsão das variáveis de cada segmento. O quadro 5, a seguir, explicita esta classificação: 
Quadro 5: Segmentação Ambiental

\begin{tabular}{|c|c|c|c|}
\hline Segmento Ambiental & Variáveis Ambientais & Características & Método de Análise \\
\hline Macro ambiente Clima & $\begin{array}{l}\text { São as variáveis } \\
\text { decorrentes do Poder } \\
\text { Político: } \\
\text { Inflação, Crescimento do } \\
\text { PIB, Legislação }\end{array}$ & $\begin{array}{l}\text { É difícil de ser previsto } \\
\text { em curto prazo, mas } \\
\text { podemos projetar uma } \\
\text { tendência em longo prazo }\end{array}$ & $\begin{array}{l}\text { Deve-se ouvir a opinião de } \\
\text { Experts e apostar em uma } \\
\text { tendência política em longo } \\
\text { prazo. Na análise tem-se } \\
\text { que traduzir em fatos } \\
\text { políticos como eleição, e } \\
\text { aprovação de leis }\end{array}$ \\
\hline Macro ambiente Solo & $\begin{array}{l}\text { São variáveis do futuro da } \\
\text { população e suas } \\
\text { características: } \\
\text { crescimento por região, } \\
\text { por faixa de renda, por } \\
\text { sexo. }\end{array}$ & \begin{tabular}{|lrr}
\multicolumn{2}{|c|}{ As previsões são precisas } \\
e & disponíveis & em \\
organismos como o IBGE
\end{tabular} & $\begin{array}{|lr|}\text { Devem-se usar } & \text { estudos } \\
\text { estatísticos, } & \text { que } \\
\text { normalmente } & \text { estão } \\
\text { disponíveis. } & \\
\end{array}$ \\
\hline Ambiente Operacional & $\begin{array}{l}\text { São variáveis decorrentes } \\
\text { das operações: } \\
\text { concorrentes, } \\
\text { fornecedores, clientes } \\
\text { diretos }\end{array}$ & $\begin{array}{l}\text { As previsões procuram } \\
\text { identificar como serão as } \\
\text { relações operacionais no } \\
\text { futuro, levando-se em } \\
\text { conta a evolução } \\
\text { tecnológica } \\
\end{array}$ & $\begin{array}{l}\text { O método de análise é o } \\
\text { estudo de Cenários, que se } \\
\text { utiliza das tendências atuais } \\
\text { para identificar o } \\
\text { relacionamento operacional } \\
\text { futuro. }\end{array}$ \\
\hline Ambiente Interno & \begin{tabular}{lrr} 
São os & \multicolumn{2}{c}{ valores } \\
aspirações & das & pessoas \\
relevantes. & No & caso de \\
empresas & & pode-se \\
segmentar & & entre \\
proprietários & & e \\
funcionários & &
\end{tabular} & $\begin{array}{l}\text { Os valores e aspirações } \\
\text { das pessoas são difíceis } \\
\text { de serem mudados. As } \\
\text { empresas ou suas áreas } \\
\text { normalmente } \\
\text { pessoas com agrupam } \\
\text { semelhantes }\end{array}$ & $\begin{array}{l}\text { Para identificação dos } \\
\text { valores de empresas ou de } \\
\text { suas áreas, é utilizado o } \\
\text { sistema de análise da } \\
\text { Cultura Organizacional }\end{array}$ \\
\hline
\end{tabular}

Fonte: Almeida (2010, p. 14)

Os resultados obtidos foram os explicitados a seguir:

a) Oportunidades: Reestruturação dos hospitais universitários (física e pessoal); Participação nas políticas públicas do SUS, o HUSM atende 100\% SUS e participa ativamente em nível municipal e regional das demandas assistenciais de ensino e pesquisa e sobre tudo atua como hospital de referência de alta complexidade num sistema hospitalar regional organizado em rede; Certificação como hospital de ensino; Trabalhar com os princípios da qualidade e produtividade; Fontes externas de financiamento, elaboração de projetos junto ao MEC e MS, bem como obtenção de recursos através de outras fontes públicas e privadas de fomento.

b) Ameaças: Indefinição da missão dos hospitais universitários; Instabilidade das políticas públicas de saúde; Atendimento à legislação; Judicialização da saúde; Custo cada vez mais elevado da saúde; Rápida obsolescência tecnológica. 
Seguiu-se a análise dos aspectos internos:

c) Pontos Fortes: Oportunidades de qualificação do quadro: política da UFSM na área de recursos humanos, núcleo de educação permanente do HUSM; Credibilidade do HUSM junto ao usuário; Representatividade política; Responsabilidade social; Contratualização; Implantação da rede integrada; Ser hospital-ensino; Possibilidade de recurso do REHUF; Credenciamentos de alta complexidade.

d) Pontos Fracos: Descompromisso e descomprometimento institucional; Falta de gestão de processos: diagnóstico, padronização, regulação; Infraestrutura do HUSM insuficiente e inadequada a legislação vigente; Comunicação interna inadequada; Limitação no desenvolvimento de competências gerenciais; Regimento interno desatualizado; Ausência de setor de desenvolvimento de projetos; Não informatização do HUSM; Falta de pessoal do quadro; Excessivo gasto com pessoal contratado; Pouca produção cientifica; Processo de gestão de cobrança deficiente; Falta de leitos de UTI; Ausência de um programa de saúde e segurança ocupacional; Inexistência de um programa de qualidade; Deficiência de gestão de indicadores; Morosidade dos processos de compras; Descontrole de gastos x arrecadação; Pouco estimulo a inovação; Demanda excessiva de pacientes no pronto socorro.

Reunidos em oficinas de trabalho, os representantes de todos os Setores definiram, discutiram e consolidaram a análise do ambiente externo (oportunidades e ameaças), dos aspectos internos (pontos fortes e pontos fracos) os possíveis cenários, os valores, a missão e a visão de futuro do HUSM, os quais balizaram o estabelecimento das diretrizes gerais, das estratégias, dos objetivos estratégicos, dos indicadores e das ações que compõem o Processo de Planejamento do HUSM.

A seguir, apresentam-se a Visão de Futuro, Missão Institucional, Princípios e Valores, Diretrizes Gerais e Objetivos Estratégicos. 
a) Visão de Futuro

"Ser um referencial público de excelência no ensino, na pesquisa e na extensão promovendo a saúde das pessoas".

b) Missão Institucional

"Desenvolver ensino, pesquisa e extensão promovendo assistência à saúde das pessoas contemplando os princípios do SUS com ética, responsabilidade social e ambiental."

c) Princípios e Valores

Ética, Transparência e Qualidade nas ações, Responsabilidade Institucional, Compromisso com as Pessoas, Respeito às Diversidades, e Comprometimento Social e Ambiental.

d) Diretrizes Gerais 2010 a 2013

- Aprimoramento do Ensino, Pesquisa e Extensão;

- Promoção da Assistência;

- Política de Gestão de Pessoas;

- Política de Gestão Financeira;

- Modernização da infra-estrutura e incremento tecnológico;

- Aprimoramento dos processos de gestão.

e) Objetivos Estratégicos 2010-2013

- Fortalecer a integração do ensino, da pesquisa e da extensão entre HUSM, CCS e reitoria no sentido de consolidar a missão de um hospital-escola.

- Estimular a produção e institucionalização de tecnologias visando a excelência dos processos de gestão: de pesquisa, de assistência, de ensino e de extensão.

- Reestruturar a função de extensão do HUSM a fim de fortalecer a missão institucional na sua inserção regional.

- Reduzir o impacto ambiental nos processos institucionais de trabalho.

- Buscar o equilíbrio receita \& despesa

- Regular, em parceria com os órgãos competentes, o acesso dos usuários aos serviços do HUSM. 
Durante o desenvolvimento do Plano de Ação do sexto objetivo acima, "Regular, em parceria com os órgãos competentes, o acesso dos usuários aos serviços do HUSM”, constante dos seis passos a seguir explicitados:

a) Realizar reunião para definir responsabilidades e competências de cada segmento na saúde em Santa Maria com elaboração de fluxo de referência e contra referência;

b) Estabelecer com a Secretaria Municipal de Saúde de Santa Maria as contra referencias para a rede básica;

c) Pactuar entre os gestores percentuais de consultas e referências internas;

d) Realizar reuniões sistemáticas com os Gestores da saúde de Santa Maria;

e) Levantar as questões que comprometem a qualidade da saúde local e regional;

f) Definir estratégias de melhoria com responsabilização de cada Instituição.

Solidificou-se a constatação que o HUSM, sem prejuízo da continuidade de seu PE, não poderia mais avançar no processo isoladamente, mas sim, passando a envidar esforços no sentido da condução do processo de Planejamento da saúde de Santa Maria conjuntamente com as demais unidades produtoras de serviços de saúde - SUS em Santa Maria - RS e Região.

Claro exemplo desta necessidade de planejamento conjunto é o fato da hierarquização dos procedimentos hospitalares qualificados como de alta e média complexidades. O HUSM, único credenciado SUS para procedimentos de alta complexidade em Santa Maria e Região, por possuir Pronto Socorro, acaba drenando para si muitos casos de médias complexidades que poderiam ser atendidos por estabelecimentos congêneres, acabando por superlotar as suas dependências inviabilizando o nobre atendimento das altas complexidades, evidenciando a necessidade de uma melhor triagem conjunta dos casos segundo sua complexidade.

Em ambos os casos pode-se afirmar que o Planejamento Estratégico, como ferramenta de Gestão Estratégica, trata-se de um caminho sem volta e que em muito ajudou o HU a atravessar o período de grandes mudanças e conseqüentes turbulências fruto das políticas 
públicas adotadas pelo Governo Federal, passando a apresentar indicadores altamente positivos.

\subsubsection{Análise e interpretação dos resultados}

Os resultados desta etapa da pesquisa possuem duas fontes principais de informação. Uma é a pesquisa-ação. A outra, uma pesquisa exploratória realizada com os participantes na pesquisaação e responsáveis pelo PE que baseou-se em instrumento próprio (apêndice1). Para maior clareza, dividiu-se a análise dos resultados em quatro grandes blocos a saber: perfil; processo preliminar; implementação e condução; avaliação das sugestões; e finalmente a proposta de modelo proposto.

No primeiro, é avaliado e introduzido o perfil dos participantes, como uma forma de caracterizar e embasar, de forma consistente, o melhoramento da proposta do processo de PE objeto desta pesquisa.

No segundo bloco analisa-se os resultados do processo preliminar, apresentado e proposto aos participantes como instrumento de trabalho. Essa proposta preliminar é uma dedução lógica e adaptada às condições do HUSM, do modelo de PE - MIRA, proposto por Almeida (2010).

O terceiro bloco trata das dificuldades encontradas na Implementação e Condução do Processo. As informações deste bloco são fundamentais para as sugestões da etapa seguinte, que é o refino da proposta.

No quarto bloco fez-se uma avaliação das sugestões e da validade do fluxo das etapas e atividades de cada uma, visando a um refinamento do processo preliminar proposto e utilizado pelos participantes.

Finalmente, este capítulo termina com um item que se refere à proposta do modelo do processo de PE proposto como resultado final desta etapa do trabalho. 
Metodologicamente, neste capítulo, as informações, advindas da pesquisa-ação, são comentadas no início de cada bloco e complementadas com as informações e resultados obtidos com a pesquisa exploratória. A seguir, comenta-se cada bloco.

a) Perfil: $O$ que se verifica na tabela 1 é a elevada incidência de servidores mestres e doutores na área de saúde. Isso se explica pela exigência de qualificação individual, exigida para o exercício dos cargos e funções, de acordo com as especificidades de um Hospital Escola Público Federal. Para esta pesquisa, o nível de qualificação elevado dos sujeitos sociais, da amostra pesquisada, é um fator positivo, tanto de reforço à capacidade crítica dos respondentes, quanto da sua capacidade de sugestão para aperfeiçoamento do processo proposto. De uma população de 100 participantes treinados, obteve-se um retorno do questionário de 85respondentes, distribuídos da seguinte maneira: 5 diretores, 14 coordenadores, 43 chefes de serviço, 8 chefes de setor, 4 coordenadores de cursos e de 11 outros representantes.

Tabela 1: Perfil do respondente

\begin{tabular}{c|c|c|c|c|c}
\hline \multirow{2}{*}{ Área de Trabalho } & \multicolumn{4}{|c|}{ Escolaridade } & \multirow{2}{*}{ Total } \\
\cline { 2 - 5 } & Doutor & Mestre & Graduado & Outro & \\
\hline Área de Saúde & $15 \%$ & $35 \%$ & $17 \%$ & $33 \%$ & $100 \%$ \\
\hline Área Administrativa & $6 \%$ & $24 \%$ & $28 \%$ & $42 \%$ & $100 \%$ \\
\hline Outro & $0 \%$ & $2 \%$ & $15 \%$ & $83 \%$ & $100 \%$ \\
\hline
\end{tabular}

b) Processo preliminar proposto: Para facilitar o desenvolvimento das atividades de PE, da interdependência e seqüência das tarefas, normalmente são utilizados modelos. $\mathrm{O}$ modelo do processo de PE preliminar, proposto para ser utilizado no HUSM, é resultante do modelo MIRA (ALMEIDA, 2010). O modelo, devidamente discutido e detalhado no referencial teórico, está ilustrado na figura 6 . O modelo que foi oferecido para o treinamento, elaboração e implementação foi uma adaptação do MIRA. As principais adaptações foram: 
- Exclusão da etapa de viabilidade, tendo em vista que o HUSM, por ser Hospital Escola de uma universidade pública, funciona, orçamentariamente, com base nos recursos estatais;

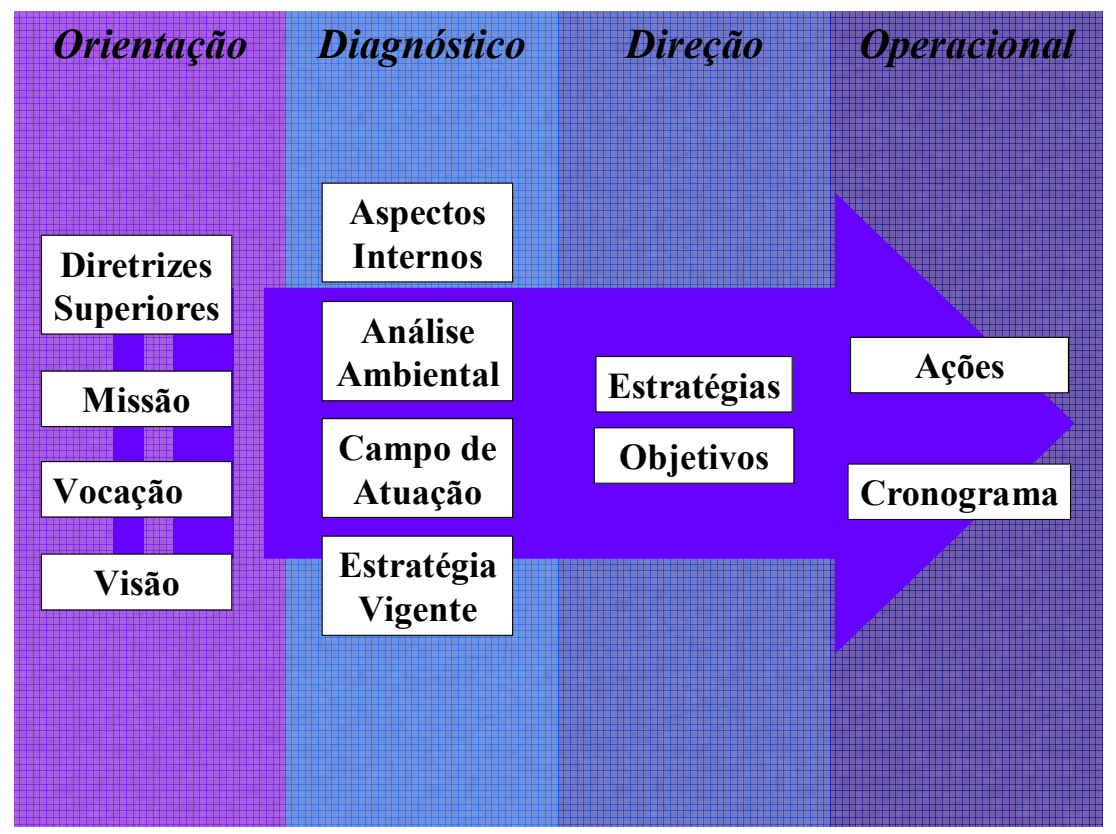

Figura 6: Modelo de PE HUSM

- Para a implementação do modelo do processo preliminar, proposto, foram utilizadas planilhas de trabalho do modelo MIRA adaptadas pelo autor desta pesquisa. A partir dessa instrumentação, foram oferecidos baterias de treinamento aos participantes.

- Para avaliação da exeqüibilidade do processo, este foi posto em ação após um acordo prévio na origem de seu início. Convencionou-se que seriam adotadas as diretrizes estratégicas vigentes da UFSM, que dariam origem à operacionalização do processo.

c) Avaliação do processo: Nesta etapa do trabalho, pesquisou-se a percepção dos participantes acerca da facilidade de compreensão e execução do processo proposto. Adicionalmente, foi pesquisada a importância atribuída ao modelo, para o 
desenvolvimento das estratégias e a utilização do mesmo no processo proposto. A seguir, a Tabela 2, representativas das respostas dos participantes, indicam um excelente grau de exeqüibilidade do processo proposto, dadas as elevadas percentagens de concordância acerca da necessidade de uso e facilidade de implementação do processo.

Tabela 2: Avaliação do Processo

\begin{tabular}{l|c|c|c|c}
\hline \multicolumn{1}{c|}{ Fatores } & Sim & Não & $\begin{array}{c}\text { Sem } \\
\text { Resposta }\end{array}$ & Total \\
\hline Aprova a Utilização do MIRA? & $\mathbf{6 2}$ & $\mathbf{2 0}$ & $\mathbf{3}$ & $\mathbf{8 5}$ \\
\hline Facilidades para odesenv.do PE & $\mathbf{6 5}$ & $\mathbf{1 2}$ & $\mathbf{8}$ & $\mathbf{8 5}$ \\
\hline Aprova a forma de condução? & $\mathbf{5 8}$ & $\mathbf{2 5}$ & $\mathbf{2}$ & $\mathbf{8 5}$ \\
\hline
\end{tabular}

A implementação do processo foi realizada por meio do método da pesquisa-ação, conforme indicado no capítulo de Método e Técnicas de Pesquisa. A atividade iniciou com o treinamento dos envolvidos no PE. Esse treinamento envolveu 100 (cem) servidores do HUSM, incluindo-se toda a diretoria executiva, bem como todos os integrantes da estrutura administrativa, isto é, em posição de tomar decisões com impacto no desempenho em longo prazo, na universidade. Durante o treinamento foi possível discutir a pertinência do modelo, do processo preliminar proposto, e adequação do mesmo às características das várias unidades envolvidas. Durante a prática foi dado todo o suporte necessário facilitando um conhecimento maior de suas realidades.

\subsubsection{Seminários de treinamento e suporte ao processo de PE}

O período de cada um dos treinamentos foi de aproximadamente 8 horas, abrangendo conceitos e exercícios de preenchimento das planilhas de trabalho. As atividades foram realizadas fora do ambiente de trabalho, em infraestrutura locada com a disponibilidade de salas para trabalhos em pequenos e grandes grupos, almoço e coffe-break no local. Para esse trabalho, houve o suporte logístico da equipe de técnicos da Pró-reitoria de Planejamento (PROPLAN). 


\subsubsection{Forma de Condução do Processo}

Não houve qualquer tipo de obrigatoriedade de participação. Dessa forma, cada servidor optou por participar voluntariamente. Quanto à forma de condução do processo, pode-se citar:

- Reuniões em Pequenos Grupos de trabalho: com até dez (10) componentes, de preferência estruturados com a participação de pessoas de diferentes níveis hierárquicos (chefias e chefiados);

- A seguir, reunião em Grande Grupo, para promover a discussão das proposições originárias dos Pequenos Grupos;

- Aprovação: Uma vez apresentadas e aprovadas as propostas, estas foram sistematizadas em documento único, encaminhado para aprovação final por parte da Diretoria Executiva (DIREX).

Após a elaboração do PE, foi feita a avaliação da implementação de sua elaboração e forma de condução da mesma, por meio da pesquisa exploratória, cujos resultados, mais relevantes, estão indicados a seguir.

A pesquisa compreendeu o levantamento da percepção dos participantes acerca de oito (8) itens, considerados como importantes para a facilidade de compreensão, incorporação e uso do processo de PE proposto. Os itens considerados envolveram: a) conhecimento pelos participantes de outro modelo de PE; b) forma de condução do processo; c) tipo e envolvimento dos participantes da Comunidade; d) análise cruzada de impacto das variáveis ambientais externas e internas; e) oportunidade de elaboração, ou complementação, de missão e visão; f) avaliação da estratégia vigente, campo de atuação e formulação de novas estratégias e objetivos estratégicos; g) estabelecimento de indicadores de desempenho e, por fim, h) estabelecimento de ações relativas às estratégias e objetivos.

Os resultados indicaram, de uma forma geral, que apesar de os participantes não terem conhecimento aprofundado de outros modelos, este foi compreendido e incorporado com razoável facilidade. Na composição do grupo participante houve não só o envolvimento das 
autoridades administrativas, mas também dos demais funcionários, demonstrando ser o processo altamente democrático e participativo.

Os resultados da pesquisa exploratória mostram, ainda, que, para a maioria dos participantes, o processo de PE proposto oportunizou a compreensão, realização e ou a complementação da análise ambiental cruzada de impacto (externo e interno) e da missão e visão. Além disso, indica, ainda, que a maioria dos grupos procedeu à avaliação das estratégias vigentes e campos de atuação, propiciando as condições para o refinamento das estratégias correntes, o estabelecimento de novas estratégias e novos objetivos estratégicos institucionais. Ademais, essa análise permitiu o estabelecimento dos indicadores de desempenho, que suportariam um posterior sistema de avaliação de desempenho do PE, bem como o estabelecimento de ações que levariam ao cumprimento das estratégias e objetivos anteriormente definidos. As tabelas 3 e 4 mostram os resultados acima comentados.

Tabela 3: Avaliação quanto ao Modelo e forma de condução

\begin{tabular}{l|c|c|c|c}
\hline \multicolumn{1}{c}{ Fatores } & Sim & Não & $\begin{array}{c}\text { Sem } \\
\text { Resposta }\end{array}$ & Total \\
\hline Conhece outros modelos? & $\mathbf{1 0}$ & $\mathbf{6 8}$ & $\mathbf{7}$ & $\mathbf{8 5}$ \\
\hline O PE foi aprovado pela DIREX? & $\mathbf{7 7}$ & $\mathbf{0}$ & $\mathbf{8}$ & $\mathbf{8 5}$ \\
\hline Faltou colaboração dos Dirigentes? & $\mathbf{6}$ & $\mathbf{7 9}$ & $\mathbf{0}$ & $\mathbf{8 5}$ \\
\hline
\end{tabular}

Tabela4: Avaliação quanto ao Produto Obtido

\begin{tabular}{l|c|c|c}
\multicolumn{1}{c}{ Produtos } & $\begin{array}{c}\text { Não havia e } \\
\text { foi elaborada }\end{array}$ & $\begin{array}{c}\text { Foi } \\
\text { complementa } \\
\text { da }\end{array}$ & $\begin{array}{c}\text { Não } \\
\text { Respondeu }\end{array}$ \\
\hline Missão & & $\mathbf{8 0}$ & $\mathbf{5}$ \\
\hline Visão & & $\mathbf{8 0}$ & $\mathbf{5}$ \\
\hline Aspectos Internos & $\mathbf{9}$ & $\mathbf{6 6}$ & $\mathbf{1 0}$ \\
\hline Ambiente Organizacional & & $\mathbf{8 5}$ & $\mathbf{1 0}$ \\
\hline Estratégia Vigente & & $\mathbf{8 1}$ & $\mathbf{4}$ \\
\hline Campo de Atuação & $\mathbf{8 2}$ & & $\mathbf{3}$ \\
\hline Grandes Estratégias & & $\mathbf{8 2}$ & $\mathbf{3}$ \\
\hline Grandes Objetivos & & $\mathbf{8 1}$ & $\mathbf{4}$ \\
\hline Indicadores & $\mathbf{8 2}$ & $\mathbf{0}$ & $\mathbf{3}$ \\
\hline Estabelecimento de Ações & & $\mathbf{8 1}$ & $\mathbf{4}$ \\
\hline
\end{tabular}

\subsubsection{Refino}

Após a avaliação o processo preliminar proposto pode ser refinado com as informações coletadas, tanto durante a pesquisa-ação quanto com as informações advindas da pesquisa 
exploratória. O refinamento do processo preliminar, na pesquisa-ação, obedeceu a uma reavaliação do trabalho, como um todo, iniciando por uma reflexão acerca da arquitetura do processo até a proposição de um fluxo apropriado de execução dos elementos e estágios constituintes do PE para o HUSM.

Em todo processo de PE descentralizado é necessário que se estabeleça uma diretriz superior, de forma a evitar que a organização tome direções diferentes. No caso do HUSM, utilizaramse as diretrizes do nível superior, isto é, da UFSM, denominadas: "Diretrizes Estratégicas". Essas constam como ponto inicial dos trabalhos de elaboração, propriamente dita do PE.

A arquitetura do processo envolve a identificação dos elementos e variáveis interdependentes, justapostos de forma lógica, de maneira a criar um fluxo de atividades coerentes (processo) e que levem ao resultado desejado (Plano Estratégico). A justaposição desses elementos, e variáveis, é estruturada em etapas coerentes e interdependentes. Nesse processo de PE, as etapas foram idealizadas da seguinte maneira:

- Estabelecimento das Diretrizes Estratégicas da Reitoria;

- Treinamento em PE;

- Estabelecimento das Diretrizes Estratégicas do HUSM;

- Discussões sobre os pontos a serem aprimorados no HUSM;

- Revisão das estratégias com base nos relatórios dos Avaliadores Externos.

As Diretrizes Estratégicas possibilitam, ao HUSM executar, adequadamente, as tarefas que lhe competem, dentro das premissas do Processo de PE proposto. Adicionalmente, os participantes contaram com a orientação dos técnicos da PROPLAN, que funcionaram como consultores para o processo do PE. A etapa seguinte foi a síntese das discussões estratégicas, realizadas.

Além das informações coletadas no processo da pesquisa-ação, explicitadas acima, procedeuse a um levantamento de como as dificuldades enfrentadas, durante a realização do processo preliminar proposto, poderiam ser minimizadas. Assim, as informações coletadas, nesta pesquisa, referem-se a: sugestões de etapas a serem mudadas; ao lócus de discussão e geração 
das estratégias e das diretrizes estratégicas; do processo da análise cruzada de impacto interno e da responsabilidade pela organização do processo.

Em termos de etapas do processo, os respondentes indicam, maciçamente, não haver necessidade de mudança nas etapas do processo proposto. Isso indica um ótimo grau de satisfação para os usuários, acerca das etapas (tipo e forma) do processo, no sentido de que tais etapas suprem as necessidades das atividades necessárias à elaboração do Plano Estratégico.

Os resultados das respostas da pesquisa exploratória, relativos à necessidade de definição das estratégias, por instâncias superiores, indicam uma quase totalidade negativa em relação à pré-definição das estratégias por aquelas instâncias. Isso mostra um elevado grau de descentralização administrativa.

Esse é um ponto crítico do modelo político de governança, que possui um importante impacto sobre o processo de PE proposto. A auto definição dos valores e atitudes, e as decisões obedecendo a acordos políticos dos grupos constituintes da instituição, criam um ambiente extremamente sensível a conflitos. Um bom processo de PE deve permitir ampla discussão em torno das questões, porém deve ajuizá-las ao redor de causas comuns que evitem conflitos localizados. Ao permitir a ampla discussão, o processo proposto cumpre o primeiro requisito, porém, corre o risco de não poder evitar conflitos. Esse risco, por outro lado, é mantido sob controle por meio da sistematização das atividades, em etapas lógicas e interdependentes, não apenas em termos de sua operacionalização, mas, também, em termos da manutenção das competências e das hierarquias institucionais.

A pesquisa indica também que todo o processo deve ser organizado por um grupo externo aos setores participantes, visando a um bom funcionamento da logística de operação do processo.

Os dados, e resultados comentados acima, estão representados na tabela 5a seguir. 
Tabela 5: Avaliação do Refino do Processo

\begin{tabular}{c|c|c|c|c}
\hline Fatores & Sim & Não & $\begin{array}{c}\text { Sem } \\
\text { Resposta }\end{array}$ & Total \\
\hline As etapas deveriam ser diferentes? & $\mathbf{8}$ & $\mathbf{6 8}$ & $\mathbf{9}$ & $\mathbf{8 5}$ \\
\hline $\begin{array}{c}\text { As estratégias deveriam ser } \\
\text { estabelecidas pela Reitoria? }\end{array}$ & $\mathbf{1}$ & $\mathbf{8 3}$ & $\mathbf{1}$ & $\mathbf{8 5}$ \\
\hline $\begin{array}{c}\text { A reitoria deveria apresentar as } \\
\text { suas diretrizes para o HUSM? }\end{array}$ & $\mathbf{8 3}$ & $\mathbf{2}$ & $\mathbf{0}$ & $\mathbf{8 5}$ \\
\hline $\begin{array}{c}\text { O processo deveria ser organizado } \\
\text { por grupo externo? }\end{array}$ & $\mathbf{8 2}$ & $\mathbf{0}$ & $\mathbf{3}$ & $\mathbf{8 5}$ \\
\hline
\end{tabular}

\subsubsection{Processo de PE Resultante}

Como resultado da implementação do processo preliminar, os aperfeiçoamentos propostos ao longo da pesquisa-ação, e dos ajustes realizados por meio das informações obtidas da pesquisa exploratória, sugere-se o processo mostrado na figura 7 ,a seguir, que consiste de uma adaptação do modelo proposto por Almeida (2004, p. 102) como um modelo de processo final para o PE de Hospitais Universitários Públicos, 


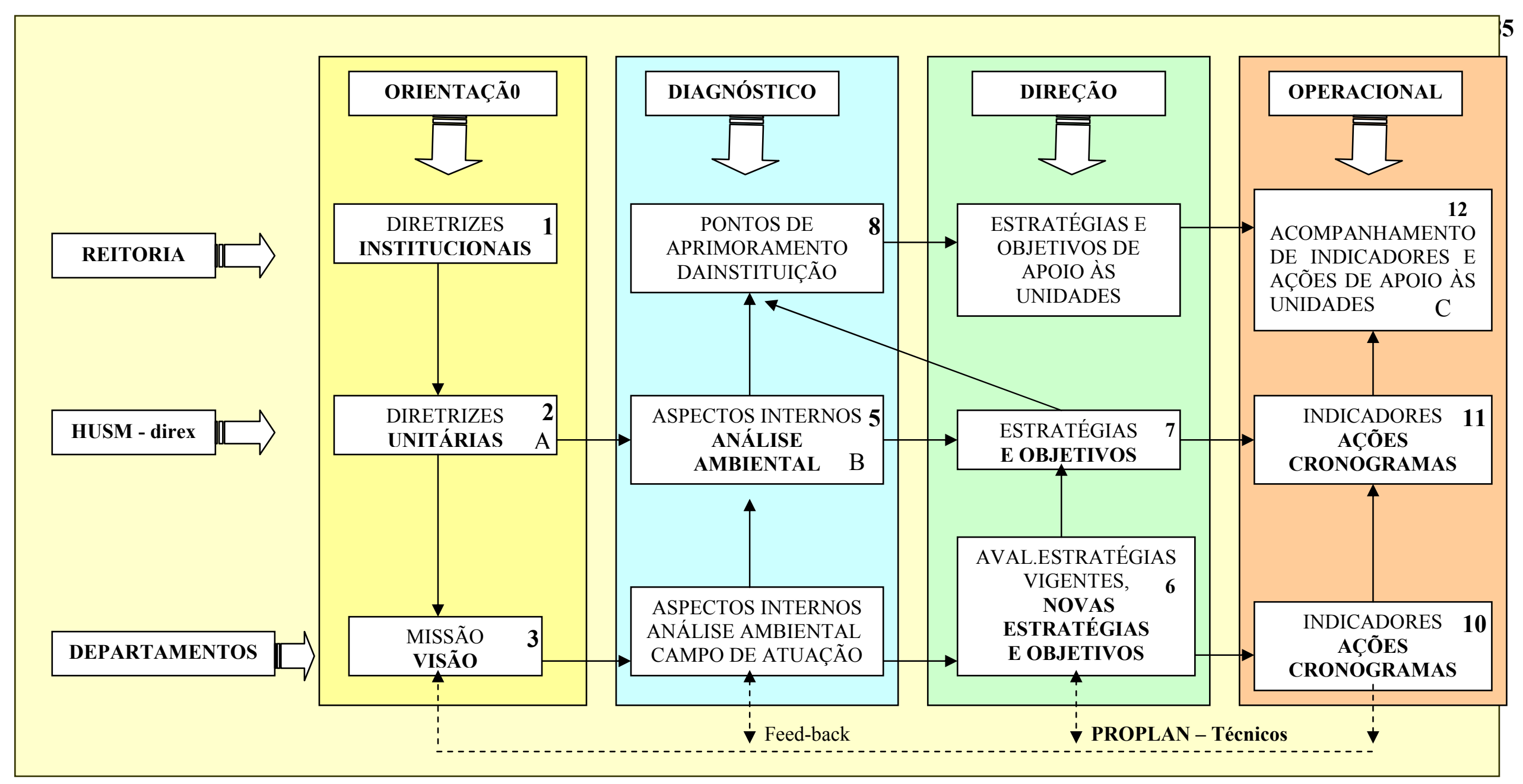

Figura 7: Processo de PE Resultante

Fonte: Adaptado de Almeida (2004, pág. 102)

\section{LEGENDA:}

A: Eventualmente, nas unidades onde as atividades dos departamentos têm uma grande interdependência, o PE pode concentrar-se na unidade.

B: O diagnóstico das unidades se beneficiará das análises ocorridas nos departamentos.

C: Por ser um PE de uma unidade da UFSM, cabe à reitoria (mais especificamente a PROPLAN) acompanhar os indicadores dessas entidades. 
É importante observar, no processo descrito na figura 7, alguns fatores e características fundamentais:

a) As Diretrizes Estratégicas emanam originalmente, da Reitoria e descem para o restante da Instituição, incluindo-se o HUSM.

b) Os departamentos constitutivos do HUSM, em geral, são os responsáveis pela análise e discussão das estratégias vigentes e proposição de redirecionamento, novas estratégias e novos objetivos estratégicos;

c) O processo proposto acima, porém, é flexível o suficiente para permitir, ao HUSM se preferir proceder à discussão e elaboração das suas estratégias específicas;

d) A definição dos Indicadores Chave de Desempenho é feita com base nas estratégias e objetivos gerados.

e) Por fim, a avaliação do desempenho do PE é feita pela entidade institucional competente, no caso da UFSM, a PROPLAN.

\subsection{Planejamento conjunto com as demais UPSS.}

Diante da constatação da necessidade de um processo de planejamento mais abrangente, no mês de agosto de 2012 reuniu-se, mediante convite da Senhora Diretora Geral do HUSM, todos os dirigentes das UPSS, englobando além da direção do HUSM, as direções do Hospital Municipal Casa de Saúde, do Hospital filantrópico privado Alcides Brum, da Unidade de Pronto Atendimento (UPA), da $4^{\text {a }}$ Coordenadoria Regional de Saúde do Estado, e da Secretaria Municipal de Saúde de Santa Maria bem como contando com a presença do Autor desta pesquisa.

Com a concordância de todos iniciou-se o processo de planejamento estratégico conjunto, deliberando por convidar um especialista para proferir palestra motivacional e orientar na seleção do modelo e condução do processo. A escolha recaiu na pessoa do Dr. Martinho Isnard Ribeiro da Almeida, Professor Livre Docente da Universidade de São Paulo.

No dia 14 de setembro de 2012, às nove horas, no Auditório GULERPE do HUSM, o Professor Martinho Isnard Ribeiro de Almeida proferiu palestra motivacional reforçand 
importância do processo de Planejamento Estratégico, expondo detalhadamente os principais conceitos inerentes ao Processo, quais sejam: Planejamento X Plano; Aspectos Internos X Ambiente organizacional; Missão X Vocação X Visão; Unidade Estratégica de Negócio; Níveis da Unidade - Estratégico, Administrativo e Operacional; Planejamento Estratégico X Administração Estratégica; Decisão Estratégica; Eficiência X Eficácia; Sinergia e Fatores Críticos de Sucesso; Estratégia, Objetivos, Meta, Política, Valores; e Competitividade.

A seguir, em reunião realizada às onze horas do dia quatorze de setembro de dois mil e doze, na sala de reuniões da Direção Geral do Hospital Universitário de Santa Maria, presentes a Diretora Geral do HUSM, o Diretor Clínico do HUSM, a Diretora de Ensino e Pesquisa do HUSM, a Diretora de Enfermagem do HUSM, o Diretor Administrativo do HUSM), a Coordenadora do Núcleo de Qualidade e Apoio Gerencial (NAG) do HUSM), o Consultor convidado, a Coordenadora da $4^{\mathrm{a}}$ Coordenadoria Regional de Saúde, o Secretário Municipal da Saúde, o Diretor da Unidade de Pronto Atendimento (UPA) e representante do Hospital Casa de Saúde, a Diretora Executiva do Hospital de Caridade Dr. Astrogildo de Azevedo, o Coordenador de Planejamento PROPLAN-UFSM), e o Doutorando em Administração, autor desta pesquisa, passaram a discutir questões sobre o Planejamento Estratégico do HUSM de forma integrada com os demais dirigentes das UPSS de Santa Maria.

Durante as discussões, sob a orientação do Consultor Professor Livre Docente da USP Dr. Martinho Isnard Ribeiro de Almeida, foi unânime o consenso de que a saúde de Santa Maria deve ser discutida em conjunto por gestores e dirigentes das unidades produtoras de serviços de saúde - SUS em Santa Maria - RS e Região, constituindo-se um Grupo de Trabalho. Após serem discutidos vários aspectos sobre a saúde pública e a importância do trabalho conjunto, ficou agendada uma próxima reunião para o dia dezessete de outubro de dois mil e doze, as quatorze horas, na Sala de Reuniões da Direção Geral do HUSM, com a presença de todas as Direções e Gestores acompanhados de, no mínimo um técnico com conhecimento em gestão de saúde e envolvido com atividades de planejamento. O grupo deliberou que essas reuniões se tornassem sistemáticas e periódicas, ocorrendo em locais alternados entre as unidades envolvidas. Definiu-se, ainda, que o agendamento, contatos e organização para a realização das reuniões ficassem sob a responsabilidade do autor desta pesquisa. 
Por ocasião do envio do convite aos membros do Grupo de Trabalho, enviou-se o documento intitulado "Planejamento Estratégico - Referencial Teórico para um Modelo de Desenvolvimento do Processo". O referido material constante do conteúdo da palestra apresentada pelo Prof. Martinho, devidamente complementado e enriquecido pelo Modelo Almeida (2010), ver figura 8 , bem como por exemplos aplicados à gestão hospitalar, foi organizado e uma vez editado, passou a constituir o guia para a posterior seqüência de atividades do processo de Planejamento Estratégico.

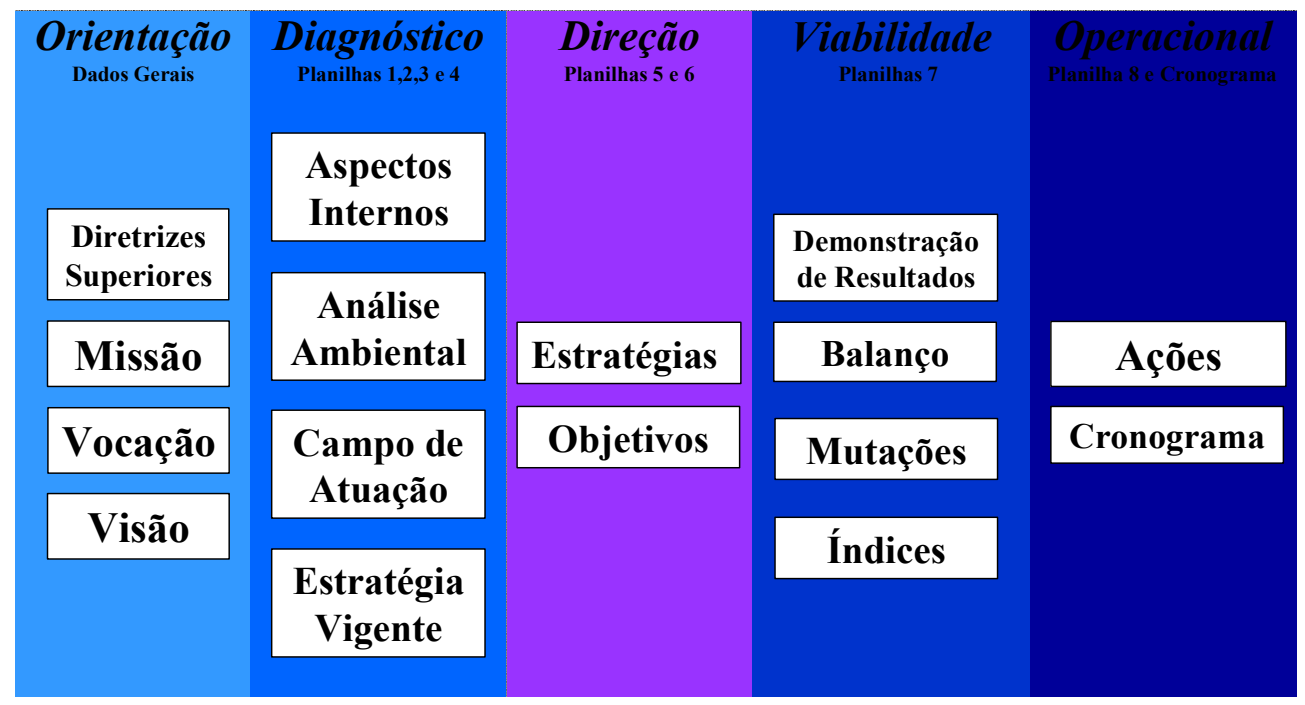

Figura 8:Modelo de desenvolvimento de um PE Fonte: Almeida (2010, p. 42)

Por ocasião desta primeira reunião do Grupo de Trabalho, foi apresentado o referencial teórico para, em pequenos grupos, serem desenvolvidos os exercícios práticos relativos à análise ambiental e aos aspectos internos para em reuniões posteriores, ser analisados e consolidados.

Um fato novo surgiu com o convite endereçado a todos os membros do Grupo de Trab para participar das atividades desenvolvidas pela Agência de Desenvolvimento de $\subseteq$ Maria (ADESM) que em parceria com a sociedade santa-mariense, começara a construir uma visão conjunta de longo prazo para o desenvolvimento de Santa Maria e região, por meio do Movimento “A Santa Maria que Queremos”. 
O movimento iniciado em novembro de 2009, em 2013 criou o eixo temático SAÚDE, e tomando conhecimento do GT de planejamento estratégico conjunto para a área de saúde, esperava contar com a soma de esforços, evitando a duplicidade de meios para idênticos fins, com provável ganho de qualidade.

\subsection{O processo de PE em 2013 - 2014 (ADESM)}

Aceito o convite, o grupo de dirigentes somou-se aos esforços da ADESM e juntamente com os demais voluntários, passaram a trabalhar no processo de Planejamento Estratégico Conjunto para a área da saúde de Santa Maria.

\subsubsection{A Gênese da Agência de Desenvolvimento de Santa Maria}

Fundada em 18 de abril de 2011, a Agência de Desenvolvimento de Santa Maria (ADESM) teve seus alicerces construídos por uma trajetória que se inicia muito antes da data que marca sua fundação oficial.

O início se deu em 1988, com a criação do Fórum das Entidades Empresariais (FEE). A organização de uma instituição para planejamento, como o Escritório da Cidade (fundado em 2005 e transformado em Instituto de Planejamento em 2013), de um Parque Tecnológico (como a Associação Parque Tecnológico de Santa Maria, criada em 2008) e de uma Agência de Desenvolvimento (criada em 2011) eram bandeiras do Fórum das Entidades Empresariais desde sua fundação.

Das articulações entre empresários e poder público, outras vivências positivas foram fundamentais para a consolidação da ADESM. A partir da criação do Comitê de Empreendedorismo e Inovação, em 2005, e das experiências de trabalho em conjunto entre poder público, universidades, empresários, sistema "S" e voluntários, a idéia da consolidação de uma Agência de Desenvolvimento foi amadurecendo. 
Em 2009, a Secretaria Municipal de Desenvolvimento com o apoio do Comitê de Empreendedorismo e Inovação coordenaram o Pavilhão de Inovação e também o Movimento “A Santa Maria Que Queremos” que, em parceria com a sociedade, começaram a construir uma visão conjunta de longo prazo para o desenvolvimento de Santa Maria e região.

Vinte e dois anos após a consolidação do Fórum das Entidades Empresariais, o sonho da criação de uma Agência de Desenvolvimento começa a se tornar realidade. Em 2010, através da articulação entre diversas instituições, pessoas físicas e jurídicas, lideradas pelo Comitê de Empreendedorismo e Inovação e pela Secretaria Municipal de Desenvolvimento, o esboço da Agência de Desenvolvimento de Santa Maria começa a ser elaborado.

Em 29 de março de 2011, após uma série de reuniões e uma importante articulação entre empresários e a Prefeitura Municipal de Santa Maria, o município enviou um Projeto de Lei à Câmara de Vereadores para buscar autorização legislativa para participar da criação da ADESM em parceria com outras pessoas físicas e jurídicas de direito privado. O projeto foi aprovado em tempo recorde: 31 de março, resultando na Lei Municipal nº 5439.

Em 18 de abril de 2011, a Assembléia Geral, realizada na Câmara Municipal de Vereadores, aprovou a fundação da Agência de Desenvolvimento de Santa Maria. Desde então, a ADESM ficou consolidada como uma associação de direito privado, sem fins lucrativos e econômicos e aberta à participação da sociedade.

Em seu estatuto, foram estabelecidos 11 objetivos principais, que no seu conjunto visam articular o desenvolvimento sustentável de Santa Maria e Região, pela ação integrada entre o Poder Público, Instituições de Ensino, Setor Empresarial, Associações afins e Voluntários da Sociedade; fomentar e divulgar oportunidades de investimento no Município e potencializar as empresas já instaladas em Santa Maria; e realizar a coordenação do Movimento "A Santa Maria que Queremos", viabilizando encontros de pessoas interessadas em debater idéias, estudos e projetos relacionados ao desenvolvimento sustentável de Santa Maria e região. 


\subsubsection{O Eixo Temático Saúde}

O Plano de Desenvolvimento "A Santa Maria que Queremos, contemplou oito eixos temáticos listados a seguir. Destes, a pesquisa focou apenas o GT Saúde.

- Gestão Pública;

- Infraestrutura;

- Educação;

- Saúde;

- Segurança;

- Cultura;

- Meio Ambiente;

- Crescimento Econômico.

A seguir, alguns dos principais indicadores da área da saúde em Santa Maria.

Tabela 3: IDESE Saúde e a posição de Santa Maria comparada com os municípios do RS ao longo dos anos

\begin{tabular}{c|c|c}
\hline Ano & Índice & Posição \\
\hline 2009 & 0,845 & $346^{\mathbf{o}}$ \\
\hline 2008 & 0,847 & $304^{\text {o }}$ \\
\hline 2007 & 0,847 & $334^{\text {o }}$ \\
\hline 2006 & 0,849 & $336^{\circ}$ \\
\hline 2005 & 0,851 & $288^{\circ}$ \\
\hline 2004 & 0,845 & $300^{\circ}$ \\
\hline 2003 & 0,837 & $350^{\circ}$ \\
\hline 2002 & 0,851 & $299^{\circ}$ \\
\hline 2001 & 0,865 & $225^{\circ}$ \\
\hline 2000 & 0,862 & $254^{\circ}$ \\
\hline 1999 & 0,828 & $223^{\circ}$ \\
\hline
\end{tabular}

Fonte: Fundação de Economia e Estatística (2013) 
Na Tabela 3, verifica-se que o IDESE Saúde apresentou variações durante os anos analisados. Neste período o índice passou 0,828 em 1999 para 0,845, em 2009. Analisando sobre o viés da classificação geral dos municípios do Rio Grande do Sul, identifica-se que está havendo uma tendência de queda de posição, haja vista que, em 1991, a posição era $223^{\circ}$ e, em 2009 a posição está na $346^{\circ}$.

Já a tabela 4, demonstra que o IDESE Saúde/2009 do município de Santa Maria obteve a $5^{\text {a }}$ posição entre os 10 maiores municípios do RS.

Tabela 4: Ranking do IDESE Saúde de 2009 comparado com os 10 maiores municípios do RS

\begin{tabular}{|c|c|c|}
\hline MUNICÍPIO & ÍNDICE & POSIÇÃO NO RANKING \\
\hline Porto Alegre & 0,832 & $7^{\circ}$ \\
\hline Caxias do Sul & 0,837 & $6^{\circ}$ \\
\hline Pelotas & 0,814 & $10^{\circ}$ \\
\hline Canoas & 0,851 & $3^{\circ}$ \\
\hline Gravataí & 0,867 & $1^{\mathrm{o}}$ \\
\hline Santa Maria & 0,845 & $5^{\circ}$ \\
\hline Viamão & 0,866 & $2^{o}$ \\
\hline Novo Hamburgo & 0,851 & $4^{\mathrm{o}}$ \\
\hline São Leopoldo & 0,835 & $8^{\circ}$ \\
\hline Rio Grande & 0,83 & $9^{\circ}$ \\
\hline
\end{tabular}

Fonte: FEE (2013)

Os dados da Tabela 5apresentam o número de leitos por especificidade revelam um equilíbrio entre leitos ofertados pelo SUS (48,90\%) e demais tipos de leitos $(51,10 \%)$. Pode-se constatar que entre leitos clínicos e cirúrgicos perfazem um total de 554 leitos, resultando no total de $64,04 \%$ de leitos. Considerando a população de Santa Maria (IBGE/2010), pode-se inferir que existe 1 leito a cada 302 habitantes no município. 
Tabela 5: Número de leitos por especialidade nos hospitais em Santa Maria (2010)

\begin{tabular}{c|c|c|c}
\hline TIPOS DE LEITOS & $\begin{array}{c}\text { LEITOS } \\
\text { SUS }\end{array}$ & $\begin{array}{c}\text { LEITOS - Particulares, } \\
\text { Convênios e Associações }\end{array}$ & TOTAL \\
\hline Cirúrgicos & 99 & 178 & 277 \\
\hline Clínicos & 116 & 161 & 277 \\
\hline Complementares & 32 & 38 & 70 \\
\hline Obstétricos & 60 & 33 & 93 \\
\hline Pediátricos & 60 & 10 & 70 \\
\hline Outras especialidades & 56 & 22 & 865 \\
\hline Total & 423 & 442 & \\
\hline
\end{tabular}

Fonte: Portal DATASUS (2013)

A Tabela 6 descreve o total de estabelecimentos de saúde pela sua tipologia.

Tabela 6: Total de estabelecimentos de Saúde em Santa Maria (2012)

\begin{tabular}{l|c}
\hline \multicolumn{1}{c}{ ESTABELECIMENTOS DE SAÚDE } & TOTAL \\
\hline Hospital & 8 \\
Unidades de Saúde & 36 \\
Clínicas e Consultórios & 620 \\
Maternidades & 7 \\
Laboratórios & 124 \\
Farmácias e Drogarias & 143 \\
TOTAL & $\mathbf{9 3 8}$ \\
\hline
\end{tabular}

Fonte: Elaborado com base Santa Maria em Dados (2013)

Atualmente, o município de Santa Maria possui um total de 8.410 profissionais que prestam serviços na área saúde. Os dados, que foram fornecidos pelos conselhos regionais de cada profissão, são apresentados em comparação aos números referentes ao Estado do Rio Grande do Sul conforme a Tabela 7 . 
Tabela 7: Número de profissionais da área da saúde em Santa Maria e no Rio Grande do Sul (2012)

\begin{tabular}{l|c|c|c|c}
\hline \multicolumn{1}{c|}{ Profissional } & $\begin{array}{c}\text { Santa } \\
\text { Maria }\end{array}$ & $\begin{array}{c}\text { Participação da } \\
\text { profissão Município }\end{array}$ & $\begin{array}{c}\text { Rio } \\
\text { Grande do } \\
\text { Sul }\end{array}$ & $\begin{array}{c}\text { Participação da } \\
\text { profissão Estado }\end{array}$ \\
\hline Fonoaudiólogos & 136 & $1,6 \%$ & 1.827 & $7,4 \%$ \\
\hline Nutricionistas & 278 & $3,3 \%$ & 6700 & $4,1 \%$ \\
\hline Fisioterapeutas & 554 & $6,5 \%$ & 8.727 & $6,3 \%$ \\
\hline Psicólogos & 598 & $7,1 \%$ & 15.385 & $3,9 \%$ \\
\hline Farmacêuticos & 717 & $8,4 \%$ & 11.771 & $0,6 \%$ \\
\hline Dentistas & 1.055 & $12,5 \%$ & 24.503 & $4,3 \%$ \\
\hline Médicos & 1.132 & $13,4 \%$ & 25.515 & $4,3 \%$ \\
\hline Enfermeiros & 1.185 & $14 \%$ & 18595 & $6,4 \%$ \\
\hline Técnicos em & 2.755 & $32,7 \%$ & 67499 & $4,1 \%$ \\
enfermagem & & $100 \%$ & 180.522 & $4,6 \%$ \\
\hline TOTAL & 8.410 & & & \\
\hline
\end{tabular}

Fonte: Elaborado com base Santa Maria em Dados (2013)

Visando a atender aos objetivos, em especial ao de ampliar a quantidade de leitos hospitalares, alguns projetos estão sendo desenvolvidos, como a construção da nova central de Unidades de Tratamento Intensivo (UTI) do HUSM, principalmente da UTI Neonatal, UTI Adulto e UTI Cardiológica que passarão a contar com maior número de leito.

Uma das expectativas para área da saúde do município é inserção de novas empresas, em especial a Empresa Brasileira de Serviços Hospitalares (EBSERH) que vai possibilitar contratação de novos profissionais da área, qualificando o atendimento de serviços especializados.

No entanto, dentre os objetivos e propostas que serão apresentados, destacam-se a importância da assistência na rede básica de saúde, que pode proporcionar novas demandas ambulatoriais e exames especializados. Um dos resultados esperados para o ano de 2014 será o inicio das atividades do Hospital Regional Estadual (HRE), que vai proporcionar ampliação da assistência na área de trauma, neurologia e reabilitação neuromotora. 


\subsubsection{Condução do processo do Grupo Temático Saúde - ADESM}

Para descrever as atividades desenvolvidas na condução do processo do GT Saúde, é necessário antes relatar a metodologia empregada pela ADESM para a elaboração do Plano “A Santa Maria que Queremos".

A arquitetura para a elaboração do plano originou-se das discussões em oficinas de trabalho de uma equipe multidisciplinar de especialistas juntamente com a equipe da ADESM. A equipe foi constituída por nove professores doutores da UFSM com especialidades em Administração, Comunicação Social, Economia, Educação, Engenharia da Produção, Gestão Pública, Sustentabilidade e por dois especialistas: um Administrador especialista em gestão de saúde, integrante do corpo funcional da UFSM, e um especialista ad hoc em segurança pública. Também participaram dois mestrandos e um doutorando em Administração. O trabalho dessa equipe foi coordenado por professores do Departamento de Ciências Administrativas (DCA), do Centro de Ciências Sociais e Humanas (CCSH) da UFSM.

A construção do Plano Estratégico de Desenvolvimento de Santa Maria orientou-se pelos pressupostos do Planejamento Estratégico Municipal (RESENDE e CASTOR, 2006).

- Caráter integral e integrado, por abordar tanto as questões econômicas quanto as sociais, culturais e territoriais, nas áreas urbana e rural, e por ter as suas dimensões compatibilizadas entre si de forma equilibrada;

- Contempla ações e políticas cooperativas com os demais níveis federativos, apontando soluções não circunscritas somente às competências típicas e exclusivas do Município;

- Caráter técnico e político, procurando não só racionalizar as condutas humanas, mas negociar na conciliação dos interesses diversos;

- Racionalidade substantiva, levando em conta a qualidade substantiva dos fins almejados;

- Participação ativa da comunidade em sua elaboração, acompanhamento e permanente avaliação; 
- Baseia-se em um modelo organizacional burocrático-empresarial-comunitário, envolvendo o poder público, as empresas e as organizações do Terceiro Setor.

A proposta metodológica, ilustrada na Figura 9, tomou como referência a Visão Geral do Planejamento Estratégico Municipal (Resende e Castor, 2006), ressaltando-se a necessidade de adaptação às especificidades do planejamento e ao processo vivenciado na realidade do Município de Santa Maria. Sendo assim, o processo evoluiu considerando as fases de: (i) Análises de Contexto, (ii) Definição da Diretriz Estratégica, (iii) Objetivos Estratégicos e Propostas e (iv) Monitoramento e Articulação.

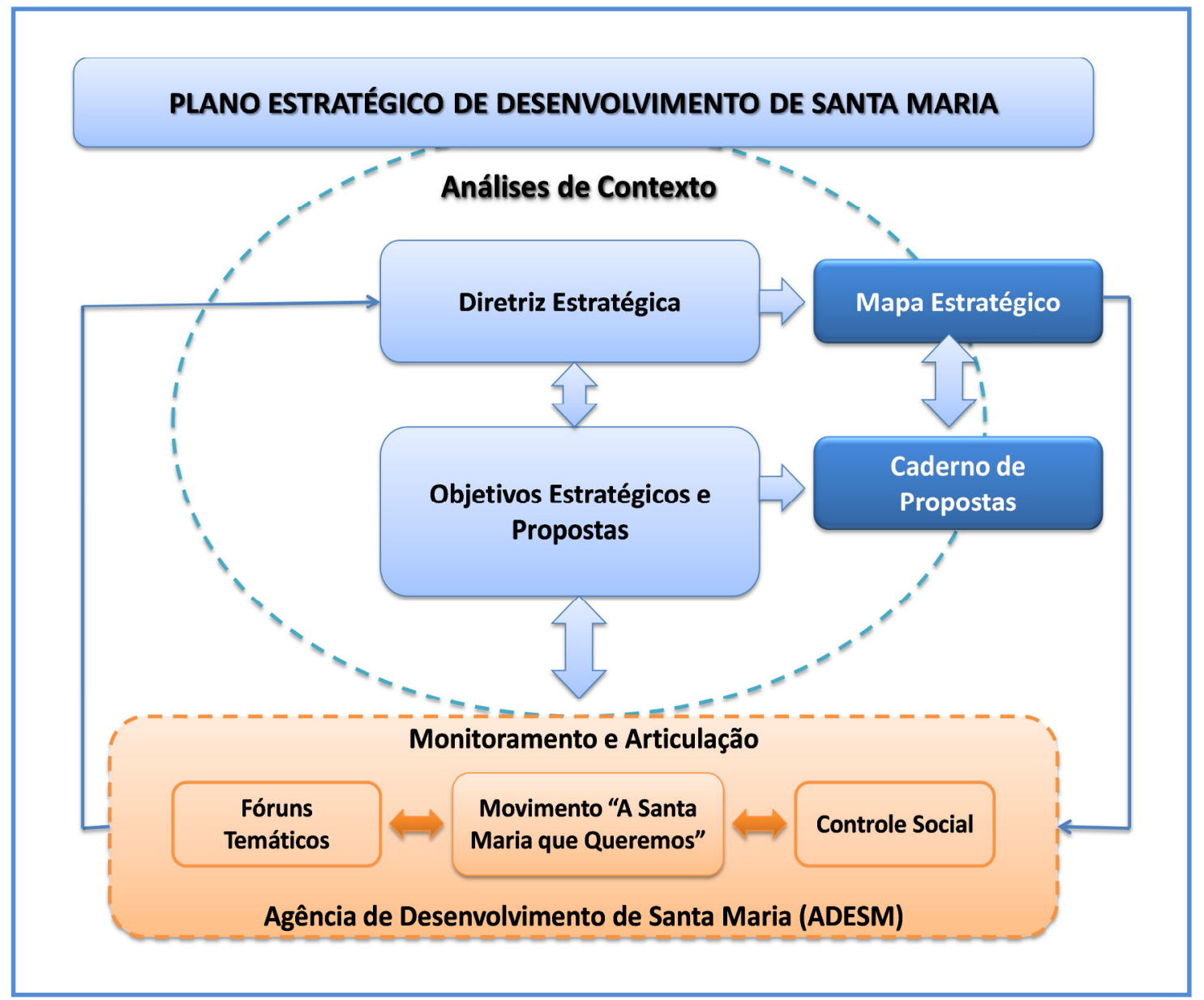

Figura 9-Proposta metodológica do Plano Estratégico de Desenvolvimento de Santa Maria Fonte: Adaptado de Resende e Castor, 2006, p. 146.

As Análises de Contexto levaram em conta o contexto externo e o interno. A análise do contexto externo procurou situar o Município no ambiente onde se insere, confrontando a sua situação com a realidade que o cerca comparativamente aos dez maiores municípios do 
Estado do Rio Grande do Sul. Em âmbito geral, essa análise concentrou-se nos aspectos demográficos e socioeconômicos e, em âmbito específico, considerou aspectos relevantes de cada Eixo Estratégico de Desenvolvimento. A análise do contexto interno considerou o desenvolvimento histórico do Município, apresentando um panorama geral sobre a sua evolução.

Seguindo esta metodologia, a Agência de Desenvolvimento de Santa Maria (ADESM) coordenou 144 reuniões de Grupos Temáticos, que contaram com 2.506 presenças de 803 voluntários e 210 Entidades representadas. A seguir, planilha com o resumo das reuniões para elaboração do Plano.

Planilha Resumo das Reuniões para elaboração do PED-SM

\begin{tabular}{|l|c|c|c|c|}
\hline Fórum Temático (FT) & $\begin{array}{c}\text { Número de } \\
\text { Reuniões }\end{array}$ & $\begin{array}{c}\text { Número de } \\
\text { Voluntários }\end{array}$ & $\begin{array}{c}\text { Número total de } \\
\text { Presenças }\end{array}$ & $\begin{array}{c}\text { Número de } \\
\text { Entidades }\end{array}$ \\
\hline FT de Desenvolvimento & 55 & 387 & 1064 & 44 \\
\hline FT de Infraestrutura & 32 & 164 & 448 & 38 \\
\hline FT de Educação & 8 & 90 & 154 & $\mathbf{1 6}$ \\
\hline FT de Saúde & $\mathbf{6}$ & $\mathbf{6 0}$ & 236 & 23 \\
\hline FT de Segurança & 17 & 58 & 125 & 26 \\
\hline FT de Cultura & 6 & 52 & 274 & 11 \\
\hline FT de Meio Ambiente & 13 & 126 & 69 & 24 \\
\hline FT de Gestão Pública & 6 & 30 & $\mathbf{1 8 3}$ & \\
\hline Audiência Pública & 1 & 55 & & 215 \\
\hline Total Geral & $\mathbf{1 4 4}$ & & & \\
\hline
\end{tabular}

Fonte: Site da ADESM consulta em 18/03/2014.

Especificamente na condução do processo do GT Saúde, tomando em consideração a participação dos seis (6) gestores das UPSS que já haviam recebido o treinamento, bem como 
realizado o diagnóstico (aspectos internos e análise ambiental) com base no modelo MIRA, exerceram grande influência.

Numa primeira fase, reunidos em oficinas de trabalho, foram desenvolvidos exercícios práticos durante os quais, os representantes voluntários de vários setores da sociedade familiarizaram-se com os conceitos e categorias do processo de planejamento.

Foram realizadas seis reuniões de trabalho durante as quais se contou, além dos gestores das unidades produtoras de saúde em Santa Maria, com a participação de 40 voluntários representantes de 21 entidades.

Frutos deste trabalho foram consolidados a análise ambiental (oportunidades e ameaças), os aspectos internos (pontos fortes e pontos fracos), bem como se definiram possíveis cenários, valores, e visão de futuro da área de saúde de Santa Maria, os quais balizaram o estabelecimento das diretrizes gerais, das estratégias, dos objetivos estratégicos, dos indicadores e das ações que compuseram o Processo de Planejamento do eixo temático.

Concluídas as etapas do processo, chegou-se às seguintes Missão e Visão para o eixo temático da saúde:

- Missão do Eixo Temático: Procurar ofertar uma melhor qualidade de vida em termos de serviços de saúde para a população da Região Central do Estado do Rio Grande do Sul.

- Visão do Eixo Temático: Que Santa Maria seja o principal Pólo na Área de Saúde do interior do Rio Grande do Sul.

A saúde é reconhecida com um direito humano fundamental e um dos mais importantes recursos para o desenvolvimento sustentável, bem como proporciona alcançar uma das mais importantes dimensões para a qualidade de vida. Este tema relaciona-se com um conjunto de fatores sociais, econômicos, políticos e culturais, coletivos e individuais, que com equilíbrio, 
podem resultar em sociedades mais saudáveis. Para qualificar estas condições, são necessárias mudanças nos padrões econômicos e sociais, desenvolvendo planejamento de políticas públicas e ações que busquem estes objetivos.

Como principais propostas estabelecidas destacam-se a busca de maior disponibilidade de leitos hospitalares, aperfeiçoamento dos profissionais e parcerias com instituições afins. Buscando atender a visão estabelecida neste eixo, o município deve manter o equilíbrio em vários fatores nos resultados apresentados pelo IDESE Saúde, que estão abaixo da colocação geral. Para atender estas expectativas várias ações deverão ser encaminhadas aos gestores da área saúde, visando um alinhamento estratégico dos objetivos.

Para alcançar a Visão e cumprir a Missão, existe a necessidade da definição de Estratégias e Gestão conjuntas dos responsáveis pela oferta dos serviços de saúde no Município.

\subsubsection{Objetivos Estratégicos e Propostas}

\section{OBJETIVO 1}

Garantir uma ampla participação da sociedade na elaboração dos próximos Planos Municipal de Saúde (PMS) e atingir as metas estabelecidas.

Proposta 1 - Apoiar a Secretaria Municipal de Saúde juntamente com o Conselho Municipal de Saúde (CMS) para realização da Conferência Municipal de Saúde, com ampla participação da comunidade.

Proposta 2 - Viabilizar as propostas previstas no Plano Municipal de Saúde, através da atuação conjunta e articulada da Secretaria Municipal de Saúde (SMS), com a $4^{\mathrm{a}}$ Coordenadoria Regional de Saúde (CRS), o CMS e as demais instituições de saúde do município.

Proposta 3 - Desenvolver uma sistemática de revisão periódica das propostas e metas estabelecidas no PMS, visando adequação e/ou atualização desses, em consonância com a realidade epidemiológica do município. 


\section{OBJETIVO 2}

Ampliar a interação do Poder Público Municipal com os órgãos responsáveis pela área da saúde, em especial o Conselho Municipal de Saúde (CMS).

Proposta 1: Realizar reuniões semestrais da SMS com a participação do CMS, $4^{\mathrm{a}} \mathrm{CRS}$, Comissão de Saúde da Câmara Municipal de Vereadores de Santa Maria (CSCMVSM) e outras instituições.

\section{OBJETIVO 3}

Realizar o mapeamento e zoneamento da população a ser atendida, buscando ampliar e melhorar a qualidade de atendimento na atenção básica à saúde.

Proposta 1 - Desenvolver estratégias para melhoria do acesso e qualificação da Atenção Básica, por meio de Agentes Comunitários e Estratégia Saúde da Família (ESF).

Proposta 2 - Realizar projeção de demandas e levantamento do suporte técnico e profissional das Unidades Básicas de Saúde (UBS), implantando o $3^{\circ}$ turno de atendimento nas áreas de maior demanda.

Proposta 3 - Ampliar e qualificar o apoio ao diagnóstico especializado.

Proposta 4 - Implementar as redes prioritárias de atenção à saúde do Ministério da Saúde, como os Programas: Rede Cegonha, Rede de Atenção às Urgências e Emergências, Rede de Atenção Psicossocial, Rede de Atenção Oncológica.

Proposta 5 - Estabelecer estratégias para implementar o programa Núcleo de Apoio à Saúde da Família (NASF).

Proposta 6 - Desenvolver estratégias para implementação do Programa Saúde na Escola, no município de Santa Maria.

Proposta 7 - Aderir ao Programa Tele saúde RS e desenvolver estratégias em busca de maior resolutividade do atendimento aos usuários. 
Proposta 8 - Implementar outros programas de atenção básica, incentivados pelo Ministério da Saúde, em todas as regiões administrativas do município, considerando o perfil epidemiológico de alerta, como o Programa Academia da Saúde, para orientação de atividade física, de esporte e lazer.

\section{OBJETIVO 4}

Que os gestores públicos e privados desenvolvam estratégias conjuntas, na área da saúde, com objetivo de consolidar o município de Santa Maria como o maior polo de serviços em saúde, no interior do Rio Grande do Sul.

Proposta 1 - Desenvolver estratégias conjuntas com gestores públicos e privados da área de saúde do município, buscando a viabilização do Pólo.

Proposta 2 - Articular, com os gestores públicos e privados da área da saúde, a organização de palestras, seminários e cursos, para qualificar profissionais e gestores.

\section{OBJETIVO 5}

Ampliar a quantidade de leitos hospitalares em Santa Maria, garantindo o acesso necessário em tempo oportuno, observando critérios de acolhimento e avaliação de classificação de risco.

Proposta 1 - Implantar os Protocolos de Classificação de Risco, em todas as instituições hospitalares, e criar uma central de regulação de leitos públicos e privados.

Proposta 2 - Aumentar a oferta de leitos de média e alta complexidades que garantam o atendimento a pacientes do SUS (Sistema Único de Saúde).

Proposta 3 - Concluir e operacionalizar o Hospital Estadual Regional (HR).

Proposta 4 - Propor e apoiar a ampliação de áreas de internação do HUSM (Hospital Universitário de Santa Maria) e sua adesão à EBSERH.

Proposta 5 - Ampliar o atendimento médico-hospitalar do Hospital da Brigada Militar. 
Proposta 6 - Apoiar ações que tornem o Hospital da Guarnição Militar de Santa Maria pólo regional de atendimento ao Exército.

\section{OBJETIVO 6}

\section{Articular a Regionalização do Planejamento e do Atendimento da Saúde.}

Proposta 1 - Articular políticas municipais de saúde conjuntas, para a região central do estado.

Proposta 2 - Implementar os Contratos Organizativos da Ação Pública, na região Verdes Campos, visando soluções para o financiamento da saúde na região.

\section{OBJETIVO 7}

Ampliar a formação de recursos humanos do município, com qualificação na área de saúde.

Proposta 1 - Apoiar programas e ações de pesquisa na área de saúde, para tornar o município referência de pesquisa em saúde.

Proposta 2 - Diversificar os cursos técnicos, na área da saúde, apoiando a criação de novos cursos de curta duração, voltados à qualificação de profissionais em gestão, atenção, promoção e prevenção à saúde.

Proposta 3 - Propor a ampliação do número de vagas de residência multiprofissional nas IES, disponibilizadas na rede de saúde do município.

\section{OBJETIVO 8}

\section{Analisar a viabilidade de criação de uma Fundação Pública de Saúde.}

Proposta 1 - Realizar audiência para debater a criação da Fundação Pública de Saúde, articulada pela Comissão de Saúde da Câmara de Vereadores. 


\section{OBJETIVO 9}

Implantar um sistema informatizado que dê agilidade e resolutividade às demandas de atenção a saúde do município.

Proposta 1 - Adquirir ou desenvolver um software que integre todas as unidades de saúde do município com segurança, rapidez e que seja de fácil manuseio.

Proposta 2 - Implantar a informatização da Central de Regulação de Consultas e Exames e a de Regulação de Internações Hospitalares.

Proposta 3 - Implantar e disponibilizar na rede o prontuário único e informatizado do paciente.

Proposta 4 - Diagramar e publicar todos os fluxos de processos de atendimento do paciente das unidades na rede de atenção.

Proposta 5 - Implantar um sistema que gerencie o fornecimento de materiais e medicamentos aos pacientes e o monitoramento dos estoques das farmácias e almoxarifados da rede.

Em vista do foco da pesquisa, selecionaram-se para a seqüência do trabalho, apenas aqueles objetivos estratégicos relativos ao tema estratégias conjuntas.

\subsection{AVALIAÇÃO DA PERCEPÇÃO DOS GESTORES DAS UNIDADES PRODUTORAS DE SERVIÇOS DE SAÚDE}

$\mathrm{Na}$ presente seção, buscou-se aferir a percepção dos Gestores das Unidades Produtoras de Serviços de Saúde via SUS em Santa Maria, quais sejam a Coordenadora da $4^{\mathrm{a}} \mathrm{CRS}$; a Diretora Geral do Hospital Universitário de Santa Maria; a Secretaria Municipal de Saúde; o Provedor do Hospital de Caridade Astrogildo de Azevedo, mantenedor do Hospital Alcides Brum; a Diretora Presidente da SEFAS, Administradora do Hospital Municipal Casa de Saúde e o Diretor da Unidade de Pronto Atendimento, com relação às diretrizes estratégicas 
conjuntas propostas por ocasião do processo de PE do Grupo Temático Saúde, integrante do PE da ADESM.

Para tanto entre os objetivos definidos, selecionou-se seis (6) questões relativas a estratégias conjuntas, objeto do estudo, dizendo respeito à maximização dos leitos hospitalares; à prática profissional dos acadêmicos da área da saúde; ao credenciamento SUS aos hospitais por nível de complexidade, tomando em consideração a máxima eficiência no uso dos equipamentos adquiridos; à municipalização plena da saúde; ao papel da Coordenadoria Regional de Saúde; e quanto à gestão estratégica considerando que de nada valem estabelecer-se estratégias se estas não saem do papel.

A metodologia adotada acha-se descrita na subseção 3.3, acima, e os resultados da transcrição das entrevistas realizadas, estão detalhados no Apêndice 4.

\subsubsection{Quanto à Maximização dos Leitos Hospitalares}

Desdobrou-se a questão em quatro (4) quesitos. No primeiro, interrogou-se quanto à crença do processo estar caminhando na direção certa. Dos seis (6) dirigentes entrevistados, três (3), a Coordenadora da $4^{\mathrm{a}} \mathrm{CRS}$, responsável pelo referenciamento e contra referenciamento, juntamente com outros dois (2) de instituições privadas, responderam afirmativamente. Os demais, Diretora do HUSM, Diretora da Casa de Saúde, e a Secretária Municipal de Saúde, esta responsável pelo encaminhamento dos pacientes demandantes, referiram-se explicitamente à ocupação desordenada de leitos com média complexidade, inviabilizando o atendimento de pacientes demandantes por procedimentos de alta complexidade.

O segundo quesito, disse respeito à indicação da possibilidade de melhorias. Neste, todos os entrevistados apresentaram contribuições. Chamou a atenção o depoimento da Coordenadora da $4^{\text {a }}$ CRS que afirmou: "O que pode ser melhorado é continuar realizando as contratualizações através do Estado de acordo com as necessidades e demandas da população."; a Diretora do HUSM sugeriu "a regulação dos leitos pela Rede", clara afinidade com o objeto, estratégias conjuntas, ou a intersetorialidade, conforme identificado na revisão bibliográfica, seção 2.2; a Diretora da Casa de Saúde foi incisiva em relação ao despreparo de 
gestores por "não conhecer os fluxos que o usuário percorre e os processos a que estão submetidos", o que sugere treinamento conjunto, sugestão compartilhada pelo diretor da UPA que sugeriu "melhorar a informatização da SMS e o treinamento do pessoal que opera o sistema"; os demais sugeriram melhorias no sentido da prevenção e promoção de saúde em relação às doenças crônicas, caso da Secretária Municipal de Saúde. Por último, a relativa surpresa causada por parte do provedor do HCAA, que sugeriu "a concentração dos leitos em menos hospitais".

No terceiro quesito indagou-se quanto à necessidade de haver uma gestão conjunta entre os produtores de serviços de saúde observou-se, com exceção da Coordenadora da $4^{\mathrm{a}} \mathrm{CRS}$, que declarou já acontecer, a unanimidade dos demais dirigentes afirmou que sim, reforçando mais uma vez a intersetorialidade, conforme detalhado na revisão bibliográfica, seção 2.2. Destacase a manifestação do Coordenador da UPA que afirmou que "deveria ser institucionalizado um Comitê Executivo, ou algo semelhante, composto por todos os prestadores de serviços de saúde, a fim de definirem estratégias conjuntas".

Por fim, o quarto quesito no qual se perguntou quanto ao desenvolvimento de treinamento para o pessoal operacional visando uma triagem mais eficiente. Observou-se a unanimidade dos entrevistados, que consideraram importante o desenvolvimento da capacitação.

\subsubsection{Quanto à prática profissional dos acadêmicos da área da saúde}

Esta questão foi desdobrada em apenas dois (2) quesitos. No primeiro, questionou-se quanto à possibilidade dos cursos da saúde poder estagiar e/ou cursarem as suas residências nos vários hospitais da cidade. Observou-se na transcrição das entrevistas, que a totalidade dos entrevistados respondeu afirmativamente. Destaca-se a colocação da Secretária Municipal de Saúde que afirmou ver com: "bons olhos, pois ampliaria o potencial de atendimento, reforçando a prática profissional dos alunos". O Provedor do HCAA, hospital privado, bem como o Coordenador da UPA, afirmaram: "desde que haja preceptoria adequada é interessante, caso contrário seria apenas mão de obra disfarçada de estágio". A resposta mais longa foi a da Diretora da Casa de Saúde que embora concordando, apresentou uma série de ressalvas, destacando-se a afirmação: "acredito que, primeiramente, os programas de 
residência devam estar vinculados a serviços que façam parte da grande rede pública de cuidado ao paciente desde a rede de atenção básica, postos de urgência e emergência e hospitais públicos facilitando a referência e a contra referência do paciente entre serviços coirmãos".

Quanto ao segundo quesito que indagou: caso positivo, como poderia ser o processo? Todos apresentaram sugestões, no caso da Diretora do HUSM, que acumula as funções de Docente do Curso de Medicina, esta afirmou que: “A gestão será sempre pelas coordenações dos cursos que detêm o compromisso legal da execução do programa e que podem delegar responsabilidades aos preceptores da instituição conveniada prevendo mecanismos de avaliação". A Coordenadora da $4^{\text {a }}$ CRS declarou que: "a gestão do processo deve ser compartilhada entre instituição formadora e serviço". Os demais sugeriram procedimentos semelhantes.

\subsubsection{Quanto ao credenciamento SUS aos hospitais por nível de complexidade}

Nesta questão, a pergunta foi formulada tomando em consideração a máxima eficiência no uso dos equipamentos adquiridos. De maneira análoga à anterior, também se desdobrou em dois (2) quesitos. No primeiro, perguntou-se se a compra de equipamentos poderia ser acordada entre os produtores de serviços de saúde. Todos se manifestaram afirmativamente. Novamente destaca-se a resposta por parte da Diretora do HUSM que declarou: "Sim, as tecnologias na saúde são muito caras e de rápida obsolescência. Por isso é sempre importante a utilização plena de cada capacidade instalada, priorizando, no caso do SUS, as instituições públicas." O Provedor do HCAA, embora concordando, afirmou que: "melhor do que comprar seria o aluguel (ou quando factível o comodato) onde cada instituição paga por exame realizado." Novamente identifica-se a concordância com a prática das estratégias conjuntas.

O segundo quesito indagou: Você é favorável à especialização por área entre os hospitais? Todos se manifestaram positivamente, destacando-se a afirmação do Provedor do HCAA que declarou: "Posto que são vários hospitais é uma forma de torná-los mais eficientes. Mas a vinculação diversificada destes hospitais é um entrave". 


\subsubsection{Quanto à Municipalização Plena da Saúde}

Desdobrado em dois (2) quesitos. O primeiro relativo à concordância ou não com o processo, evidenciou concordância por parte de cinco (5) entrevistados, mas todos eles foram unânimes nas alegações que o Município ainda não apresenta as condições para assumir a municipalização. A Diretora do HUSM, por exemplo, declarou: "Sim, desde que analisada a condição financeira e a capacidade municipal instalada de instituições, profissionais e tecnologia". A única resposta negativa se deu por parte do Provedor do HCAA que declarou: "No caso de Santa Maria, dada a baixa renda da população, com poucos detentores de convênios particulares, acho ser muito difícil ser vantajoso". Pode-se concluir então que este ainda não seja o momento da Municipalização Plena.

O segundo quesito inquiriu sobre a possível forma de proceder-se a contratualização, em caso da Municipalização Plena. A resposta que pareceu mais completa foi apresentada pela Secretária Municipal da Saúde, que em caso de adoção do sistema passaria a ser a sua principal gestora.

A Senhora Secretária declarou: “Atualmente e a Judicialização da saúde inviabiliza qualquer gestor de saúde municipal a assumir responsabilidades para uma gestão plena na área de saúde. Também o planejamento de recursos humanos para a assistência, monitoramento e avaliação de todo o processo também deve ser levado em consideração. A complexidade da saúde vinculada a determinantes e condicionantes sociais, e os recursos de teto financeir a saúde sem um diagnóstico situacional (indicadores, metas físico-financeiras, centrais de regulação de leitos, entre outros) inviabiliza qualquer ação em Santa Maria. Não temos o controle da subjetividade do usuário em relação a seu autocuidado. Outra atividade para a Plena do Sistema é a falta de um sistema integrado de informatização no município. Mas seria muito bom para a Cidade, adquiridas todas as condições, regular seus processos de convênios e contratos para a área da saúde”.

Pode-se concluir, portanto, que embora aumentando os graus de liberdade do Município na Gestão da área da saúde, fato inconteste, ainda não é chegado o momento de fazê-lo dadas as condições atuais daí salientar-se novamente a necessidade da ação em conjunto, sob a forma da gestão compartilhada. 


\subsubsection{Quanto ao papel da Coordenadoria Regional de Saúde}

Para esta questão formulou-se uma única pergunta, Você acredita que a atual contratualização da saúde está sendo feita de forma adequada? Neste quesito verificaram-se quatro (4) concordâncias, contra apenas dois (2) discordantes. As concordâncias foram observadas nos depoimentos da Diretora da Casa de Saúde, do Coordenador da UPA, da Secretária Municipal de Saúde e, como era de se esperar, da Coordenadora da $4^{\text {a }}$ CRS. O depoimento da Secretária merece destaque, que declarou: "É um processo que vem sendo construído. Tem sido um grande avanço - paga pela saúde e não pela doença - vários serviços que seriam não rentáveis tornaram-se interessantes. O modelo antigo é perverso - quanto mais doença, mais lucro". Já entre os discordantes, destacam-se as afirmações por parte da Diretora do HUSM, que assim se manifestou: "A Coordenadoria Regional necessita de estrutura e informatização melhor para ter os indicadores em tempo real, com o objetivo de realizar contratos mais eficientes e de melhor custo-benefício por usuário".

\subsubsection{Quanto à Gestão Estratégica}

Nesta última questão, a única pergunta formulada disse respeito à preocupação para que as estratégias conjuntas não ficassem no papel. Perguntou-se quanto à concordância com a criação de um Comitê Estratégico de Saúde, ou algo semelhante, que envolvesse as Unidades Prestadoras de Serviços de Saúde. Todos os seis dirigentes foram unânimes em responder favoravelmente.

Destaca-se a resposta da Diretora da Casa de Saúde que lembrando o processo da ADESM declarou: "Sim, de certa forma já existe um comitê que trata das questões de saúde do município. Dentro da ADESM, o movimento a Santa Maria que queremos, já foi criado um grupo de trabalho que, após muitas reuniões das quais participaram gestores e membros voluntários da comunidade santa-mariense levantou demandas e estabeleceu um plano estratégico conjunto para a saúde para os próximos anos”, outro destaque para o depoimento da Diretora do HUSM que assim se pronunciou: "Sim, o comitê estratégico com a coordenação do gestor, $4^{\mathrm{a}} \mathrm{CRS}$, poderia otimizar os contratos, sobretudo o conhecimento quanto ao papel e desempenho de cada um”. 
Mais uma vez, e concluindo a análise da pesquisa exploratória qualitativa, pode-se afirmar da necessidade e acerto na decisão de elaborar estratégias conjuntas para a área de saúde de Santa Maria.

\subsection{AVALIAÇÃO DA PERCEPÇÃO DOS PARTICIPANTES DO EIXO TEMÁTICO DA SAÚDE DO PROCESSO DE PE DA ADESM}

Nesta parte da análise, utilizou-se o método descritivo quantitativo. Para tanto, conforme descrito na metodologia, subseção 3.4, elaborou-se um questionário dividido em dois (2) blocos. No primeiro, buscou-se identificar o perfil dos respondentes, e no segundo, a percepção em relação às diretrizes conjuntas em saúde.

Com base nos dados obtidos através da pesquisa do tipo survey, passa-se, agora, ao processamento da análise, inicialmente das características que constituem o perfil dos respondentes. Na seqüência são apresentados os valores assumidos pelas variáveis referentes à percepção em relação às diretrizes conjuntas da saúde.

\subsubsection{Perfil dos respondentes}

O perfil do respondente é analisado a partir da idade, formação, cargo, entidade a que pertence, tempo de atuação na entidade, tempo de atuação no setor de saúde e, conforme dados apresentados nas Tabelas 8 a13.

Analisando-se a Tabela 8, observa-se tratar-se de pessoas maduras, totalizando aproximadamente $73 \%$ com idades superiores aos trinta e um (31) anos. Quanto aos cargos exercidos (Tabela 9), identifica-se que 51,3\% exercem cargos de direção, 14,7\% são docentes e os restantes ou são discentes de cursos superiores ou profissionais da área de saúde, médicos ou enfermeiros, evidenciando-se parcela representativa de participantes com experiência de gestão, o que qualifica as respostas. 
Tabela 8 - Idade dos respondentes

\begin{tabular}{|c|c|c|}
\hline Idade & Freqüência & $\%$ \\
\hline $25-30$ & 3 & 8,8 \\
\hline $31-40$ & 4 & 11,8 \\
\hline $41-50$ & 8 & 23,5 \\
\hline $51-60$ & 7 & 20,6 \\
\hline Acima de 60 anos & 6 & 17,6 \\
\hline Não resposta & 6 & 17,6 \\
\hline $\mathrm{N}$ & 34 & $100 \%$ \\
\hline
\end{tabular}

Tabela 9-Cargo dos respondentes

\begin{tabular}{|c|c|c|}
\hline Cargo & Freqüência & $\%$ \\
\hline Administrativo & 4 & 11,8 \\
\hline Assessor Político & 1 & 2,9 \\
\hline Conselheira & 1 & 2,9 \\
\hline Coordenadora & 1 & 2,9 \\
\hline Diretor Administrativo & 1 & 2,9 \\
\hline Diretora Geral & 1 & 2,9 \\
\hline Discente & 1 & 2,9 \\
\hline Docente & 5 & 14,7 \\
\hline Empresária & 1 & 2,9 \\
\hline Enfermeira & 2 & 5,9 \\
\hline Gerente Projetos & 1 & 2,9 \\
\hline Gerente & 1 & 2,9 \\
\hline Major/Enfermeiro & 1 & 2,9 \\
\hline Médico & 2 & 5,9 \\
\hline Presidente Câmara Municipal. & 1 & 2,9 \\
\hline Presidente & 4 & 11,8 \\
\hline Procuradora & 1 & 2,9 \\
\hline Provedor & 1 & 2,9 \\
\hline Secretário Executivo & 2 & 5,9 \\
\hline Superintendente & 1 & 2,9 \\
\hline Vereadora & 1 & 2,9 \\
\hline $\mathrm{N}$ & 34 & $100 \%$ \\
\hline
\end{tabular}

Quanto à formação dos respondentes, Tabela 10, abaixo, 88,2\% possuem curso superior ou pós-graduação, identificando o correspondente discernimento que qualifica as respostas. 
Tabela 10-Formação dos respondentes

\begin{tabular}{l|c|c}
\hline \multicolumn{1}{c}{ Formação } & Freqüência & $\%$ \\
\hline Ensino médio & 3 & 8,8 \\
Ensino Superior & 15 & 44,1 \\
Pós-graduação & 15 & 44,1 \\
Não resposta & 1 & 2,9 \\
\hline \multicolumn{1}{c}{$\mathrm{N}$} & 34 & $100 \%$ \\
\hline
\end{tabular}

Em termos de Entidades representadas, Tabela 11, observa-se a participação de dezessete (17) identificadas, mais um grupo de voluntários, denotando não só a participação de gestores e trabalhadores da área da saúde, mas também, pela primeira vez, de usuários dos serviços, razão de ser das atividades.

Tabela 11-Entidade a que pertence

\begin{tabular}{|c|c|c|}
\hline Entidade & Freqüência & $\%$ \\
\hline $4^{\mathrm{a}} \mathrm{CRS}$ & 2 & 5,9 \\
\hline ABEM & 1 & 2,9 \\
\hline ADESM & 3 & 8,8 \\
\hline ANIMATI & 1 & 2,9 \\
\hline Câmara Municipal & 3 & 8,8 \\
\hline CMS & 2 & 5,9 \\
\hline COREDES Centro & 1 & 2,9 \\
\hline HBM & 1 & 2,9 \\
\hline HCAA / A. Brum & 2 & 5,9 \\
\hline HUSM & 3 & 8,8 \\
\hline PMSM & 2 & 5,9 \\
\hline SMS & 2 & 5,9 \\
\hline TOTVS Sist. & 1 & 2,9 \\
\hline UFSM & 4 & 11,8 \\
\hline UNIFRA & 1 & 2,9 \\
\hline UNIMED SM & 1 & 2,9 \\
\hline UNIPAMPA & 1 & 2,9 \\
\hline Voluntário & 3 & 8,8 \\
\hline $\mathrm{N}$ & 34 & $100 \%$ \\
\hline
\end{tabular}

Quanto ao tempo de atuação, a parcela maior, 53\%, é representada por respondentes na faixa de 1 a 10 anos, seguidos por outros $35 \%$ na faixa de 11 a 30 anos de atuação. 


\begin{tabular}{l|c|c}
\hline \multicolumn{1}{c}{ Tempo de atuação na entidade } & Freqüência & $\%$ \\
\hline De 1 a 10 anos & 18 & 52,9 \\
De 11 a 20 anos & 8 & 23,5 \\
De 21 a 30 anos & 4 & 11,8 \\
Acima de 30 anos & 2 & 5,9 \\
Não resposta & 2 & 5,9 \\
\hline \multicolumn{1}{c}{ N } & 34 & $100 \%$ \\
\hline
\end{tabular}

Tabela 13-Tempo de atuação no setor de saúde

\begin{tabular}{l|c|c}
\hline Tempo de atuação no setor de saúde & Freqüência & $\%$ \\
\hline De 1 a 10 anos & 2 & 5,9 \\
De 11 a 20 anos & - & - \\
De 21 a 30 anos & 9 & 26,5 \\
Acima de 30 anos & 4 & 11,8 \\
Não resposta & 19 & 55,9 \\
\hline \multicolumn{1}{c}{$\quad \mathrm{N}$} & 34 & $100 \%$ \\
\hline
\end{tabular}

Em termos de tempo de atuação no setor de saúde, verifica-se que aproximadamente $38 \%$ atuam entre 21 a mais de 30 anos. Importante salientar que mais da metade, 56\% não responderam, o que pode significar a confirmação dos participantes usuários do sistema, bem como parcela de profissionais que desempenham trabalhos administrativos e de apoio.

4.5.2 Percepção em relação às diretrizes definidas para a saúde no processo de Planejamento Estratégico

Os dados relativos à análise da percepção dos participantes em relação à maximização de leitos hospitalares são apresentados na Tabela 14.

A partir do exposto na Tabela 14, percebe-se que a maioria dos respondentes atribui elevada importância às questões relacionadas à maximização de leitos hospitalares. 
Tabela 14 - Percepção em relação à maximização de leitos hospitalares

\begin{tabular}{|c|c|c|c|c|c|c|c|}
\hline \multirow[t]{2}{*}{ Maximização dos leitos hospitalares } & \multicolumn{6}{|c|}{ Nível de importância (\%) } & \multirow[b]{2}{*}{ Total } \\
\hline & $\begin{array}{l}\text { NA } \\
0\end{array}$ & $\begin{array}{c}\text { Menor } \\
\text { importância } \\
1\end{array}$ & 2 & 3 & 4 & $\begin{array}{l}\text { Maior } \\
\text { importância } \\
5\end{array}$ & \\
\hline $\begin{array}{l}\text { 1. Ampliar a quantidade de leitos } \\
\text { hospitalares em Santa Maria, } \\
\text { garantindo o acesso necessário em } \\
\text { tempo oportuno, observando } \\
\text { critérios de acolhimento e avaliação } \\
\text { de classificação de risco. }\end{array}$ & - & - & - & - & 8,8 & 91,2 & 100 \\
\hline $\begin{array}{l}\text { 2. Implantar os Protocolos de } \\
\text { Classificação de Risco, em todas as } \\
\text { instituições hospitalares, e criar uma } \\
\text { central de regulação de leitos } \\
\text { públicos e privados. }\end{array}$ & - & - & 2,9 & 2,9 & 11,8 & 82,4 & 100 \\
\hline $\begin{array}{l}\text { 3. Aumentar a oferta de leitos de } \\
\text { média e alta complexidade que } \\
\text { garantam o atendimento a pacientes } \\
\text { do SUS (Sistema Único de Saúde). }\end{array}$ & - & - & & 2,9 & 8,8 & 88,2 & 100 \\
\hline $\begin{array}{l}\text { 4. Concluir e operacionalizar o } \\
\text { Hospital Estadual Regional (HR). }\end{array}$ & - & - & - & 14,7 & 26,5 & 58,8 & 100 \\
\hline $\begin{array}{l}\text { 5. Propor e apoiar a ampliação de } \\
\text { áreas de internação do HUSM } \\
\text { (Hospital Universitário de Santa } \\
\text { Maria) e sua adesão à EBSERH. }\end{array}$ & 2,9 & - & & 11,8 & 35,3 & 50,0 & 100 \\
\hline $\begin{array}{l}\text { 6. Ampliar o atendimento médico- } \\
\text { hospitalar do Hospital da Brigada } \\
\text { Militar. }\end{array}$ & 5,9 & - & - & 64,7 & 26,5 & 2,9 & 100 \\
\hline $\begin{array}{l}\text { 7. Apoiar ações que tornem o } \\
\text { Hospital da Guarnição Militar de } \\
\text { Santa Maria pólo regional de } \\
\text { atendimento ao Exército. }\end{array}$ & 2,9 & - & - & 67,6 & 23,5 & 5,9 & 100 \\
\hline
\end{tabular}

Apenas no que se refere à ampliação do atendimento médico-hospitalar do Hospital da Brigada Militar e ao apoio às ações que tornem o Hospital da Guarnição Militar de Santa Maria pólo regional de atendimento ao Exército, a maior parte dos respondentes atribuíram um grau de importância intermediário. Certamente, porque estes casos atendem apenas as suas respectivas corporações, no primeiro, aos militares da Brigada Militar, e no segundo, aos militares do Exército. 
A Tabela 15 apresenta a avaliação dos entrevistados quanto à importância da maximização dos leitos hospitalares com uma nota (de 0 a 10$)$.

Tabela 15 - Avaliação com uma nota (de 0 a 10) da importância da maximização dos leitos hospitalares

\begin{tabular}{|c|c|c|}
\hline Nota & Freqüência & $\%$ \\
\hline Nota 8 & 3 & 8,8 \\
\hline Nota 9 & 7 & 20,6 \\
\hline Nota 10 & 24 & 70,6 \\
\hline $\mathrm{N}$ & 34 & $100 \%$ \\
\hline
\end{tabular}

Os dados novamente confirmam a elevada importância atribuída pelos respondentes em relação a maximização dos leitos hospitalares reforçando o acerto da proposição da estratégia.

A Tabela 16 apresenta a percepção dos respondentes em relação ao aprimoramento da prática profissional dos Acadêmicos da Área da Saúde.

Tabela 16 - Percepção em relação ao Aprimoramento da prática profissional dos Acadêmicos da Área da

\begin{tabular}{|c|c|c|c|c|c|c|c|}
\hline \multirow{2}{*}{$\begin{array}{l}\text { Aprimoramento da prática } \\
\text { profissional dos Acadêmicos da Área } \\
\text { da Saúde }\end{array}$} & \multicolumn{6}{|c|}{ Nível de importância (\%) } & \multirow[b]{2}{*}{ Total } \\
\hline & $\begin{array}{l}\text { NA } \\
0\end{array}$ & $\begin{array}{c}\text { Menor } \\
\text { importância } \\
1\end{array}$ & 2 & 3 & 4 & $\begin{array}{l}\text { Maior } \\
\text { importância } \\
5\end{array}$ & \\
\hline $\begin{array}{l}\text { 1. Ampliar a formação de recursos } \\
\text { humanos do município, com } \\
\text { qualificação na área de saúde. }\end{array}$ & - & - & - & 2,9 & 20,6 & 76,5 & 100 \\
\hline $\begin{array}{l}\text { 2. Apoiar programas e ações de } \\
\text { pesquisa na área de saúde, para } \\
\text { tornar o município referência de } \\
\text { pesquisa em saúde. }\end{array}$ & - & - & 11,8 & 20,6 & 26,5 & 41,2 & 100 \\
\hline $\begin{array}{l}\text { 3. Diversificar os cursos técnicos, na } \\
\text { área da saúde, apoiando a criação } \\
\text { de novos cursos de curta duração, } \\
\text { voltados à qualificação de } \\
\text { profissionais em gestão, atenção, } \\
\text { promoção e prevenção à saúde. }\end{array}$ & - & - & 2,9 & 5,9 & 47,1 & 44,1 & 100 \\
\hline $\begin{array}{l}\text { 4. Propor a ampliação do número } \\
\text { de vagas de residência } \\
\text { multiprofissional nas IES, } \\
\text { disponibilizadas na rede de saúde do } \\
\text { município. }\end{array}$ & - & - & - & - & 32,4 & 67,6 & 100 \\
\hline
\end{tabular}

A partir do exposto na Tabela 16, evidenciou-se que a maior parte dos respondentes atribui elevada importância às questões referentes ao aprimoramento da prática profissional dos 
acadêmicos da área da saúde. A Tabela 17 apresenta a avaliação dos entrevistados quanto a esta questão.

Tabela 17- Avaliação com uma nota (de 0 a 10) a importância do aprimoramento da prática profissional dos acadêmicos da área de saúde.

\begin{tabular}{lc|cc}
\hline & Nota & Freqüência & $\%$ \\
\hline Nota 8 & 6 & 17,6 \\
Nota 9 & 13 & 38,2 \\
Nota 10 & 15 & 44,1 \\
\hline & $\mathrm{N}$ & 34 & $100 \%$ \\
\hline
\end{tabular}

Os dados novamente confirmam a elevada importância atribuída pelos respondentes em relação ao aprimoramento da prática profissional dos acadêmicos da área da saúde sendo que $83 \%$ concederam os graus máximos, notas nove (9) ou dez (10).

A Tabela 18 apresenta a percepção dos respondentes em relação à municipalização do setor de Saúde, contratualização e criação de comitê estratégico.

Tabela 18 - Percepção em relação à Municipalização do Setor de Saúde, Contratualização e Criação de Comitê Estratégico

\begin{tabular}{|c|c|c|c|c|c|c|c|}
\hline \multirow[t]{2}{*}{ Municipalização do setor de saúde } & \multicolumn{6}{|c|}{ Nível de importância (\%) } & \multirow[b]{2}{*}{ Total } \\
\hline & $\begin{array}{c}\text { NA } \\
0\end{array}$ & $\begin{array}{c}\text { Menor } \\
\text { importância } \\
1\end{array}$ & 2 & 3 & 4 & $\begin{array}{l}\text { Maior } \\
\text { importância } \\
5\end{array}$ & \\
\hline $\begin{array}{l}\text { 1. Implantar a municipalização } \\
\text { plena da saúde }\end{array}$ & - & - & 5,9 & 52,9 & 29,4 & 11,8 & 100 \\
\hline $\begin{array}{l}\text { 2. Adequada contratualização da } \\
\text { saúde }\end{array}$ & - & - & - & - & 11,8 & 88,2 & 100 \\
\hline $\begin{array}{l}\text { 3. Criação de um "Comitê } \\
\text { Estratégico de Saúde", ou algo } \\
\text { semelhante que envolva as } \\
\text { Unidades Prestadoras de Serviços de } \\
\text { Saúde }\end{array}$ & - & - & - & - & 17,6 & 82,4 & 100 \\
\hline
\end{tabular}

A partir do exposto na Tabela 18, é possível perceber que a implantação da municipalização plena da saúde é considerada uma questão de moderada importância pelos entrevistados. Além disso, evidenciou-se que a maior parte dos respondentes atribui elevada importância, acima de $80 \%$ à adequada contratualização e a criação de um comitê estratégica da saúde, corroborando a percepção por parte dos dirigentes. 
A Tabela 19 apresenta a avaliação dos entrevistados quanto à municipalização do setor de saúde.

\begin{tabular}{|c|c|c|}
\hline Nota & Freqüência & $\%$ \\
\hline Nota 5 & 2 & 5,9 \\
\hline Nota 6 & 8 & 23,5 \\
\hline Nota 7 & 9 & 26,5 \\
\hline Nota 8 & 8 & 23,5 \\
\hline Nota 9 & 4 & 11,8 \\
\hline Nota 10 & 3 & 8,8 \\
\hline $\mathrm{N}$ & 34 & $100 \%$ \\
\hline
\end{tabular}

Os dados apresentados na Tabela 19 revelam que a municipalização do setor de saúde é uma questão que os entrevistados avaliam com menor importância, uma vez que 55,9\% dos respondentes avalia a importância da municipalização do setor de saúde com uma nota de 5 a 7.

A Tabela 20 apresenta a avaliação dos entrevistados quanto ao processo de elaboração de estratégias conjuntas.

Tabela 20 - Avalição com uma nota (de 0 a 10) o processo de elaboração das estratégias conjuntas de saúde em Santa Maria

\begin{tabular}{lc|cc}
\hline & \multicolumn{1}{c}{ saúde em Santa Maria } & $\%$ \\
\hline Nota 7 & Freqüência & 1 & 2,9 \\
Nota 8 & 2 & 5,9 \\
Nota 9 & 2 & 5,9 \\
Nota 10 & $\mathrm{~N}$ & 29 & 85,3 \\
\hline
\end{tabular}

Os dados apresentados na Tabela 20evidenciam que a maioria dos respondentes avalia com elevada importância o processo de elaboração das estratégias conjuntas de saúde em Santa Maria, fato importantíssimo em relação ao objeto deste trabalho.

Por fim, os respondentes priorizaram as ações estratégicas conjuntas, numerando de 1 a 3 , da mais à menos importante. Os resultados são expostos na Tabela 21. 
Tabela 21-Priorização das ações estratégicas numerando de 1 a 3, da mais a menos importante:

\begin{tabular}{|c|c|c|c|}
\hline \multirow[t]{2}{*}{ Ações estratégicas } & \multicolumn{3}{|c|}{$\%$} \\
\hline & 1 & 2 & 3 \\
\hline Maximização dos leitos hospitalares & 91,2 & 5,9 & 2,9 \\
\hline $\begin{array}{l}\text { Aprimoramento da prática profissional dos } \\
\text { acadêmicos da área da saúde }\end{array}$ & 5,9 & 85,3 & 8,8 \\
\hline Municipalização do setor de saúde & 2,9 & 8,8 & 88,2 \\
\hline
\end{tabular}

A maximização dos leitos hospitalares refere-se à ação estratégica mais importante na visão da maioria dos respondentes, seguida do aprimoramento da prática profissional dos acadêmicos da área da saúde. A questão de menor importância para a maior parte dos entrevistados refere-se à municipalização do setor de saúde. 


\section{CONCLUSÕES}

Pode-se concluir que todos os objetivos específicos foram atendidos, a saber: definição e avaliação do processo de condução do PE junto ao HUSM; descrição do processo de definição de estratégias conjuntas pelos gestores das UPSS; descrição do processo de PE desenvolvido pelo GT saúde da ADESM; avaliação da percepção dos gestores das UPSS em relação às estratégias conjuntas definidas pelo GT; e avaliação da percepção dos participantes do processo de PE em relação às estratégias conjuntas definidas pelo GT, conforme detalhado no capítulo anterior, fato este que permite afirmar que a pergunta de pesquisa foi satisfatoriamente respondida.

Conclui-se que as atividades de definição de estratégias conjuntas para a área da saúde pública, para a realidade do Município de Santa Maria, tratou-se de processo inovador, cujos frutos já vêm sendo colhidos conforme citados a seguir:

- - Os casos de subutilização dos leitos do HUSM com a internação de pacientes de média complexidade, superlotando os leitos e inviabilizando o acolhimento de pacientes de alta complexidade, reduziu-se grandemente, quer pela melhora da resolutividade da atenção básica, tanto para soluções pré-hospitalar como pós-alta, na continuidade dos tratamentos, mas principalmente, em função dos referenciamentos e contra referenciamentos definidos segundo as capacidades e competências dos estabelecimentos, com maiores cuidados por parte da SMS por ocasião do encaminhamento de pacientes. O Hospital Alcides Brum, obteve os seus primeiros credenciamentos para a alta complexidade em traumatologia e cardiologia, até então exclusividades do HUSM, e a Casa de Saúde teve ampliado o seu credenciamento para as médias complexidades;

- - Ampliou-se grandemente a prática profissional dos estudantes da área da saúde, mediante a realização de convênios com grande número de estabelecimentos de saúde do Município e Região, seja para a prática de estágios para os alunos de graduação, seja para os já graduados realizarem as suas práticas e o conseqüente aperfeiçoamento, através da residência multiprofissional;

- - Quanto à gestão estratégica conjunta, embora não institucionalizada, pode-se dizer que o fato da participação de todos os gestores das UPSS desde o processo iniciado 
junto ao HUSM, até a definição das estratégias conjuntas no grupo temático da ADESM, criou um espírito colaborativo que por si só já teria valido à pena;

- - Quanto à Municipalização Plena, embora a concordância com os seus pontos favoráveis, processo de PE permitiu concluir que ainda não chegou o seu momento em vista da ausência de capacidade instalada por parte da SMS;

- - Importante fato a destacar, tratou-se da evolução em termos dos participantes do processo. No caso HUSM, apenas prestadores de serviços de saúde, pessoal da instituição, dirigentes e colaboradores; no caso dos dirigentes, conforme o próprio nome, apenas dirigentes; no caso ADESM, não só dirigentes e colaboradores, mas também os usuários do sistema participaram amplamente das discussões e proposições de estratégias conjuntas;

- - O processo de PE desenvolvido junto ao HUSM mostrou-se adequado, exercendo verdadeiro efeito demonstração para o restante da Universidade. Hoje, as oficinas e seminários tornaram-se práticas adotadas para a avaliação anual do plano de trabalho, permitindo uma verdadeira prestação de contas com vistas à sua revisão e atualização;

- - Muitos inicialmente céticos em relação ao processo por tratar-se de um estabelecimento complexo, hospital de ensino, público e federal, foram convencidos na prática, pelas virtudes do modelo, sua arquitetura, forma de condução e principalmente dos resultados;

- - O HUSM, sem dúvida, graças ao seu processo de Planejamento Estratégico pode colher os melhores frutos, comparativamente aos seus congêneres, de decisões governamentais como o REHUF, programa para o reequipamento dos hospitais de ensino, e mais recentemente com a criação da EBSERH, empresa pública de personalidade jurídica privada destinada a prover os Hospitais Universitários com a contratação de mão de obra. Inclusive o de PE do HUSM serviu de modelo aos demais HU's para a elaboração de seus Planos de Desenvolvimento Institucionais, quando se tornaram exigência dos Ministérios da Educação e da Saúde por ocasião da liberação de recursos financeiros especiais.

A principal contribuição desta pesquisa para a ciência da administração entende-se ser justamente no sentido de aperfeiçoar um dos instrumentos de gestão por excelência que é o Planejamento Estratégico. 
Finalmente, sugere-se a continuidade da pesquisa no sentido da implementação e avaliação das estratégias conjuntas, bem como na continuidade do processo de PE do HUSM. 


\section{REFERÊNCIAS}

AGUIAR, Zenaide Neto. SUS: Sistema Único de Saúde: Antecedentes, Percurso, Perspectivas. São Paulo, SP. Editora: Martinari, 2011.

ALLIANCE for Nonprofit Management.What are the basic steps in a strategic planning process? 2004. Disponível em http://www.allianceonline.org/FAQ/strategic planning. Acesso em 01 de junho de 2012.

ALMEIDA, Martinho I. R. Manual de Planejamento Estratégico: Desenvolvimento de um Plano Estratégico com a Utilização de Planilhas de Planilhas Excel, Editora Atlas, São Paulo, 2010.

- Planejamento Estratégico para Unidades e Departamentos da USP: Uma proposta de arquitetura, modelo e condução do processo. Tese de Livre Docência. Defendida no Departamento de Administração da Faculdade de Economia, Administração e Contabilidade da Universidade de São Paulo, 2004.

. Por que não desenvolver uma análise ambiental para o planejamento estratégico que

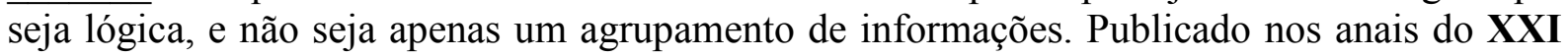
Encontro da ANPAD-ENANPAD. Rio das Pedras. Rio de Janeiro, 1997.

ANSOFF, H. I. Strategic Management: Classic Edition. London: MacMillan, 2007.

ANSOFF, H. Igor. Estratégia Empresarial. São Paulo: McGraw-Hill do Brasil, 1977.

Strategic Issue Management. Strategic Management Journal, v. 1, n.2, p. 131-148, 1980.

ANSOFF, H. Igor, DECLERK, Roger P., HAYES, Robert L. (Org.) Do planejamento estratégico à administração estratégica.São Paulo: Atlas, 1987.

ASTLEY, W. G. Toward an Appreciation of Collective Strategy. Academy of Management Review, v. 9, n. 3, p. 526-535 1984.

ASTLEY, W. G.; FOMBRUM, C. J. Collective Strategy: Social Ecology of Organizational Environments. Academy of Management Review, v. 8, n. 4, p. 576-587, 1983.

AXELROD, R. The Evolution of Cooperation. London, Penguin Books, 1990.

BARROS, M.E.D. Política de Saúde: a complexa tarefa de enxergar a mudança onde tudo parece permanência... In: \CANESQUI, A M. (org.) Ciências Sociais em Saúde. SP: HUCITEC - ABRASCO, 1997 p.113-133. 1997.

BASSO, Maristela. Joint ventures manual prático das associações empresariais. Porto Alegre: Livraria do Advogado, 1998.

BELLINI, M. I. B. et al. Políticas públicas e intersetorialidade em debate. In: I Seminário Internacional Sobre Políticas Públicas, Intersetorialidade e Família, Porto Alegre, RS, EDIPUCRS, 2013.

BERTERO, Carlos Osmar et al. Estratégia empresarial: a produção científica brasileira entre 1991 e 2002. Revista de Administração de Empresas-RAE. v. 43, n. 4, out./dez, 2003, p. 48-62.

Estratégia Empresarial e Teoria Organizacional. Boletim de Pós Graduação do Instituto Metodista de Ensino Superior. , 1983. 
BORTOLASO, I. V.; VERSCHOORE, J. R.; ANTUNES, J. A. V. O Desenvolvimento Estratégico de Redes Interorganizacionais: uma Avaliação de Redes de Pequenas e Médias Empresas no Rio Grande do Sul. In.: VI Encontro de Estudos Organizacionais da ANPAD, Curitiba-PR, 2012.

BRASIL. Constituição da República Federativa do Brasil. Promulgada em 5 de outubro de 1988, com as alterações adotadas pelas Emendas Constitucionais n. 1/92 a 46/2005 e pelas Emendas Constitucionais de Revisão n. 1 a 6/94. Brasília, 2005.

BRASIL. Portaria $n^{\circ} 4.279$, de 30 de dezembro de 2010. Estabelece diretrizes para a organização da Rede de Atenção à Saúde no âmbito do Sistema Único de Saúde (SUS), 2010. Lei no 8.080, de 19 de setembro de 1990. Brasília, 1990.

Lei Complementar $\mathbf{n}^{\mathbf{0}}$ 141, de 13 de janeiro de 2012. Disponível em

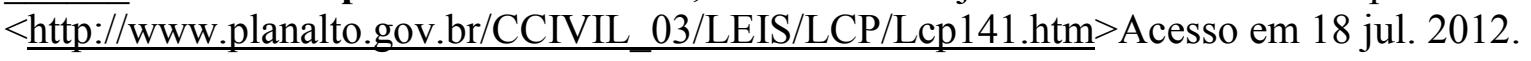

BRASIL/MINISTÉRIO DA SAÚDE. Manual Básico de Gestão Financeira do Sistema Único de Saúde. 3. ed. Brasília: MS, 2003.

BRASIL/CONSELHO NACIONAL DE SECRETÁRIOS DE SAÚDE. Sistema Único de Saúde. Brasília: CONASS, 2011 a.

BRESSER, R.; HARL, J. E. Collective Strategy: Vice or Virtue? Academy of Management Review, v.11, n. 2, p. 408-427, 1986.

BRESSER, R. Matching collective and competitive strategies. Strategic Management Journal, v. 9, p. 375-385, 1988.

BRONZERI, M. S.; BULGACOV, S. Estratégias na cadeia produtiva do café no norte pioneiro do Paraná: competição, colaboração e conteúdo estratégico. Organizações Rurais \& Agroindustriais, Lavras, v. 16, n. 1, p. 77-91, 2014.

BRYSON, John M. Strategic Planning for Public and Nonprofit Organization: a guide to strengthening and sustaining organizational achievement. São Francisco: Jossey-Bass, 1995.

CAPELLA, A. C. N. Perspectivas teóricas sobre o processo de formulação de políticas públicas. In: HOCHMAN, G. et al. (Org.). Políticas públicas no Brasil. Rio de Janeiro: Fiocruz, p. 87-121, 2007.

CERTO, S. C. e PETER, J. P. Administração Estratégica. São Paulo: Makron Books, 1993.

CUNHA, Cristiano J. C. A. Planejamento Estratégico: uma abordagem prática. Florianópolis: Publicação do NEST- Núcleo de Estudos - Departamento de Engenharia de Produção e Sistemas, Universidade Federal de Santa Catarina, 76 p. 1996.

ENAP. Curso de Planejamento Estratégico - Escola Nacional de Administração Pública. Brasília, 1999.

FERNANDEZ, J. C. A.; MENDES, R. Subprefeituras da cidade de São Paulo e políticas públicas para a qualidade de vida. São Paulo: CEPEDOC Cidades Saudáveis/Mídia Alternativa, 2003.

FERNANDEZ, J. C. A. et al. Gestão intersetorial e participativa: análise de modelo de uma subprefeitura de São Paulo. Planejamento e Políticas Públicas - PPP, n. 42, 2014. 
FISCHMANN, Adalberto A.; BOAVENTURA, João Maurício Gama. A Epistemologia da Estratégia: Uma Proposta para a Classificação de seu Conteúdo. Anais do XVI SLADE, 2003.

FISCHMANN, Adalberto A. Implementação de estratégias: identificação e analise de problemas. 207 f. Tese (livre docência em administração) - Faculdade de Economia Administração e Contabilidade, Universidade de São Paulo, São Paulo, 1987.

FISCHMANN, Adalberto A e ALMEIDA, Martinho I. R. Planejamento estratégico na prática. São Paulo: Atlas, 1991.

GAJ, Luis. Administração Estratégica. São Paulo: Ática, 1987.

GARAJAU, N. I. Reflexões sobre a intersetorialidade como estratégia de gestão social. In. : III Simpósio Mineiro de Assistentes Sociais. Belo Horizonte-MG, 2013.

GERSCHMAN, S. A descentralização da política de saúde no final dos anos 90 In: Revista de Administração Pública. Rio de Janeiro, 34(4): 159 jul./ago de 2000.

GIL, Carlos A. Como elaborar projetos de pesquisa. 4 ed. São Paulo: Atlas: 2002.

GOLDENBERG, S. Considerações éticas a respeito da publicação do trabalho científico. Ética, moral e ontologia médicas. Rio de Janeiro: Editora Guanabara Koogan, 2000.

GOTTEMS, L. B. D. et al. O modelo dos múltiplos fluxos de Kingdonn a análise de políticas de saúde: aplicabilidades, contribuições e limites. Saúde Soc. São Paulo, v. 22, n. 2, p. 511 $520,2013$.

HAMBRICK, Donald C. Some test of the effectiveness and functional attributes of Miles and Snow strategic types. Academy of Management Journal, v. 26, n. 1, p. 05-26, 1983.

HAMEL, Gary, PRAHALAD, C. K. Competindo pelo Futuro. Rio de Janeiro: Editora Campus, 1995.

HERBERT, Theodore T.; DERESKY, Helen. Generic strategies: an empirical investigation of typology validity and strategy content. Strategic Management Journal, v.8, p. 135-147, 1987.

INOJOSA, R. M. Intersetorialidade e a configuração de um novo paradigma organizacional. Revista de Administração Pública - RAP, Rio de Janeiro, v. 32, n. 2, p. 35-48, 1998.

INOJOSA, R. M. Sinergia em políticas e serviços públicos: desenvolvimento social com intersetorialidade. Cadernos Fundap, n. 22, p. 102-110, 2011.

JUNQUEIRA, Luciano A. Prates. Intersetorialidade, transetorialidade e redes sociais na saúde. RAP, v. 34, n. 6, p. 35-45, 2000.

KAPLAN, R. S.; NORTON, D. P. A estratégia em ação: balanced scorecard. Rio de Janeiro: Campus, 1997.

KAY, John. Fundamentos do Sucesso Empresarial. Rio de Janeiro: Campus, 1996.

KINGDON, J. W. Agendas, alternativas and public policies. 2. ed. Ann Arbor: University of Michigan, 2003.

KOTLER, P. Marketing de A a Z: 80 conceitos que todo profissional precisa saber. Rio de Janeiro: Elsevier, 2003.

LEFEBVRE, G. e ROSA, J.A. Planejamento Estratégico - Implantação. Management Center do Brasil, 1983. 
LEON, M.E. e AMATO, J. N. Redes de cooperação produtiva: uma estratégia de competitividade e sobrevivência para pequenas e médias empresas. I workshop: redes de cooperação e gestão do conhecimento, PRO - EPUSP. São Paulo, 2001.

LOTUFO Márcia, Gestão Pública em Saúde: análise da capacidade de governo da alta direção da SES - Mato Grosso. Tese (doutorado) Universidade Federal da Bahia. Instituto de Saúde Coletiva. 2003.

MAINARDES, E.; FERREIRA, J.; RAPOSO, M. Conceitos de estratégia e gestão estratégica. FACEF Pesquisa, Franca, v. 14, n. 3, p. 278-298, 2011.

MANNHEIMER, L.N. Introducing Health Impact Assessment: an analysis of political and administrative intersectoral working methods. European Journal of Public Health, vol. 17, n. 5, p. 526-531, 2007.

MAXIMIANO, Antônio César A. Introdução à Administração. São Paulo, Editora Atlas, 1995.

MILES, Raymond E.; SNOW, Charles C. Organizational strategy, structure and process. New York: McGraw-Hill, 1978.

MILLER, Alex; DESS, Gregory G. Assessing Porter (1980): model in terms of its generability, accuracy and simplicity. Journal of Management Studies, v.30, n.4, p.553-585, july 1993.

MINISTÉRIO DA SAÚDE, Secretaria de Políticas de Saúde Relatório Final do Seminário Nacional "Gestão Estadual do SUS: Tendências e Perspectivas", Brasília, 14 e 15 de Novembro, 1999, 39 p.

MINISTÉRIO DO PLANEJAMENTO, ORÇAMENTO E GESTÃO, Secretaria de Orçamento Federal. Mensagem de Encamihamento LOA 2014. Disponível em $<$ http:www.orçamento federal.gov.br $>$ Acesso em 23 set. 2014.

MINTZBERG, H.; QUINN, J. O processo da estratégia. Tradução de James Sunderland Cook. 3. ed. Porto Alegre: Bookman, 2001.

MINTZBERG, H. et al. O processo da estratégia: conceitos, contextos e casos selecionados. Porto Alegre: Editora Bookman, 2006.

MINTZBERG, H.; AHSTRAND, B.; LAMPEL, J. Safári de estratégia: um roteiro pela selva do planejamento estratégico. Porto Alegre, RS: Bookman, 2000.

MINTZBERG, Henry. Five Ps for Strategy. California Management Review, p. 12-19, fall 1987.

Atlas, 1995, p. 250.

OLIVER, C. The Collective Strategy Framework: An Application to Competing Predictions of Isomorphism. Administrative Science Quarterly, v. 33, p. 543-561, 1988.

OLVE, N. G.; ROY, J.; WETTER, M. Condutores da performance: um guia prático para o uso do balanced scorecard. Rio de Janeiro: Qualitymark, 2001.

PARK, S. H. Managing an Interorganizacional Network: A framework of the institutional mechanism for network control. Organization Studies, v. 17, n. 5, p. 795-824, 1996

PORTER, Michael E. Vantagem Competitiva. Rio de Janeiro: Campus, 1986. 
. Generic strategies: toward a comprehensive framework. Advances in strategic Management, v. 5, p. 01-67, 1988.

. A competência Essencial. HSM Management. Março-abril, p. 12-17, 1997.

. A Vantagem Competitiva das Nações. Rio de Janeiro: Campus, 1993.

Estratégia competitiva. $7^{\text {a }}$ ed. Rio de Janeiro: Campus, 1996 a.

. What is strategy? Harvard Business Review. November-december, p. 59-78, $1996 \mathrm{~b}$.

. Clusters e competitividade. HSM management. N 15, anos 3 julho/agosto 1999.

PREFEITURA MUNICIPAL DE SANTA MARIA. Secretaria Municipal de Saúde. Relatório de Gestão 2013, Santa Maria, março 2014.

QUICKMBA. Análise PEST 2004. Disponível em: $<$ http:/www.quickmba.com>. Acesso em: 02 jun. 2012.

REZENDE e CASTOR. Planejamento estratégico municipal: empreendedorismo participativo nas cidades, prefeituras e organizações públicas. $2^{\mathrm{a}}$ ed. Rio de Janeiro: Brasport, 2006

RIES, Al; TROUT, Jack. Posicionamento: A batalha pela sua mente. $5^{\text {a }}$ ed. São Paulo: Pioneira, 1995.

RIGBY, Darrell. Management Tolls 2003. Disponível em: <http://www.bain.com/ management_tools/strategy_brief.pdf $>$. Acesso em: 08 abr. 2010.

ROESCH, Silvia M. A. - Dissertação de método em administração: Proposta de uma tipologia. Revista de Administração. v. 31, n 1, p. 75-83, Jan/mar,1996.

SLYWOTZKY, Adrian J.; MORRISON, David J. A estratégia focada no lucro: the profit zone. Rio de Janeiro: Campus, 1998.

SOUZA, Vildete L.R.; Participação Popular em saúde: interação da representação usuária do CMS com sua base social em municípios da $8^{\mathrm{a}} \mathrm{CRS}$. Escola de Saúde Pública, Porto Alegre, RS, 2001.

SPINK, Peter K. Pesquisa-ação e análise de problemas sociais e organizacionais complexos. Revista de Psicologia, vol. 5, n. 1, 1978.

STEAD, J.G.; STEAD, W.E. Sustainable strategic management: an evolutionary perspective. International Journal of Sustainable Strategic Management, v.1, n.1, p.62-81, 2008.

STEPHEN, Isaac. Handbook of social research, 1969.

TAKASHINA, Newton Tadashi, FLORES, Mario Cesar X. Indicadores da qualidade e do desempenho: como estabelecer metas e medir resultados, Rio de Janeiro: Qualitymark, 1999. $103 p$

TIFFANY, P. e PETERSON, S. D. Planejamento Estratégico. Rio de Janeiro: Ed. Campus, 1998.

THOMPSON JR., Arthur A.; STRICKLAND III, A. J. Planejamento Estratégico: elaboração, implementação e execução. São Paulo: Editora Pioneira, 2000.

THIOLLENT, Michel. Metodologia da Pesquisa-ação. 12 ed. São Paulo: Cortez, 2003.

TREGOE Benjamin B.; ZIMMERMAN, John W. A estratégia da alta gerência. 2. ed. Rio de Janeiro: Guanabara, 1988. 
TRIPP, David. Pesquisa-ação: uma introdução metodológica. Educação e Pesquisa, São Paulo, v. 31 n $^{\text {o }} 3$ p. 443-466, set./dez. 2005.

TRIVIÑOS, A. N. S. Introdução à pesquisa em ciências sociais: a pesquisa qualitativa em educação. São Paulo: Atlas, 2007.

UNIVERSIDADE FEDERAL DE SANTA MARIA, Pró Reitoria de Planejamento. UFSM em Números 2012. Santa Maria: EDUFSM, 2013.

WRIGHT, Peter; KROLL, Mark; PARNELL, John. Administração estratégica. São Paulo: Atlas, 2000.

ZACCARELLI, Sérgio Baptista. Estratégia Moderna nas Empresas. São Paulo: Zarco Editora, 1996.

Estratégia e Sucesso nas Empresas. São Paulo: Saraiva, 2000.

ZAHARIADIS, N. The multiple streams framework: structure, limitations, prospects. In: SABATIER, P. A. (Ed.). Theories of the policy process. Boulder: Westview, p. 65-92, 2007. 
APENDICES 


\section{APÊNDICE 1 - INSTRUMENTO DE AVALIAÇÃO MODELO HUSM}

Pesquisa sobre o Processo de Planejamento Estratégico desenvolvido no HUSM

Prezado Servidor,

O objetivo do questionário em anexo é identificar o que pode ser aprimorado no processo de Planejamento Estratégico adotado no HUSM .

Os resultados da pesquisa não terão identificação dos respondentes.

Estimamos que o preenchimento do questionário tomará cerca de 10 minutos, e deverá ser enviado para o Professor Roberto da Luz Jr, e-mail otreborluz@yahoo.com.br, ou entrar em contato pelo fone 9131-5452 para ser buscado pessoalmente.

Obrigado.

\begin{tabular}{|c|c|}
\hline $1-$ Perfil & \\
\hline 1. Qual seu Setor de Trabalho & $\begin{array}{ll}\text { 3. Qual sua Escolaridade } \\
\text { 1. Doutor } & \text { } 2 \text { 2. Mestre } \\
\text { 4. } 2^{\circ} \mathrm{Grau} & \bigcirc \text { 5. Outro }\end{array}$ \\
\hline $\begin{array}{l}\text { 2. Qual sua função } \\
\bigcirc \text { 1. Saúde } \quad \text { 2. Administrativa }\end{array}$ & 4. Se 'Outra',defina: \\
\hline 2 - Processo Proposto & \\
\hline $\begin{array}{l}\text { 5. O modelo MIRA foi utilizado? } \\
\begin{array}{lll} & \\
\text { 1. Sim } & \text { 2. Não } & \text { 3. Sem resposta }\end{array}\end{array}$ & $\begin{array}{l}\text { 10. O respondente acredita que o treinamento tenha } \\
\text { sido útil para o desenvolvimento do Planejamento }\end{array}$ \\
\hline $\begin{array}{l}\text { 6. O respondente tomou conhecimento do modelo } \\
\text { MIRA? }\end{array}$ & $\begin{array}{lll}\text { Estratégico? } \\
\text { O1. Sim } & \text { O2. Não } & \text { O3. Sem resposta }\end{array}$ \\
\hline 3. Sem resposta & 11. O conteúdo do treinamento foi adequado? \\
\hline 7. O respondente acredita que o modelo MIRA & O1. Sim $\quad$ 2. Não $\quad$ 3. Sem resposta \\
\hline $\begin{array}{l}\text { facilitou o desenvolvimento do Planejamento } \\
\text { Estratégico? }\end{array}$ & $\begin{array}{l}\text { 12. A duração do treinamento foi curta? } \\
\begin{array}{lll}\text { 1. Sim } & \text { ○. Não } & \text { O3. Sem resposta }\end{array}\end{array}$ \\
\hline O1. Sim $\quad$ 2. Não $\quad$ 3. Sem resposta & 13. A duração do treinamento foi longa? \\
\hline $\begin{array}{l}\text { 8. O respondente acredita que não há necessidade de } \\
\text { se utilizar um modelo? }\end{array}$ & O1. Sim $\quad$ 2. Não $\quad$ O3. Sem resposta \\
\hline 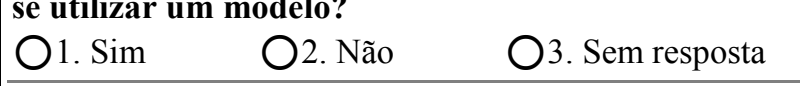 & $\begin{array}{l}\text { 14. O material disponibilizado foi adequado? } \\
\begin{array}{lll}\text { 1. Sim } & \text { 2. Não } & \text { O3. Sem resposta }\end{array}\end{array}$ \\
\hline $\begin{array}{l}\text { 9. O respondente participou do seminário de } \\
\text { treinamento sobre o modelo MIRA? } \\
\begin{array}{lll}\text { 1. Sim } \quad \text { 2. Não } \quad \text { 3. Sem resposta }\end{array}\end{array}$ & $\begin{array}{l}\text { 15. Em um próximo ciclo de Planejamento } \\
\text { Estratégico, você utilizaria o modelo MIRA, com as } \\
\text { adaptações resultantes desta pesquisa? }\end{array}$ \\
\hline & O1. Sim $\quad$ 2. Não $\quad$ 3. Sem resposta \\
\hline
\end{tabular}




\begin{tabular}{|c|c|c|}
\hline \multicolumn{3}{|l|}{3 - Implementação } \\
\hline $\begin{array}{l}\text { 16. O respondente tem conhecimento de um outro } \\
\text { modelo, que é mais adequado para desenvolver o } \\
\text { Planejamento Estratégico em um Hospital de Ensino } \\
\text { Público? } \\
\begin{array}{lll} & & \\
\text { 1. Sim } & \text { 2. Não } & \text { 3. Sem resposta }\end{array}\end{array}$ & \multicolumn{2}{|c|}{$\begin{array}{l}\text { 24. Análise do Ambiente Organizacional (Oportunidades e } \\
\text { Ameaças) } \\
\text { O1. Foi elaborada O2. Não foi elaborada } \\
\text { O3. Foi complementada } \\
\text { 25. Análise Estratégia Vigente }\end{array}$} \\
\hline $\begin{array}{l}\text { 17. Houve participação da maioria dos servidores? } \\
\text { O1. Sim } \quad \text { 2. Não } \quad \text { O3. Sem resposta }\end{array}$ & \multirow{2}{*}{\multicolumn{2}{|c|}{ 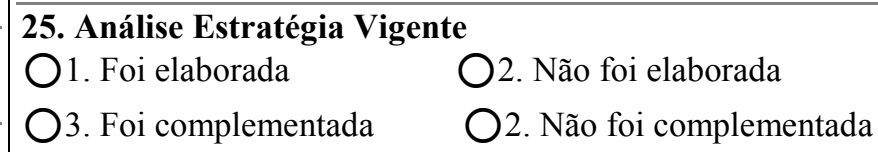 }} \\
\hline 18. Houve participação de alunos? & & \\
\hline O1. Sim & \multirow{3}{*}{\multicolumn{2}{|c|}{$\begin{array}{l}\begin{array}{l}\text { 26. Análise do Campo Atuação (Se está seguindo a } \\
\text { orientação da Missão, Visão, Vocação e Diretrizes } \\
\text { Superiores) }\end{array} \\
\begin{array}{ll}\text { O1. Foi elaborada } & \text { O2. Não foi elaborada } \\
\text { O3. Foi complementada } & \text { ○2. Não foi complementada }\end{array}\end{array}$}} \\
\hline $\begin{array}{l}\text { 19. Os textos discutidos foram submetidos à } \\
\text { comunidade para que fizessem sugestões? }\end{array}$ & & \\
\hline 1. Sim & & \\
\hline $\begin{array}{l}\text { 20. Foram utilizados meios eletrônicos para obter as } \\
\text { sugestões? }\end{array}$ & \multirow{3}{*}{\multicolumn{2}{|c|}{$\begin{array}{l}\text { 27. Estabelecimento de Grandes Estratégias } \\
\text { O1. Foi elaborada? } \\
\text { O3. Foi complementada? }\end{array}$}} \\
\hline O1. Sim & & \\
\hline 21. Missão & & \\
\hline $\begin{array}{l}\text { O1. Foi elaborada } \text { O2. Não foi elaborada } \\
\text { O3. Foi complementada }\end{array}$ & \multirow{2}{*}{\multicolumn{2}{|c|}{ 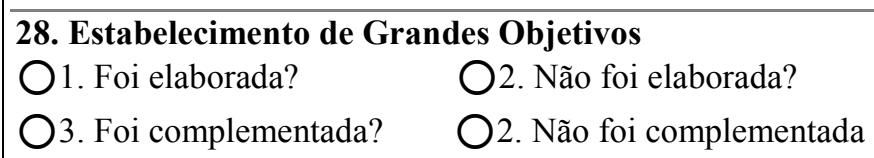 }} \\
\hline 22. Visão & & \\
\hline $\begin{array}{l}\text { 1. Foi elaborada } \text { 2. Não foi elaborada } \\
\text { O3. Foi complementada }\end{array}$ & \multicolumn{2}{|c|}{ 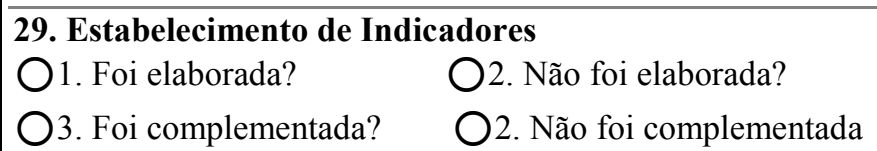 } \\
\hline $\begin{array}{l}\text { 23. Análise dos Aspectos Internos (Pontos Fortes e } \\
\text { Fracos) } \\
\begin{array}{ll}\text { O1. Foi elaborada } & \text { 2. Não foi elaborada } \\
\text { O3. Foi complementada } & \end{array}\end{array}$ & $\begin{array}{l}\text { 30. Estabelecimento de } \mathbf{A} \\
\text { 1. Foi elaborada? } \\
\text { 3. Foi complementada? }\end{array}$ & $\begin{array}{l}\text { 2. Não foi elaborada? } \\
\text { 2. Não foi complementada }\end{array}$ \\
\hline
\end{tabular}

\begin{tabular}{|c|c|}
\hline 4 - Refino do Processo & \\
\hline $\begin{array}{l}\text { 31. As etapas do Processo? como foram } \\
\text { idealizadas deveriam ser diferentes? } \\
\begin{array}{llll} & \text { 1. Sim } \quad & \text { 2. Não } \quad & \text { 3. Sem resposta }\end{array}\end{array}$ & \multirow{5}{*}{$\begin{array}{l}\text { 36. Quem deveria conduzir o processo de Planejamento } \\
\text { Estratégico (assinale mais de uma opção se for o caso)? } \\
\square \text { 1. Direção Geral } \\
\square \text {. Equipe da PROPLAN } \\
\square \text { 3. Equipe externa } \\
\text { 37. Sugestões }\end{array}$} \\
\hline $\begin{array}{l}\text { 32. As estratégias das Unidades e Departamentos } \\
\text { deveriam ser estabelecidas pela Reitoria? } \\
\begin{array}{llll}1 \text {. Sim } & \text { 2. Não } & \text { 3. Sem resposta }\end{array}\end{array}$ & \\
\hline $\begin{array}{llll}\text { 33. As estratégias dos Departamentos deveriam } \\
\text { ser estabelecidas nas Unidades? } \\
\begin{array}{llll} & \text { 1. Sim } \quad & \text { 2. Não } \quad & \text { 3. Sem resposta }\end{array}\end{array}$ & \\
\hline $\begin{array}{l}\text { 34. A Reitoria deveria apresentar as suas } \\
\text { diretrizes para as Unidades? } \\
\begin{array}{llll} & \text { 1. Sim } \quad & \text { 2. Não } \quad & \text { 3. Sem resposta }\end{array}\end{array}$ & \\
\hline 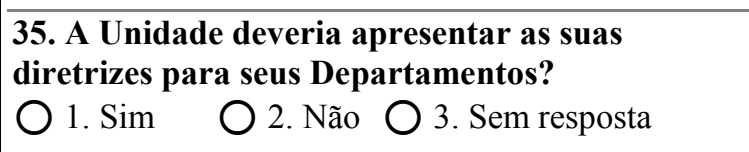 & \\
\hline
\end{tabular}




\section{APÊNDICE 2 - QUESTÕES PARA ENTREVISTA DIRIGENTES UPSS}

\section{Questões entrevista com gestores de Unidades Produtoras de Serviços de Saúde}

As questões a seguir são parte integrante de pesquisa complementar à Tese de Doutorado em elaboração pelo Professor Titular da UFSM, Roberto da Luz Júnior, junto ao Programa de Pós-Graduação em Administração da Faculdade de Economia e Administração da USP.

Fruto do Planejamento obtido via "A Santa Maria que queremos", foram definidas as seguintes Diretrizes para melhorar a qualidade de Saúde da Região de Santa Maria, tornandoa o Principal Pólo na área de Saúde do interior do Rio Grande do Sul.

Solicita-se, na medida do possível, a leitura das questões para posterior agendamento de entrevista com o Doutorando. Antecipadamente agradecido.

1 - Quanto à Maximização dos leitos hospitalares.

1.1 - Você acredita que o processo está caminhando na direção certa?

1.2 - O que pode ser melhorado?

1.3 - Você considera que deveria haver uma gestão conjunta entre os Produtores de Serviços de Saúde?

1.4 -O que você acha de desenvolver-se um treinamento para o pessoal operacional visando uma triagem mais eficiente?

2 - Quanto à Prática profissional dos Acadêmicos da Área da Saúde.

2.1 - Como você vê a possibilidade dos cursos da área da saúde poderem estagiar e/ou cursarem as suas Residências nos vários hospitais da cidade?

2.2 - Caso positivo, como poderia ser a gestão do processo?

3 - Quanto ao credenciamento do SUS aos Hospitais por níveis de complexidade, tomando em consideração a máxima eficiência no uso dos equipamentos adquiridos.

3.1 - A compra de equipamentos poderia ser acordada entre os Produtores de Serviços de Saúde?

3.2 - Você é favorável à especialização por área entre os Hospitais? 
4 - Quanto à Municipalização Plena da Saúde.

4.1 - Você é favorável à Municipalização Plena da Saúde?

4.2 - Como você acha que poderia ser feita, neste caso, a contratualização?

5 - Quanto ao Papel da Coordenadoria Regional de Saúde.

5.1 - Você acredita que a atual contratualização da saúde está sendo feita de forma adequada?

6 - Quanto à Gestão Estratégica, considerando que de nada valem estabelecer-se estratégias se estas não saem do papel.

6.1 - Você é favorável à criação de um "Comitê Estratégico de Saúde", ou algo semelhante que envolvesse as Unidades Prestadoras de Serviços de Saúde?

Prof. Roberto da Luz Júnior

Pesquisador 
APÊNDICE 3 - QUESTIONÁRIO AVALIAÇÃO DA PERCEPÇÃO DOS PARTICIPANTES

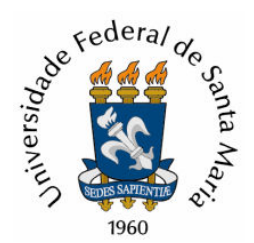

\section{CONVITE PARA PARTICIPAÇÃO DE PESQUISA CIENTÍFICA}

Prezado (a) Senhor (a):

A Universidade de São Paulo por meio do Curso de Doutorado Interinstitucional em Administração - DINTER/ USP/UFSM/UNIPAMPA está realizando uma pesquisa acadêmica e científica que pretende analisar a percepção dos participantes do eixo temático da saúde do processo de planejamento estratégico da ADESM.

A pesquisaintitulada como "Definição de estratégias conjuntas para o setor de saúde de Santa Maria/RS”, está sendo operacionalizada pelo doutorandoRoberto da Luz Júnior, Professor Titular da UFSM, sob orientação do $\mathrm{Dr}^{\mathrm{a}}$ Martinho Isnard de Almeida, Professor da Universidade de São Paulo.

Gostaríamos de convidá-lo para colaborar com a pesquisa respondendo o questionário a seguir.

Ressalte-se que as informações obtidas serão utilizadas somente para finsacadêmicos e os resultados da pesquisa serão divulgados de forma agregada.

Eventuais dúvidas poderão ser esclarecidas pelo e-mail: otreborluz@yahoo.com.br, aos cuidados de Roberto da Luz Júnior - Fone: (55)91315452.

Agradecemos desde já a atenção dispensada em responder ao instrumento de coleta de dados e colocamo-nos à disposição para quaisquer esclarecimentos.

Atenciosamente,

\section{Dra . Martinho Isnard de \\ Almeida \\ Professor da USP}

Prof. Msc Roberto da Luz Júnior Doutorando DINTER/

USP/UFSM/UNIPAMPA 


\section{PERCEPÇÃO DOS PARTICIPANTES DO EIXO TEMÁTICO DA SAÚDE DO PROCESSO DE PLANEJAMENTO ESTRATÉGICO DA ADESM}

\section{Bloco I - Perfil do respondente}

1. Nome do responsável pelas informações:

\begin{tabular}{|c|c|}
\hline 2. Idade: & 3. Cargo: \\
\hline 4. Entidade a que pertence: & 5. Tempo de atuação na entidade: \\
\hline 6. Formação: Marque com $X$ uma alternativa & 7. Tempo de atuação no setor de saúde, caso atue: \\
\hline 1.1 Ensino médio & 8. Telefone para contato: \\
\hline 1.2 Ensino superior & \\
\hline 1.3 Pós-graduação & 9. E-mail: \\
\hline
\end{tabular}

10. No caso de possuir ensino superior e pós-graduação, especifique a sua área de formação:

\section{Bloco II - Percepção em relação às diretrizes da saúde do Planejamento Estratégico}

As questões a seguir relacionadas buscam mensurar a IMPORTÂNCIA em relação a cada aspecto apresentado. Assinale o grau que melhor traduza a importância das diretrizes resultantes do Planejamento "A Santa Maria que queremos"para a melhoria da qualidade de saúde da Região de Santa Maria, de acordo com a escala abaixo, onde 1 representa o menor grau de importância,5 a máxima importância, 0 se não quiser se manifestar ou não se aplicar a sua realidade:

\section{Maximização dos leitos hospitalares}

Analise o grau de importância dos seguintes aspectos para a melhoria da qualidade de saúde da Região de Santa Maria

8. Ampliar a quantidade de leitos hospitalares em Santa Maria, garantindo o acesso necessário em tempo oportuno, observando critérios de acolhimento e avaliação de classificação de risco.

9. Implantar os Protocolos de Classificação de Risco, em todas as instituições hospitalares, e criar uma central de regulação de leitos públicos e privados.

10. Aumentar a oferta de leitos de média e alta complexidade que garantam o atendimento a pacientes do SUS (Sistema Único de Saúde).

11. Concluir e operacionalizar o Hospital Estadual Regional (HR).

12. Propor e apoiar a ampliação de áreas de internação do HUSM (Hospital Universitário de Santa Maria) e sua adesão à EBSERH.

13. Ampliar o atendimento médico-hospitalar do Hospital da Brigada Militar.

14. Apoiar ações que tornem o Hospital da Guarnição Militar de Santa Maria polo regional de atendimento ao Exército.

15. Avalie com uma nota (de $\mathbf{0}$ a 10) a importância da maximização dos leitos hospitalares

Aprimoramento da prática profissional dos Acadêmicos da Área da Saúde

Analise o grau de importância dos seguintes aspectos para a melhoria da qualidade de saúde da Região de Santa Maria

16. Ampliar a formação de recursos humanos do município, com qualificação na área de saúde.

17. Apoiar programas e ações de pesquisa na área de saúde, para tornar o município referência de pesquisa em saúde.

18. Diversificar os cursos técnicos, na área da saúde, apoiando a criação de novos cursos de curta duração, voltados à qualificação de profissionais em gestão, atenção, promoção e prevenção à saúde.

19. Propor a ampliação do número de vagas de residência multiprofissional nas IES, disponibilizadas na rede de saúde do município.

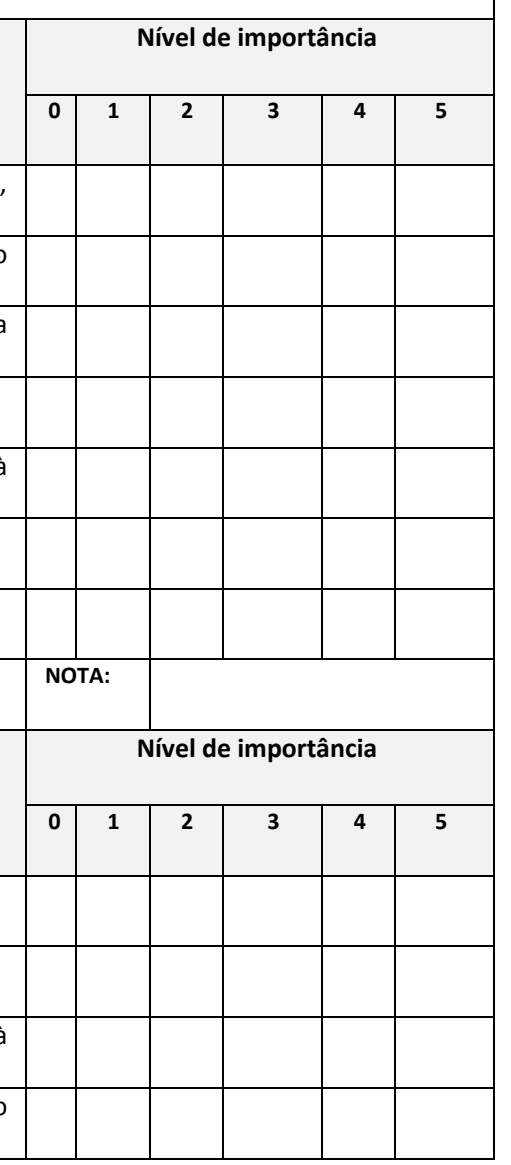


136

\begin{tabular}{|c|c|c|c|c|c|c|}
\hline $\begin{array}{l}\text { 20. Avalie com uma nota (de } 0 \text { a 10) a importância do aprimoramento da prática profissional dos acadêmicos da área de } \\
\text { saúde. }\end{array}$ & \multicolumn{2}{|c|}{ NOTA: } & & & & \\
\hline \multirow{2}{*}{$\begin{array}{l}\text { Municipalização do setor de Saúde } \\
\text { Analise o grau de importância dos seguintes aspectos para a melhoria da qualidade de saúde da Região de Santa Maria }\end{array}$} & \multicolumn{5}{|c|}{ Nível de importância } & \\
\hline & 0 & 1 & 2 & 3 & 4 & 5 \\
\hline \multicolumn{7}{|l|}{ 21. Implantar a municipalização plena da saúde } \\
\hline \multicolumn{7}{|l|}{ 22. Adequada contratualização da saúde } \\
\hline \multicolumn{7}{|l|}{$\begin{array}{l}\text { 23. Criação de um "Comitê Estratégico de Saúde", ou algo semelhante que envolva as Unidades Prestadoras de Serviços de } \\
\text { Saúde }\end{array}$} \\
\hline 24. Avalie com uma nota (de 0 a 10) a importância da municipalização do setor de saúde. & \multicolumn{2}{|c|}{ NOTA } & & & & \\
\hline 25. Avalie com uma nota (de 0 a 10) o processo de elaboração das estratégias de saúde em Santa Maria. & & & & & & \\
\hline \multicolumn{7}{|l|}{ 26. Priorize as ações estratégicas numerando de 1 a 3 , da mais a menos importante: } \\
\hline \multicolumn{7}{|l|}{ Maximização dos leitos hospitalares } \\
\hline \multicolumn{7}{|l|}{ Aprimoramento da prática profissional dos acadêmicos da área da saúde } \\
\hline Municipalização do setor de saúde & & & & & & \\
\hline
\end{tabular}




\section{APÊNDICE 4 - TRANSCRIÇÃO DAS ENTREVISTAS COM DIRIGENTES UPSS}

\begin{tabular}{|c|c|}
\hline \multicolumn{2}{|c|}{ 1. Quanto à maximização dos leitos hospitalares } \\
\hline Gestor & Evidências \\
\hline \multicolumn{2}{|c|}{ 1.1 Você acredita que o processo está caminhando na direção certa? } \\
\hline Diretora Geral HUSM & $\begin{array}{l}\text { Ainda não, visto que a otimização de leitos depende muito da } \\
\text { resolutividade da atenção básica tanto para soluções pré hospitalar como } \\
\text { pós alta na continuidade dos tratamentos ou planos terapêuticos os } \\
\text { hospitais devem ser reservados para evento agudos e não nos crônicos } \\
\text { como ainda acontece. }\end{array}$ \\
\hline Coordenadora da $4^{\mathrm{a}} \mathrm{CRS}$ & $\begin{array}{l}\text { Acredito que o processo está no caminho certo, haja vista o cuidado com } \\
\text { os referenciamentos e contra referenciamentos definidos segundo as } \\
\text { capacidades e competências dos estabelecimentos. }\end{array}$ \\
\hline Secretária Municipal de Saúde & $\begin{array}{l}\text { Não, ainda há muito leito ocupado em média complexidade em alguns } \\
\text { hospitais credenciados para a alta, enquanto sobram vagas em outros } \\
\text { credenciados para a média. }\end{array}$ \\
\hline Provedor do ALCIDES BRUM & Acredito que sim. \\
\hline Diretora da Casa de Saúde & $\begin{array}{l}\text { Não na sua plenitude. Uma das ações é o próprio aumento de leitos, que } \\
\text { parece ser o caminho mais fácil. Está aí a reestruturação do HUSM, agora } \\
\text { vinculado à Empresa Brasileira de Serviços Hospitalares, preconizando o } \\
\text { aumento de leitos hospitalares com a construção de uma nova central de } \\
\text { UTIs, que dobra a capacidade de leitos de UTIs e mais leitos clínicos e } \\
\text { cirúrgicos com a ocupação das áreas a serem desocupadas e outras a } \\
\text { serem reocupadas com leitos. Porém, em pouco tempo todos estes leitos } \\
\text { estarão ocupados e voltaremos ao mesmo ponto de partida, pois, faltam } \\
\text { outras ações que maximizem leitos mas que passam, necessariamente, por } \\
\text { mudanças políticas e estruturais do sistema de saúde que requerem } \\
\text { mudanças nos processos de atenção ao paciente. }\end{array}$ \\
\hline Coordenador da UPA & Sim. Veja-se o trabalho desenvolvido pela Secretaria Municipal da Saúde. \\
\hline \multicolumn{2}{|l|}{1.20 que pode ser melhorado? } \\
\hline Diretora Geral HUSM & $\begin{array}{l}\text { A regulação dos leitos pela Rede; Os núcleos internos de regulação que } \\
\text { agilizam os procedimentos e altas programadas; e oportunidade de } \\
\text { desospitalização precoce com ênfase na atenção domiciliar e hospitalar. }\end{array}$ \\
\hline Coordenadora da $4^{\mathrm{a}} \mathrm{CRS}$ & $\begin{array}{l}\text { O que pode ser melhorado é continuar realizando as contratualizações } \\
\text { através do Estado de acordo com as necessidades e demandas da } \\
\text { população. }\end{array}$ \\
\hline Secretária Municipal de Saúde & $\begin{array}{l}\text { Prevenção e promoção de saúde em relações as doenças crônicas. Deve } \\
\text { ser trabalhado leito hospitalar X com doenças de agravos não } \\
\text { transmissíveis (cultura do povo em relação à saúde) }\end{array}$ \\
\hline $\begin{array}{l}\text { Provedor do Hospital de Caridade / } \\
\text { ALCIDES BRUM }\end{array}$ & $\begin{array}{l}\text { O melhor seria que os leitos estivessem concentrados em menos hospitais; } \\
\text { o número excessivo de hospitais em SM maximiza custos. O ideal seria } \\
\text { um hospital público e um privado. }\end{array}$ \\
\hline Diretora da Casa de Saúde & $\begin{array}{l}\text { Primeiramente é necessário o conhecimento e o entendimento de todos } \\
\text { os atores envolvidos no processo de atenção a saúde do paciente para que } \\
\text { conheçam os fluxos que o usuário percorre; os processos os quais eles } \\
\text { estarão submetidos; para que se conscientizem e para que se } \\
\text { responsabilizem de suas obrigações e responsabilidades como gestores. A } \\
\text { grande maioria dos gestores e responsáveis por estes setores não } \\
\text { conhecem toda esta realidade, não perceberam e não estão preparados } \\
\text { para enfrentar estas mudanças.Segundo. Acredito que o papel da } \\
\text { Secretaria de Saúde do Município e do HUSM são fundamentais na } \\
\text { disseminação deste entendimento. A Secretaria de saúde deve saber qual o } \\
\text { perfil epidemiológico de seus pacientes; deve conhecer a capacidade } \\
\text { instalada de cada ente conveniado do SUS; deve suprir as necessidade e } \\
\text { demandas do HUSM no atendimento de seus programas de assistência e } \\
\text { de ensino otimizando com ofertas de serviços sua força de trabalho }\end{array}$ \\
\hline
\end{tabular}




\begin{tabular}{|c|c|}
\hline & $\begin{array}{l}\text { especializada e seu parque tecnológico público federal de ponta. Terceiro. } \\
\text { O HUSM como HU de referência não pode continuar sendo o depósito de } \\
\text { pacientes crônicos e de baixa resolutividade. Deve buscar a aproximação } \\
\text { política com os órgãos da saúde para conveniar outros hospitais de menor } \\
\text { complexidade da região, iniciando o processo de contra referencia de } \\
\text { pacientes de permanência elevada. Ou seja. O HUSM deve ser otimizante } \\
\text { nas suas intervenções graves e especializadas e ágil em contra referenciar } \\
\text { pacientes estáveis e/ou crônicos para os demais hospitais da região de } \\
\text { baixa resolutividade. A mudança deste processo é uma questão de gestão } \\
\text { onde envolve articulações junto ao SUS para credenciar estes } \\
\text { procedimentos complementares para estes hospitais parceiros. Requer } \\
\text { também, nivelamento e treinamento de todos os setores envolvidos em } \\
\text { relação aos processos como deste novo modelo de gestão da saúde da } \\
\text { região. }\end{array}$ \\
\hline Coordenador da UPA & $\begin{array}{l}\text { Melhorar a informatização da Secretaria Municipal e o treinamento do } \\
\text { pessoal que opera o sistema. }\end{array}$ \\
\hline \multicolumn{2}{|c|}{ 1.3 Você considera que deveria haver uma gestão conjunta entre os Produtores de Serviços de Saúde? } \\
\hline Diretora Geral HUSM & $\begin{array}{l}\text { Sim, desde que a gestão conjunta seja entendida como otimização e } \\
\text { organização da Rede e das Linhas de Cuidado. Linha de cuidado é o } \\
\text { trajeto que o usuário de qualquer sistema para ter seu problema resolvido. }\end{array}$ \\
\hline Coordenadora da $4^{\mathrm{a}} \mathrm{CRS}$ & $\begin{array}{l}\text { A gestão conjunta acontece pois antes de qualquer contratualização é } \\
\text { construído um plano operativo do qual participam o prestador de serviço,a } \\
\text { SES (através da } 4^{\mathrm{a}} \mathrm{CRS} \text { ),o representante do município onde o prestador } \\
\text { está inserido e representante do controle social. }\end{array}$ \\
\hline Secretária Municipal de Saúde & ( \\
\hline Provedor do ALCIDES BRUM & $\begin{array}{l}\text { Eu acho que uma gestão concentrada em uma esfera (Estado por exemplo) } \\
\text { facilitaria. Hoje há uma divisão do processo decisório que torna muito } \\
\text { difícil ser ágil em decisões cruciais. São três esferas de governo, planos } \\
\text { de saúde, filantrópicos, diversos ministérios, ONGs e outras fontes de } \\
\text { recursos que acabam participando do processo decisório. }\end{array}$ \\
\hline Diretora da Casa de Saúde & $\begin{array}{l}\text { O que deve ser em conjunto é o levantamento das demandas junto às } \\
\text { secretarias de saúde de cada município; Levantamento das } \\
\text { disponibilidades de ofertas de serviços de cada instituição de saúde } \\
\text { parceira da região. Aí sim, a gestão será conjunta entre as necessidades da } \\
\text { região com a gestão para cada prestador de serviços conveniado. }\end{array}$ \\
\hline Coordenador da UPA & $\begin{array}{l}\text { Sim. Deveria ser institucionalizado um Comitê Executivo, ou algo } \\
\text { semelhante, composto por todos os prestadores de serviços de saúde, a } \\
\text { fim de definirem estratégias conjuntas. }\end{array}$ \\
\hline \multicolumn{2}{|c|}{$\begin{array}{l}1.4 \text { O que você acha de desenvolver-se um treinamento para o pessoal operacional visando uma triagem } \\
\text { mais eficiente? }\end{array}$} \\
\hline Diretora Geral HUSM & $\begin{array}{l}\text { Importante, a capacitação do pessoal operacional melhora } \\
\text { resolutividade, sobretudo mediante classificação de risco. }\end{array}$ \\
\hline Coordenadora da $4^{\mathrm{a}} \mathrm{CRS}$ & Excelente e necessário. \\
\hline Secretária Municipal de Saúde & $\begin{array}{l}\text { Seria importante o desenvolvimento de uma capacitação para os } \\
\text { profissionais, pois a medida que aumentamos nosso conhecimento é } \\
\text { possível refletir o processo de trabalho desencadeado. }\end{array}$ \\
\hline Provedor do ALCIDES BRUM & Seria interessante embora o mais importante seja decisão política. \\
\hline Diretora da Casa de Saúde & $\begin{array}{l}\text { A mudanças só ocorrerão se houver pleno conhecimento de todos os } \\
\text { setores, de todas as pessoas e de todos os níveis sobre os fluxos, os } \\
\text { processos e do novo modelo de gestão. As pessoas responsáveis pela } \\
\text { triagem de pacientes antes de encaminhar ao hospital, como também, os } \\
\text { responsáveis pela triagem do hospital, devem receber treinamento de } \\
\text { Gestão de Risco que são ações que priorizam o atendimento do paciente } \\
\text { conforme sua gravidade. }\end{array}$ \\
\hline Coordenador da UPA & Altamente necessário e oportuno. \\
\hline
\end{tabular}




\begin{tabular}{|c|c|}
\hline \multicolumn{2}{|c|}{ 2. Quanto à prática profissional dos acadêmicos da Área da Saúde } \\
\hline Gestor & Evidências \\
\hline \multicolumn{2}{|c|}{$\begin{array}{l}2.1 \text { Como você vê a possibilidade dos cursos da saúde poderem estagiar e/ou cursarem as suas residências } \\
\text { nos vários hospitais da Cidade? }\end{array}$} \\
\hline Diretora Geral HUSM & $\begin{array}{l}\text { Os cursos de graduação e pós graduação tem normativa próprias. No caso } \\
\text { dos residentes, é permitido que até } 30 \% \text { das atividades podem ser } \\
\text { desenvolvidas em outras instituições, desde que devidamente comprovado } \\
\text { a necessidade e avaliados quanto a preceptoria e, mediante processo de } \\
\text { convênio entre as instituições. }\end{array}$ \\
\hline Coordenadora da $4^{\mathrm{a}} \mathrm{CRS}$ & $\begin{array}{l}\text { Os alunos dos cursos da área da saúde devem estagiar e realizar estágios } \\
\text { nos hospitais e serviços de saúde. Isso está preconizado nas diretrizes } \\
\text { curriculares. }\end{array}$ \\
\hline Secretária Municipal de Saúde & $\begin{array}{l}\text { Com bons olhos pois ampliaria o potencial de atendimentos, reforçando a } \\
\text { prática profissional dos alunos. }\end{array}$ \\
\hline Provedor do ALCIDES BRUM & $\begin{array}{l}\text { Desde que haja preceptoria adequada é interessante; caso contrário seria } \\
\text { apenas mão de obra barata disfarçada de estágio. }\end{array}$ \\
\hline Diretora da Casa de Saúde & $\begin{array}{l}\text { Por enquanto devemos apostar em fazer bem feito dentro da realidade } \\
\text { atual. Residência com efetiva tutoria presencial. Os programas de } \\
\text { residência são cursos de pós graduação que necessitam de preceptoria de } \\
\text { docente vinculado ao programa. Acredito que, primeiramente, os } \\
\text { programas devam estar vinculados a serviços que façam parte da grande } \\
\text { rede pública de cuidado ao paciente desde a rede de atenção básica, postos } \\
\text { de urgência e emergência e hospitais públicos facilitando a referencia e a } \\
\text { contra referência do paciente entre os serviços coirmãos. O problema dos } \\
\text { programas de residência não são os acadêmicos, mas sim, os docentes que } \\
\text { tem dificuldades de sair do seu ambiente hospitalar(o extra muros), se } \\
\text { deslocarem para outras instituições e se fazer presentes durante os } \\
\text { procedimentos. Se dentro desta lógica já é difícil esta parceria, imagine os } \\
\text { residentes atuando nos hospitais privados! Isso necessitaria uma grande } \\
\text { reformulação dos programas da academia, vinculação de hospitais e } \\
\text { docentes aos programas, responsabilidades, seguros e parceria no } \\
\text { financiamento destas operações já que, de certa forma, os programas } \\
\text { prestam serviços à instituição. }\end{array}$ \\
\hline Coordenador da UPA & $\begin{array}{l}\text { Com grandes possibilidades, desde que os cursos supervisionassem de } \\
\text { forma adequada estes alunos, não como mão de obra barata. }\end{array}$ \\
\hline \multicolumn{2}{|c|}{ 2.2 Caso positivo, como poderia ser a gestão do processo? } \\
\hline Diretora Geral HUSM & $\begin{array}{l}\text { A gestão será sempre pelas coordenações dos cursos que detém o } \\
\text { compromisso legal da execução do programa e que podem delegar } \\
\text { responsabilidades aos preceptores da instituição conveniada prevendo } \\
\text { mecanismos de avaliação. }\end{array}$ \\
\hline Coordenadora da $4^{\mathrm{a}} \mathrm{CRS}$ & $\begin{array}{l}\text { A gestão do processo deve ser compartilhada entre instituição formadora e } \\
\text { serviço. }\end{array}$ \\
\hline Secretária Municipal de Saúde & $\begin{array}{l}\text { Atualmente a área de saúde forma para o Sistema Único de Saúde - SUS, } \\
\text { portanto uma referencia para aprendizagem é: as instituições de ensino } \\
\text { e/ou hospitais sabem como formar para o SUS?? Outra demanda é } \\
\text { referente aos profissionais que atuam nos serviços: os profissionais dos } \\
\text { hospitais deveriam ser sensibilizados para a presença de ensino no } \\
\text { serviço. Os docentes sabem ser docentes? ou simplesmente exercitam na } \\
\text { sua prática clínica para ensinar?Acredito que a Gestão do Processo deve } \\
\text { ser realizado por uma universidade, compartilhado com ensino e serviço } \\
\text { potente. }\end{array}$ \\
\hline Provedor do ALCIDES BRUM & $\begin{array}{l}\text { Basta usar a legislação que existe na Comissão Nacional de Residência } \\
\text { Médica e outros órgãos adequados. A gestão sendo compartilhada entre } \\
\text { instituições concedentes do estágio e instituições formadoras e supervisão } \\
\text { do MEC. }\end{array}$ \\
\hline Diretora da Casa de Saúde & $\begin{array}{l}\text { Mediante convênio específico estabelecendo claramente as obrigações das } \\
\text { partes. }\end{array}$ \\
\hline
\end{tabular}




\begin{tabular}{|l|ll}
\hline Coordenador da UPA & Contemplando a possibilidade nos respectivos Projetos Político-
\end{tabular}

Pedagógicos dos Cursos.

\section{Quanto ao Credenciamento SUS aos Hospitais por nível de complexidade, tomando em consideração a máxima eficiência no uso dos equipamentos adquiridos}

\begin{tabular}{|c|c|}
\hline Gestor & Evidências \\
\hline \multicolumn{2}{|c|}{ 3.1 A compra de equipamentos poderia ser acordada entre os Produtores de Serviços de Saúde? } \\
\hline Diretora Geral HUSM & $\begin{array}{l}\text { Sim, as tecnologias na saúde são muito caras e de rápida obsolescência. } \\
\text { Por isso é sempre importante a utilização de cada capacidade instalada, } \\
\text { priorizando, no caso do SUS, as instituições públicas. Os critérios para os } \\
\text { planos de saúde podem variar. No caso público "a demanda se sobrepõe à } \\
\text { oferta". }\end{array}$ \\
\hline Coordenadora da $4^{\mathrm{a}} \mathrm{CRS}$ & Existem algumas formas como, por exemplo, ata de registro de preços. \\
\hline Secretária Municipal de Saúde & $\begin{array}{l}\text { Sim, conforme a necessidade e serie histórica referente a fila de espera } \\
\text { para exames. }\end{array}$ \\
\hline Provedor do ALCIDES BRUM & $\begin{array}{l}\text { Melhor do qe compra seria o aluguel (ou quando factível o comodato) } \\
\text { onde cada Instituição paga por exame realizado. Seria muito mais custo- } \\
\text { efetivo. }\end{array}$ \\
\hline Diretora da Casa de Saúde & $\begin{array}{l}\text { Sim, podem, desde que os equipamentos sejam de instituições públicas e } \\
\text { de prestação de serviço pública. Ter um acordo (ou um projeto) seria } \\
\text { muito mais benéfico ao usuário, concentraria esforços dos investimentos } \\
\text { de acordo com as competências de cada instituição de forma a otimizar as } \\
\text { demandas dos serviços. Agora, quanto aos prestadores de serviços } \\
\text { privados não tem como intervir pois depende do estudo de viabilidade que } \\
\text { cada empresa fará visando lucros. }\end{array}$ \\
\hline Coordenador da UPA & Sim. Desta forma se evitariam ociosidades. \\
\hline \multicolumn{2}{|c|}{ 3.2 Você é favorável à especialização por área entre os hospitais? } \\
\hline Diretora Geral HUSM & $\begin{array}{l}\text { Sim, mas substituiria a especialização por construção de referencia } \\
\text { especializadas. O custo/beneficio para o paciente e para o Sistema é } \\
\text { sempre melhor. }\end{array}$ \\
\hline Coordenadora da $4^{\mathrm{a}} \mathrm{CRS}$ & $\begin{array}{l}\text { Sim pois a complexidade é definida por: Capacidade Instalada e Recursos } \\
\text { Humanos disponíveis. }\end{array}$ \\
\hline Secretária Municipal de Saúde & $\begin{array}{l}\text { Sim, mas que a especialidade consiga trabalhar com uma visão de clínica } \\
\text { ampliada, possibilitando o trabalho interdisciplinar e para a construção de } \\
\text { uma linha de cuidado com o planejamento de alta hospitalar desde o } \\
\text { momento da chegada do usuário para atendimento. }\end{array}$ \\
\hline Provedor do ALCIDES BRUM & $\begin{array}{l}\text { Posto que são vários hospitais é uma forma de tornar mais eficientes. A } \\
\text { vinculação diversificada destes hospitais é um entrave. }\end{array}$ \\
\hline Diretora da Casa de Saúde & $\begin{array}{l}\text { Sim. É complexo demais ser especialista em tudo. Este formato de } \\
\text { disponibilizar todos os serviços médicos num só estabelecimento é missão } \\
\text { quase que exclusiva dos Hospitais de ensino e assim mesmo percebe-se a } \\
\text { tendência (vocação) de cada hospital pelo volume de determinados } \\
\text { atendimentos e pela especialização dos profissionais que lá atuam. Então, } \\
\text { poderia sim ter uma definição institucionalizada, em concordância com } \\
\text { todos os atores públicos autorizadores, para que os hospitais definissem } \\
\text { suas áreas de excelência para otimização e melhor atender. }\end{array}$ \\
\hline Coordenador da UPA & Sim. Aproveitando, desta forma, as vocações dos estabelecimentos. \\
\hline
\end{tabular}




\begin{tabular}{|c|c|}
\hline \multicolumn{2}{|c|}{ 4. Quanto à Municipalização Plena da Saúde } \\
\hline Gestor & Evidências \\
\hline \multicolumn{2}{|c|}{ 4.1 Você é favorável à Municipalização Plena da Saúde? } \\
\hline Diretora Geral HUSM & $\begin{array}{l}\text { Sim, desde que analisada a condição financeira e a capacidade municipal } \\
\text { instalada de instituições, profissionais e tecnologias. }\end{array}$ \\
\hline Coordenadora da $4^{\mathrm{a}} \mathrm{CRS}$ & $\begin{array}{l}\text { Após o advento do decreto } 7508 \text {, todos os Municípios serão plenos. Isto } \\
\text { está acontecendo aos poucos. }\end{array}$ \\
\hline Secretária Municipal de Saúde & Em parte. \\
\hline Provedor do ALCIDES BRUM & $\begin{array}{l}\text { No caso de Santa Maria dado a baixa renda da população, com poucos } \\
\text { detentores de convênios acho muito difícil ser vantajoso. }\end{array}$ \\
\hline Diretora da Casa de Saúde & $\begin{array}{l}\text { Sim, desde que o Município apresente todas as condições para tal, ainda } \\
\text { deficientes. }\end{array}$ \\
\hline Coordenador da UPA & $\begin{array}{l}\text { Sim, desde que o Município apresente as condições de pessoal i infra- } \\
\text { estrutura. }\end{array}$ \\
\hline \multicolumn{2}{|c|}{ 4.2 Como você acha que poderia ser feita, neste caso, a contratualização? } \\
\hline Diretora Geral HUSM & $\begin{array}{l}\text { Por metas físicas (assistenciais) e de qualidade dos serviços, com } \\
\text { indicadores, definidos e monitorados. A contratualização mais eficaz é a } \\
\text { mista onde a média complexidade receba um incentivo para cobertura de } \\
\text { seus custos e a alta complexidade por procedimento. A atenção básica já } \\
\text { tem financiamento tripartite bem definido em lei. }\end{array}$ \\
\hline Coordenadora da $4^{\mathrm{a}} \mathrm{CRS}$ & $\begin{array}{l}\text { Alguns Municípios já estão assumindo os laboratórios e as clínicas de } \\
\text { fisioterapia. }\end{array}$ \\
\hline Secretária Municipal de Saúde & $\begin{array}{l}\text { Atualmente a judicialização da saúde inviabiliza qualquer gestor de saúde } \\
\text { municipal a assumir responsabilidades para uma gestão plena na área de } \\
\text { saúde. Também o planejamento de recursos humanos para a assistência, } \\
\text { monitoramento e avaliação de todo o processo também deve ser levado } \\
\text { em consideração. A complexidade da saúde vinculada a determinantes e } \\
\text { condicionantes sociais, e os recursos de teto financeiro para a saúde sem } \\
\text { um diagnóstico situacional (indicadores, metas físico-financeiros, centrais } \\
\text { de regulação de leitos, entre outros ) inviabiliza qualquer ação em Santa } \\
\text { Maria. Não temos o controle da subjetividade do usuário em relação a seu } \\
\text { auto-cuidado. Outra atividade para a Plena do Sistema é a falta de um } \\
\text { sistema integrado de informatização no município de Santa Maria. Mas } \\
\text { seria de muito bom para Santa Maria caso conseguisse autonomia de } \\
\text { regular seus processos de convênios e contratos para área de saúde. }\end{array}$ \\
\hline Provedor do ALCIDES BRUM & Não muda na essência; apenas muda a esfera de governo. \\
\hline Diretora da Casa de Saúde & $\begin{array}{l}\text { Por metas físicas de acordo com as respectivas competências e } \\
\text { capacidades instaladas. }\end{array}$ \\
\hline Coordenador da UPA & Direta pelo Município, por metas. \\
\hline
\end{tabular}

\begin{tabular}{|c|c|}
\hline \multicolumn{2}{|c|}{ 5. Quanto ao papel da Coordenadoria Regional de Saúde } \\
\hline Gestor & Evidências \\
\hline \multicolumn{2}{|c|}{ 5.1 Você acredita que a atual contratualização da saúde está sendo feita de forma adequada? } \\
\hline Diretora Geral HUSM & $\begin{array}{l}\text { A Coordenadoria Regional necessita de estrutura e informatização melhor } \\
\text { para ter os indicadores em tempo real com objetivo de realizar contratos } \\
\text { mais eficientes e melhor custo/beneficio por usuário. }\end{array}$ \\
\hline
\end{tabular}




\begin{tabular}{|l|l|}
\hline Coordenadora da $4^{\mathrm{a}}$ CRS & Acredito que sim. \\
\hline Provedor do ALCIDES BRUM & Não, falta debate e reflexão com o nível local. \\
\hline Secretária Municipal de Saúde & $\begin{array}{l}\text { É um processo que vem sendo construído. É um grande avanço - paga } \\
\text { pela saúde e não pela doença - no HUSM vários serviços que seriam não } \\
\text { rentáveis tornaram-se interessantes. A internação domiciliar foi mantida } \\
\text { por vários anos sem custeio SUS porque diminuiu em 1 dia a média de } \\
\text { permanência. O modelo antigo é perverso - quanto maia doença mais } \\
\text { lucro. }\end{array}$ \\
\hline Diretora da Casa de Saúde & Sim, dentro das possibilidades. \\
\hline Coordenador da UPA & Sim, de acordo com diretrizes da Secretaria Estadual de Saúde. \\
\hline
\end{tabular}

\begin{tabular}{|l|l|}
\hline \multicolumn{2}{|c|}{ 6. Quanto à Gestão Estratégica, considerando que de nada valem estabelecer-se } \\
estratégias se estas não saem do papel. \\
\hline \multicolumn{1}{|c|}{ Gestor } & \multicolumn{1}{c|}{ Evidências } \\
\hline $\begin{array}{l}\text { 6.1 Você é favorável à criação de um "Comitê Estratégico de Saúde", ou algo semelhante que envolvesse } \\
\text { as Unidades Prestadoras de Serviços de Saúde? }\end{array}$ \\
\hline Diretora Geral HUSM & $\begin{array}{l}\text { Sim, o comitê estratégico com a coordenação do gestor poderia otimizar } \\
\text { os contratos, sobretudo o conhecimento quanto ao papel e desempenho de } \\
\text { cada um. }\end{array}$ \\
\hline Coordenadora da 4 ${ }^{\text {a }}$ CRS & Sim, sem dúvidas. \\
\hline Secretária Municipal de Saúde & $\begin{array}{l}\text { Sim, a construção coletiva de qualquer processo é seguramente legitimada } \\
\text { pelo grupo suprapartidário e técnico. Isso poderia assegurar algumas } \\
\text { continuidades nos processos pactuados sem prejuízo quando ocorre a } \\
\text { troca de governo. }\end{array}$ \\
\hline Provedor do ALCIDES BRUM & $\begin{array}{l}\text { É uma forma de ajudar o gerenciamento. Hoje fica muito no controle } \\
\text { social e os conselhos são passíveis de manipulação. }\end{array}$ \\
\hline Diretora da Casa de Saúde & $\begin{array}{l}\text { Sim. De certa forma já existe um comitê que trata das questões de saúde } \\
\text { do município. Dentro da ADESM, o movimento "A Santa Maria que } \\
\text { queremos", já foi criado um grupo de trabalho que, após muitas reuniões } \\
\text { com a participação de gestores e de membros voluntários da comunidade } \\
\text { santa-mariense levantou demandas e estabeleceu um plano estratégico } \\
\text { conjunto para a saúde para os próximos anos. }\end{array}$ \\
\hline Coordenador da UPA & $\begin{array}{l}\text { Sim, evitando-se assim duplicidade de meios para idênticos fins, bem } \\
\text { como ineficiências de toda ordem hoje observadas. }\end{array}$ \\
\hline
\end{tabular}

